

\section{Propositions}

1. Mixed tree plantations provide an opportunity to increase forest productivity. (this thesis)

2. Competitive interactions among trees explain stand overyielding. (this thesis)

3. In science, ideas are more important than equipment.

4. Complementarity rather than competition among scientists increases scientific productivity.

5. A PhD development trajectory resembles the stand volume development of a thinned forest with ups and downs in an ultimately upward trend.

6. Dutch people care more about the weather than about the hygiene of their food.

Propositions belonging to the thesis entitled:

'Species mixing effects on forest productivity in the Netherlands'.

Huicui Lu

Wageningen, 14 September 2017 
Species mixing effects on forest productivity

\section{in the Netherlands}

Huicui Lu 


\section{Thesis committee}

\section{Promotor}

Prof. Dr G.M.J. Mohren

Professor of Forest Ecology and Forest Management

Wageningen University \& Research

\section{Co-promotor}

Dr F.J. Sterck

Associate professor, Forest Ecology and Forest Management Group

Wageningen University \& Research

\section{Other members}

Prof. Dr N.P.R. Anten, Wageningen University \& Research

Dr D.I. Forrester, Swiss Federal Institute for Forest, Snow and Landscape Research WSL, Birmensdorf, Switzerland

Dr H.H. Bartelink, LandschappenNL, De Bilt

Dr J. van Ruijven, Wageningen University \& Research

This research was conducted under the auspices of the C.T. de Wit Graduate School for Production Ecology and Resource Conservation 


\title{
Species mixing effects on forest productivity in the Netherlands
}

\author{
Huicui Lu
}

\author{
Thesis \\ submitted in fulfilment of the requirements for the degree of doctor \\ at Wageningen University \\ by the authority of the Rector Magnificus, \\ Prof. Dr A.P.J. Mol, \\ in the presence of the \\ Thesis Committee appointed by the Academic Board \\ to be defended in public \\ on Thursday 14 September 2017 \\ at 11 a.m. in the Aula.
}




\section{Huicui Lu}

Species mixing effects on forest productivity in the Netherlands, 134 pages.

PhD thesis, Wageningen University, Wageningen, the Netherlands (2017) With references, with summary in English ISBN 978-94-6343-639-7

DOI $10.18174 / 419957$ 


\section{Table of contents}

$\begin{array}{lll}\text { Chapter } 1 & \text { General introduction } & 7\end{array}$

Chapter 2 Overyielding of temperate mixed forests occurs in evergreen-deciduous 21 but not in deciduous-deciduous species mixtures over time in the Netherlands

Published in Forest Ecology and Management, 376, 321-332 (2016)

Chapter 3 Unravelling soil effect on overyielding of species mixture in forests of the Netherlands

Submitted for publication

Chapter 4 Light limits tree growth in mixed forests across a soil fertility gradient in the Netherlands

Submitted for publication

Chapter 5 General discussion

References

Summary

Acknowledgements

Short biography

Publications 
己所不欲，勿施于人

-孔子

Treat others the way you want to be treated.

- Confucius 



\section{European and Dutch forests: history and current situation}

Forests provide multiple services to society. In Europe, forest managers have changed their focus for different services dramatically over the recent past. Starting from the middle of the $19^{\text {th }}$ century, forest managers strongly favoured an economic approach to achieve maximum and constant annual yield. There was a focus on increasing even-aged coniferous plantations by reducing the numbers of broadleaved trees and the area of uneven-aged forests (Agnoletti and Anderson, 2000; Johann et al., 2004). However, the coniferous monocultures were often negatively affected by insects and natural disturbances, such as wind throw, and they often degraded soils and decreased site productivity (Agnoletti, 2006). By the end of the $20^{\text {th }}$ century, forest managers started to convert many conifer monoculture plantations into mixed species forests, sometimes together with broadleaved species. This transition towards more mixed forests became a common practice in many areas of Europe (Agnoletti, 2006), including the Netherlands (Bartelink, 1998), and served several purposes, for example, increasing the productivity, stability, resistance and resilience of forests (Bravo-Oviedo et al., 2014; Jucker et al., 2014b; Chamagne et al., 2016; Del Río et al., 2017).

Currently, European forests (without the Russian Federation) cover about 210 million ha, i.e. $32.2 \%$ of Europe's land area by 2010 (Barbati et al., 2011). Most forests in Europe are still made up of predominantly coniferous stands (50\%) and predominantly broadleaved stands $(27 \%)$. The remaining $23 \%$ part is stands that are co-dominated by coniferous and broadleaved species. Approximately $73 \%$ of European forests are even-aged and many of them are of intermediate age, with $43 \%$ between 20 and 80 years old. However, uneven-aged forests represent a small percentage with less than $20 \%$. In the Netherlands, forests cover a relatively small area, with only about $11 \%$ (373,480 ha) of total land surface (Schelhaas et al., 2014). In this forest area, slightly over $21 \%$ is dominated by conifers, $21 \%$ by broadleaved species, and the remaining by mixtures of conifer and broadleaved species. Most Dutch forests are even-aged (62\%) and are of intermediate age, with an average age of 67 years for conifers and 55 years for broadleaved species forests. The share of uneven-aged forests is small with $16 \%$ and special forest, such as coppice or park forest occupies $24 \%$. In this thesis, plot samples of these Dutch forests are analysed, with a strong focus on the impact of mixing species on the productivity of even-aged forests.

\section{Definitions of mixed-species forests}

Forests may vary from monocultures, a term referring to stands dominated by a single species, to mixed-species stands, consisting of two or more tree species. Several methods have been developed to define, or quantify the mixing of species in a forest stand. These methods include criteria such as the presence of trees from two or more species (Bartelink and Olsthoorn, 1999), vertical distributions of different species (Leikola, 1999), and successional patterns in species composition (Oliver and Larson, 1996). Recently, a research network 
focusing on European mixed forests "Integrating Scientific Knowledge in Sustainable Management of Mixed Forests" (EuMIXFOR, http://www.mixedforests.eu/) defined a mixedspecies forest as a forest unit where at least two species coexist and share common resources (light, water, and nutrients) at any developmental stage.

Moreover, this network reviewed several alternative criteria for defining species proportion. The proportion of each species can be expressed as a percentage (\%) for different variables: number of stems (Assmann, 1970), basal area (Vallet and Pérot, 2011; Toïgo et al., 2015), tree volume or biomass (Pretzsch, 2010; Huber et al., 2014), or canopy cover (Sterba, 1998; Huber et al., 2014). A completely different approach was developed by Reineke (Reineke, 1933). He started from the concept of fully stocked even-aged stands, defined by self-thinning lines which are a function of average tree diameter and tree number per ha. He developed a method that quantified the relative distance of any stand from a fully stocked status, the index refers back to the fully stocked stand. The advantage of this method is that it expresses the level of competition between species (Weiskittel et al., 2011), and that species proportions do not depend on stand development stage or site conditions, at least not conceptually. For more details of the characterization of species proportion in mixed-species stands, see Table 1.1. In this thesis, measures of species proportion used are basal area per species (explained in chapter 2 and 3) as well as the Reineke stand density index (explained in chapter 4) to explore the impacts of mixing species on the productivity of forest stands, by comparing two-species mixture stands with their corresponding single-species stands.

Table 1.1 Variables for defining species proportion in mixed-species stands, including their units, pros and cons, and their applications in literature.

\begin{tabular}{|c|c|c|c|}
\hline Variable & Unit & Pros (+) and cons (-) & References \\
\hline Number of stems & trees $\mathrm{ha}^{-1}$ & $\begin{array}{l}\text { + easily estimated and interpreted } \\
\text { - does not take account for horizontal and vertical spatial } \\
\text { patterns and growing space requirements for each species }\end{array}$ & (Assmann, 1970) \\
\hline Stand basal area & $\mathrm{m}^{2} \mathrm{ha}^{-1}$ & $\begin{array}{l}\text { + easy to measure, common use in forest science } \\
\text { - dependent on site conditions, age and species composition }\end{array}$ & $\begin{array}{l}\text { (Del Río and Sterba, 2009; Vallet } \\
\text { and Pérot, 2011; Huber et al., 2014; } \\
\text { Toïgo et al., 2015; Thurm et al., } \\
\text { 2016b) }\end{array}$ \\
\hline Total stem volume & $\mathrm{m}^{3} \mathrm{ha}^{-1}$ & $\begin{array}{l}+ \text { of particular interest to forest managers } \\
\text { - requires species-specific volume equations or tree height }\end{array}$ & (Pretzsch, 2010; Huber et al., 2014) \\
\hline Biomass & $\mathrm{Mg} \mathrm{ha}^{-1}$ & $\begin{array}{l}\text { + important measure, e.g. for carbon sequestration } \\
\text { - requires species-specific allometric equations or tree } \\
\text { height, and wood density } \\
\text { - in mixtures, the species-specific allometric equations } \\
\text { may need modification due to inter-specific interactions }\end{array}$ & $\begin{array}{l}\text { (Pretzsch, 2010; Huber et al., 2014; } \\
\text { Forrester et al., 2017) }\end{array}$ \\
\hline Leaf area index & $\mathrm{m}^{2} \mathrm{~m}^{-2}$ & $\begin{array}{l}\text { + closely linked to light interception and primary production } \\
\text { - need detailed measurements or species-specific functions }\end{array}$ & $\begin{array}{l}\text { (Sterba, 1987, 1998; Sterba et al., } \\
\text { 2014) }\end{array}$ \\
\hline Stand density index & stem ha-1 & $\begin{array}{l}+ \text { the proportion in mixed versus monospecific stands can be } \\
\text { compared directly and interpreted } \\
\text { - strong assumptions on forest structure and development }\end{array}$ & $\begin{array}{l}\text { (Reineke, 1933; Del Río et al., } \\
\text { 2014a; Condés and Del Río, 2015) }\end{array}$ \\
\hline
\end{tabular}




\section{Productivity in mixed-species vs monoculture forests}

Since several decades, and in many regions of Europe, many conifer forests are being transformed such that conifers grow together with broadleaved species, which can contribute to a higher biodiversity, higher resilience to disturbances, and which may increase wood production (Zerbe, 2002; Felton et al., 2010). When mixed forest plantations use resources more efficiently, this may result in higher production compared to their respective monocultures. This phenomenon is often referred to as overyielding (Tilman, 1999; see Box 1.1 for definition). Overyielding may be affected by many factors, including differences in species composition, stand developmental phases, environmental conditions, forest management practices, and other factors (Hynynen et al., 2011; Forrester, 2014), as shown in Figure 1.1. Several studies indeed point out that temperate mixed-species forests are more productive than monoculture forests (Zhang et al., 2012; Pretzsch et al., 2015b; Forrester and Bauhus, 2016; Ma and Chen, 2016). However, other studies do not show this phenomenon (Bouillet et al., 2013; Epron et al., 2013; Forrester, 2014). These divergent findings might be attributed to different species combinations or to different stand ages. In addition, many studies show that overyielding occurred on poor sites and underyielding (see Box 1.1 for definition) or no species mixing effect appeared on richer sites (Del Río and Sterba, 2009; Pretzsch et al., 2013a; Toïgo et al., 2015). To the contrary, yet other studies document stronger overyielding on rich sites, and suggested that this was due to stronger complementarity (Pretzsch et al., 2010; Forrester et al., 2013a; Jucker et al., 2014a; Thurm and Pretzsch, 2016; see Box 1.1). These contrasting findings may arise from environmental conditions, forest management practices, and other factors.

For temperate European forests, this species mixing effect on productivity has been reported for few species combinations only and the effect changes with soil fertility. On the poorest soils in Dutch forests, only a limited number of species occurs and the potential for productivity gain by mixing species is unsure. In this thesis, I explore how species mixing affects productivity and how complementary resource use may contribute to this, by focusing on Dutch forests differing in species compositions, stand developmental stages and site conditions. Analysing these patterns can advance our understanding when, where and why mixed-species forests may have higher productivity compared with monoculture forests.

\section{Resource acquisition in mixed-species forests}

The niche complementarity hypothesis (Kelty, 1992; Tilman, 1999; see Box 1.1) states that different species in mixed forests can have complementary above and/or belowground resource acquisition and use. Species differences in crown architecture, shade tolerance, leaf phenology and root distribution may contribute to such complementarity and thus lead to higher productivity, i.e. overyielding. These related mechanisms are shown in Figure 1.1, and further explained below. 
Box 1.1: Glossary with concepts and their explanations used throughout this thesis

Competition: The process in which individuals take away limiting resources from each other, and thus reduce the growth of each other (Vandermeer, 1989).

Competitive reduction: Competition is weaker between trees of different species than between trees of the same species, caused by complementary resource use (Vandermeer, 1989).

Complementarity: When trees of different species grow together, they may partition resources or use resources more efficiently than when they grow together with trees of the same species (Larocque et al., 2012). Complementarity covers competitive reduction and facilitation, which often occur simultaneously and their effects are difficult to separate (Loreau and Hector, 2001).

Facilitation: The process in which individuals benefit from each other, which results in higher growth when they grow together (Vandermeer, 1989).

Inter-specific competition: Competition between individuals of different species (Harper, 1977).

Intra-specific competition: Competition between individuals within the same species (Harper, 1977).

Niche complementarity hypothesis: Different species are complementary in resource acquisition and use, which results in higher stand productivity (Kelty, 1992; Tilman, 1999).

Overyielding: Mixed-species forests grow more rapidly than the corresponding monocultures under the same growing conditions (Tilman, 1999).

Resource-ratio hypothesis: Competition among trees switches predominantly for soil resources on poor soils to predominantly for light on fertile soils (Tilman, 1985).

Size-asymmetric competition: Larger individuals often suppress the growth of smaller neighbours disproportionately. This phenomenon is considered common for trees differing in height and competing for light (Hara, 1993; Schwinning and Weiner, 1998).

Size-symmetric competition: Competing individuals, whether large or small, suppress the growth of each other proportionally. This situation is considered common for trees competing for soil resources (Hara, 1993; Schwinning and Weiner, 1998).

Stress-gradient hypothesis: The availability of soil resources for one species becomes more pronounced by the presence of another species by facilitation or improved complementary use of soil resources from rich to poor soils (Bertness and Callaway, 1994).

Underyielding: Mixed-species forests grow slower than the corresponding monocultures under the same growing conditions (Tilman, 1999).

\section{Aboveground complementarity for acquisition of light}

In mixed forest stands, trees of fast-growing light-demanding species capture light more efficiently and grow more rapidly than trees of more slow-growing shade-tolerant species. This difference in shade tolerance allows light-demanding species to occupy the upper layer of the canopy, while shade-tolerance can survive in the lower layers. Consequently, multiple crowns of different species better fill the above ground space, and result in higher light absorption and light use efficiency (Pretzsch, 2014; Jucker et al., 2015). On top of that, total annual light absorption might increase when species differ in leaf phenology. If deciduous species co-occur 
with other deciduous tree species, those trees compete for light during the summer. However, mixing evergreen conifers and deciduous species, trees of evergreen species may capture and use light in autumn and early spring when deciduous trees are without leaves. The elongated overall leaf life span of the forest through the year may allow for complementary light use and result in higher productivity (Kelty, 1989). In addition, plasticity in crown architecture has been shown to increase canopy packing (Longuetaud et al., 2013; Pretzsch, 2014; Jucker et al., 2015), and this complementarity in using space is observed to result in overyielding in mixtures by increasing both overall light interception and/or light use efficiency (Williams et al., 2017). These studies thus imply a strong potential for aboveground complementary in light use in mixed forests.

\section{Belowground complementarity for acquisition of soil resources}

Belowground, differential root distribution is considered an important potential mechanism for overyielding. A growing number of studies shows that fine root productivity was higher in mixed-species stands compared with their monoculture stands (Brassard et al., 2013; Thurm et al., 2016a; Ma and Chen, 2017). Several processes may be associated with explaining this higher fine root productivity. First, the soil resources acquisition could be enhanced if mixing shallow-rooted species dominating the top soil with deep-rooted species spreading into deeper soil layers (Hendriks and Bianchi, 1995; Forrester et al., 2010; Reyer et al., 2010; Brassard et al., 2013; Pretzsch et al., 2013b; Thomas et al., 2015). This vertical root stratification can also enhance soil resource availability, by hydraulic lift of soil water (Manso et al., 2015). Secondly, more evenly distributed roots increase horizontal soil volume filling due to intense root interactions to increase resource foraging in mixtures than monoculture stands (Brassard et al., 2013; Ma and Chen, 2017). Thirdly, the facilitative effect of nitrogen-fixing species on the growth of non-nitrogen-fixing species may cause overyielding, particularly when nitrogen is more limiting (Forrester et al., 2006). Lastly, nutrient cycling could be accelerated because of the existence of fast nutrient cycling species. Increases in nutrient availability can lead to more root growth and the carbon then can be used for stem growth (Poorter et al., 2012). In the following chapters, productivity in mixtures versus monocultures are compared on soils differing in fertility by considering these possible explanations when overyielding occurs.

\section{Below versus aboveground interactions in complementary resource use}

The belowground complementary resource use may depend on soil fertility. Here, it is important to note that two dominant hypotheses depict the changes in species interactions with soil fertility, with possible consequences on overyielding. The stress-gradient hypothesis suggests that species interactions in plant communities change from competition at high soil fertility to facilitation or better belowground complementary resource use at low soil fertility (Bertness and Callaway, 1994; see Box 1.1). The resource-ratio hypothesis states that species interactions run from competition for light at high soil fertility to competition for soil resources at low soil fertility (Tilman, 1985; see Box 1.1). 
Studies identified the competition for light as size-asymmetric since larger individuals take more than their (size-) proportional share of intercepted light compared to smaller individuals. Instead, the competition for belowground soil nutrients and water is considered size-symmetric for all the individuals, implying that trees take their (size-) proportional share of soil resources (Hara, 1993; Schwinning and Weiner, 1998) (see Box 1.1). Across a soil fertility gradient, experiment studies observed that competitive interactions generally strengthened in a boreal forest (Baribault and Kobe, 2011; Coates et al., 2013). Several studies report that complementary soil resource use is stronger at low fertility soil (Del Río and Sterba, 2009; Pretzsch et al., 2013a; Toïgo et al., 2015), supporting the stress-gradient hypothesis, whereas other studies document that complementary soil resource use is less at low soil fertility (Forrester et al., 2013a; Jucker et al., 2014a; Thurm and Pretzsch, 2016), confirming the resource-ratio hypothesis. In this thesis, both hypotheses are taken as starting points for interpreting overyielding, or lack of overyielding, in mixed stands in relation to soil fertility.

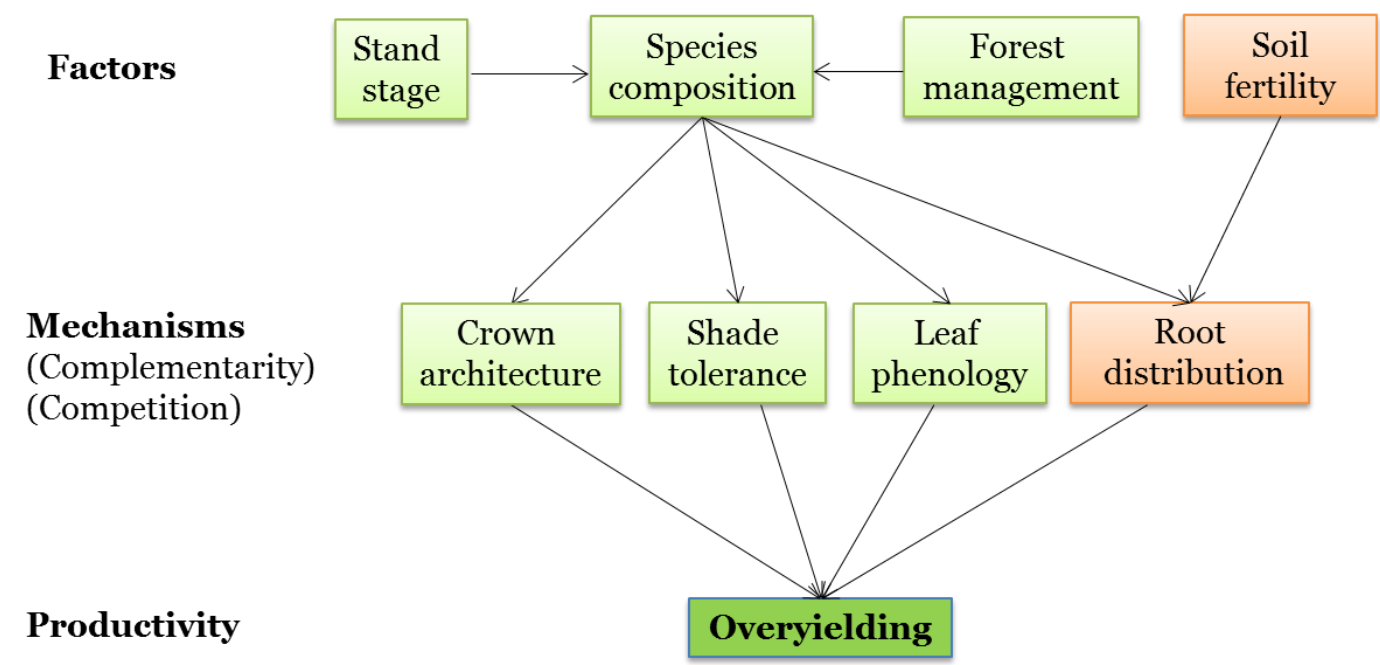

Figure 1.1 Conceptual framework representing factors and possible mechanisms that could influence overyielding. The mechanisms are due to complementarity or reduced competition for light and soils.

\section{Stand development and forest management}

The forest productivity in even-aged stands typically changes with stand development, reaching a peak at early forest age, followed by a substantial decline, probably due to the increasing costs of maintaining living wood or due to hydraulic limitations (Ryan et al., 1997). In mixed forest stands, productivity is altered by both intra- and inter-specific interactions, and may differ from productivity patterns in monocultures. These interactions between species growing in mixed stands may include competition, competitive reduction and facilitation (Vandermeer, 1989). Competitive reduction and facilitation often occur simultaneously and their effects are difficult to separate, and these two are collectively described as complementarity (Loreau and Hector, 2001; see Box 1.1). Moreover, shifts from competition 
to facilitation over time have been observed in mixed stands, but such shifts varied with species composition (Cavard et al., 2011; Del Río et al., 2014b).

At young stand age, small trees of fast-growing light-demanding species capture light more efficiently and grow more rapidly than trees of more slow-growing shade-tolerant species. Once fully occupying the growing space and closing their canopy, the competition for light increases. The trees of light-demanding species dominating the upper canopy may transmit sufficient light for trees of shade-tolerant species to survive and grow (Oliver and Larson, 1996). Several studies demonstrate strong competitive interactions in favourable growing seasons and more complementarity effects in years of poor growing conditions (Lebourgeois et al., 2013; Pretzsch et al., 2013b; Del Río et al., 2014b). Besides, recent studies suggest that species interactions can increase temporal stability of productivity in mixed stands by increasing complementarity among the neighbouring trees (Jucker et al., 2014b; Del Río et al., 2017). In some studies, it was observed that stem and fine root productivity increased with increasing stand age, in both temperate and boreal mixed forests (Thurm and Pretzsch, 2016; Ma and Chen, 2017). All those studies presented long-term, multiple decades of observations rather than single point, or data collected during short periods. The scarcity of long term data is one of the probable reasons that studies on species mixing effects on stand productivity with stand development are uncommon.

In this thesis, the species mixing effect on productivity with stand development is evaluated by using data from long-term permanent field plots from the Netherlands. In those Dutch forests, species interactions are continuously affected by forest management practices, both in monocultures and mixtures. Under given environmental conditions and tree species compositions, as illustrated in Figure 1.1, forest management aiming at increasing forest productivity often use thinning to reduce the stand density (Puettmann et al., 2015), thus increasing the availability of light, water, and nutrients for the remaining trees. This situation differs from most of the existing studies, which focussed on mixed forests where thinning operations were abandoned to assess the mixing effect on productivity (Del Río and Sterba, 2009; Jucker et al., 2014b; Toïgo et al., 2015). Therefore in the following chapters, I discuss the possible consequences of forest management, i.e. thinning operations, on the possible mixing effects on productivity. 


\section{Questions \& hypotheses}

In this thesis, productivity is compared between mixed forest stands and corresponding monoculture stands. Differences in productivity between mixtures and monocultures are explained from differences in tree attributes (crown architecture, shade tolerance, leaf phenology, and root distribution) between species, which reflect different mechanisms of complementarity. In addition, it is discussed how these trends can be affected by stand age, soil fertility and forest management (Figure 1.1). The specific research questions are:

1. What is the effect of species mixing on stand productivity with stand development?

2. How does overyielding depend on the attributes of mixed species along a soil fertility gradient?

3. What is the effect of competitive interactions on tree growth in mixed-species forests along a soil fertility gradient?

The hypotheses corresponding to these questions are:

1. In line with the niche complementarity hypothesis, it is expected that tree species of mixed stands that differ in leaf phenology and/or shade tolerance overyield more strongly. Second, it is expected that overyielding decreases with stand development because fully grown stands take all resources and limit resource partitioning (Figure $1.2 \mathrm{a}$ ).

2. It is hypothesised that the faster growing and more light-demanding species would dominate the slower growing and more shade-tolerant species in mixed-species stands, and that complementary use of light by these two species causes overyielding. Second, according to the stress-gradient hypothesis, overyielding by complementary soil resource use would be stronger at poor soils than at rich soils. Alternatively, following the resource-ratio hypothesis, overyielding would be stronger at rich soils (Figure 1.2 b).

3. First, it is predicted that intra-specific competition is stronger than inter-specific competition and the competitive reduction is greater at less fertile soils, in accordance with the stress-gradient hypothesis. Second, when light is the most important growth limiting factor in Dutch forests, size-asymmetric competition for light is more relevant for tree growth than size-symmetric competition for soil resources. Third, given that forests develop a denser canopy, size-asymmetric competition will be greater at high fertility soils, in accordance with the resource-ratio hypothesis, and this in turn may imply a higher probability of complementarity for light than for soil resources (Figure $1.2 \mathrm{c}$ ). 
(a)

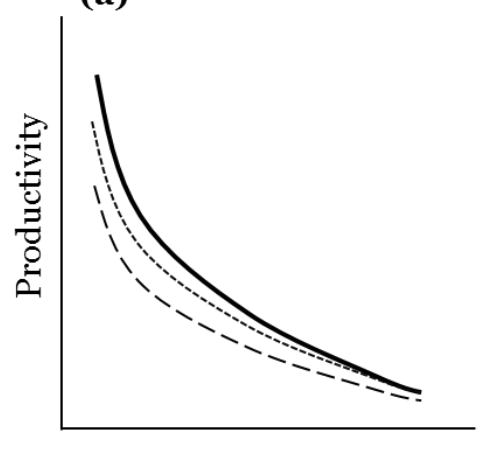

Time (years) (b)

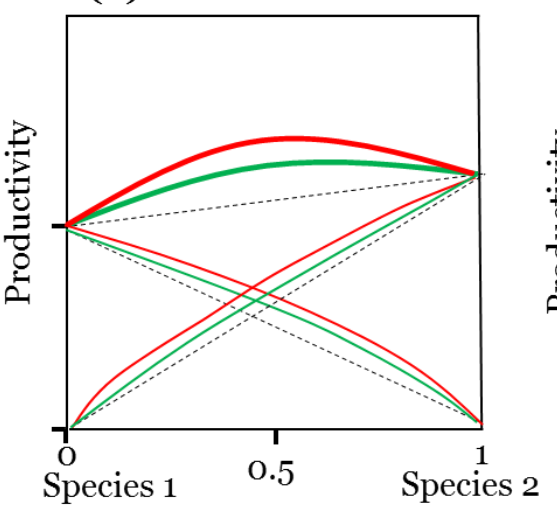

(c)

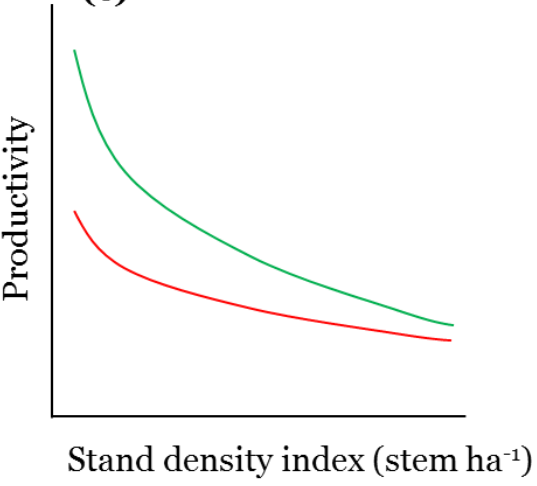

Figure 1.2 Conceptual diagram for the hypotheses in this thesis. (a): productivity expressed as stand volume growth in a mixture versus their respective monocultures over time; (b): productivity expressed as volume growth of a mixture and their respective monocultures, and in relation to the species proportions within the mixture; (c): productivity expressed as tree basal area growth changes with stand density index. In graph (a), the dashed lines represent two monoculture stands, and the solid line represents a mixture composed of the two corresponding species. In graph (b), dashed lines represent predicted values with null mixing effect, i.e. no overyielding. The solid red lines represent predicted values with stronger overyielding on poor soils, and the solid green lines represent the less overyielding at richer soils. Note that those predictions differ between the stress-gradient hypothesis and the resource-ratio hypothesis. In graph (c), the red and green line represents the tree basal area growth with stand density index in mixed stands at poor soils and at rich soils, respectively. The decrease in productivity is larger with stand density when soil fertility is richer, meaning stronger competition for light at rich soils.

\section{General approach}

In this thesis, data were taken from two datasets of forests across the Netherlands. One dataset consists of growth and yield data (GYD) from permanent field plots (Den Ouden and Mohren, 2016) and the other is the Dutch national forest inventory (NFI) data (Schelhaas et al., 2014). The GYD contains information of stand development of 319 plots in monoculture from 1929 to 2011, and of 91 plots in mixture between 1949 and 2004 (see Table 2.1 in chapter 2). Five tree species in monoculture are included: Douglas-fir (Pseudotsuga menziesii (Mirb.) Franco), common beech (Fagus sylvatica L.), Scots pine (Pinus sylvestris L.), pedunculate oak (Quercus robur L.) and silver birch (Betula pendula Roth). In two-species mixtures, they occur in the following combinations: Douglas-fir-common beech, Scots pine-pedunculate oak, pedunculate oak-common beech, and pedunculate oak-silver birch. The Dutch NFI data provide a shorter time series, with one re-census after 2003 in the period between 2011 and 2013, and thus provide information of stand productivity over a period of maximum 10 years, from plots distributed all over the Netherlands (see Methods in chapter 4). From the Dutch NFI data, 145 plots with mixed species were selected including three mixtures: pedunculate oak-silver birch, Scots pine-pedunculate oak, and Scots pine-silver birch (see Table 4.1 in chapter 4). Hereafter throughout this thesis, the five species and monocultures are written as 
Douglas-fir, beech, pine, oak and birch, and the five mixtures accordingly as Douglas-firbeech, pine-oak, oak-beech, oak-birch and pine-birch, respectively. The locations of the selected forest plots are shown in Figure 1.3. Photo images of examples of the 5 two-species mixed stands studied are shown in Figure 1.4.

Additionally, these plot data from the two datasets were coupled with soil data using the ISRIC-World Soil Information SoilGrids250m database (see Methods in chapter 3 and 4). Forest plots from both datasets come mainly from sandy soils areas (Figure 3.1 and 4.1), and cover a natural soil fertility gradient on sandy soils within the Netherlands. These plot data were used to show how species mixtures influence forest stand productivity during stand development (chapter 2). In addition, it was used to show how the productivity of individual species in mixtures compared to their monocultures, and how such species-specific productivity was affected by soil fertility (chapter 3 ). The Dutch NFI data was used to show the consequences of competitive interactions on growth of trees in forest stands differing in stand density and soil fertility (chapter 4). These three analyses and the corresponding chapters represent different organization levels, running from stand, species, to individual tree. 


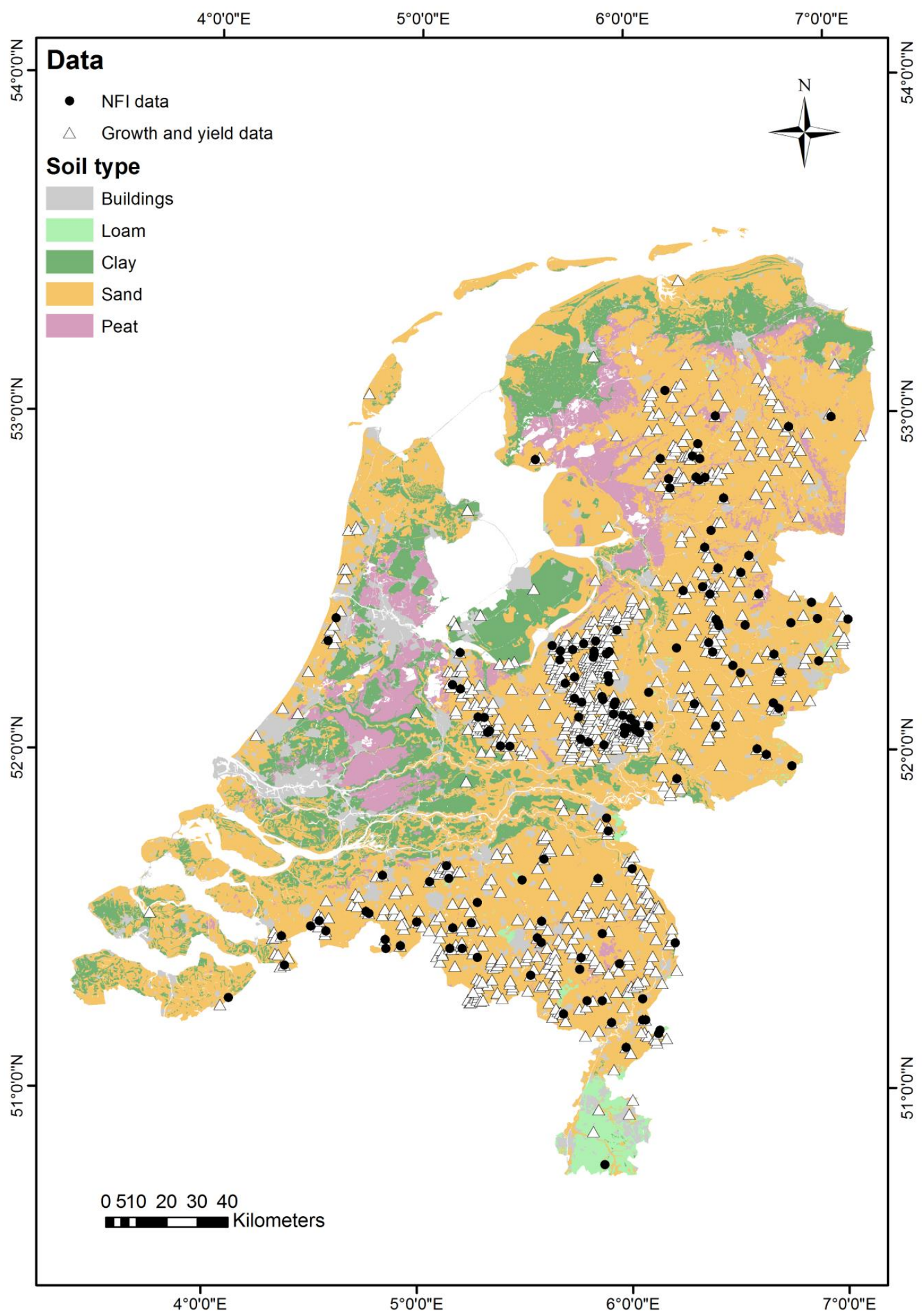

Figure 1.3 Distribution of the studied plots throughout the Netherlands. Growth and yield data: from long-term permanent field plots for study in chapter 2 and 3; NFI data: from Dutch national forest inventory data for study in chapter 4. 


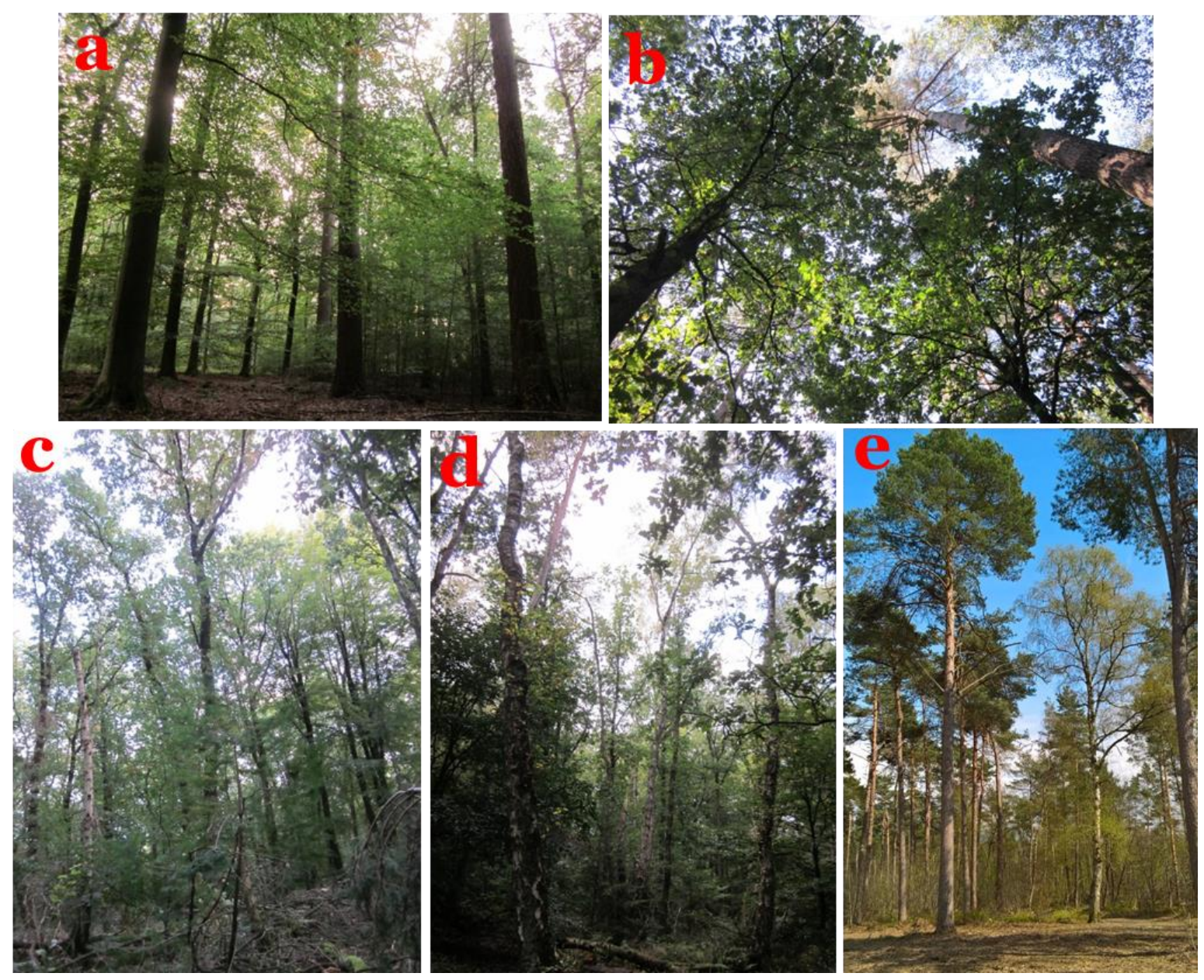

Figure 1.4 Photo images of the two-species mixtures studied in this thesis. a: Douglas-fir (Pseudotsuga menziesii (Mirb.) Franco)-common beech (Fagus sylvatica L.) mixture; b: Scots pine (Pinus sylvestris L.)pedunculate oak (Quercus robur L.) mixture; c: pedunculate oak-common beech mixture; d: pedunculate oaksilver birch (Betula pendula Roth) mixture; e: Scots pine-silver birch mixture (Photo: courtesy of Leo Goudzwaard).

\section{Thesis outline}

This thesis comprises a general introduction (this chapter), three research chapters (chapter 24) and a general discussion (chapter 5). See Figure 1.5 for an overview of the research chapters.

In chapter 2, the productivity in 4 two-species mixtures is compared with their corresponding monoculture stands, using the GYD from permanent forest plots in the Netherlands. Empirical models at stand level are applied to explore the impacts of mixing species on stand productivity for the mixtures. The results are discussed in the light of complementarity resulting from differences between species in leaf phenology and shade tolerance. 
In chapter 3, the same data are used to explore how the two species in these mixtures contributed to the productivity of the forest stand on different soil fertility. For this purpose, empirical models at species level are used to test overyielding effects of the different species at different soils.

In chapter 4, to examine the mechanism of stand and species level overyielding, the Dutch NFI data are used to explore how the growth of trees in mixtures is influenced by interand intra-specific competition, both for size-symmetric competition for soil resources and size-asymmetric competition for light on different soils.

In chapter 5, the strengths and limitations of the research are discussed, and the results of the individual chapters are integrated to understand how species mixing effect depends on stand developmental stage and soil fertility. Finally, conclusions are drawn based on the empirical studies of species mixing and recommendations are given for forests management practice.

\section{Chapter}

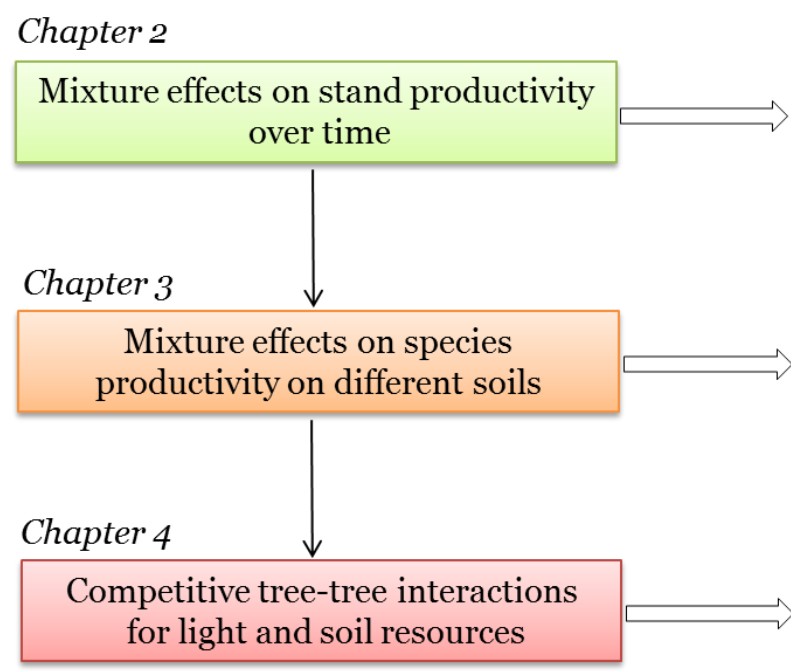

\section{Level}

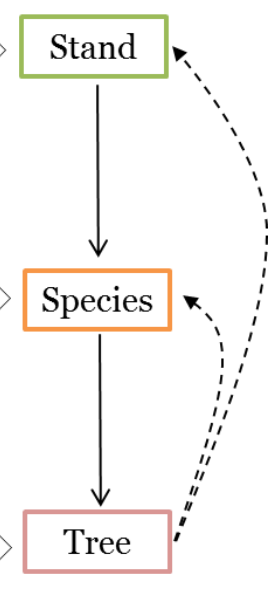

Figure 1.5 Graphical overview of the structure of this thesis. The coloured boxes show the main topics per research chapter. Chapter 2 focuses on mixture effects on stand productivity during stand development (green). Chapter 3 explores the mixture effects on the productivity of individual species on soils differing in fertility (orange). Chapter 4 explores the consequences of competitive tree-tree interactions for soil resources and light for the growth of trees (red). The solid downwards arrows indicate from higher to lower organization levels to understand patterns of species interactions in mixed stands. The dashed arrows represent upscaling from lower to higher organizations levels, but they are not directly linked. 


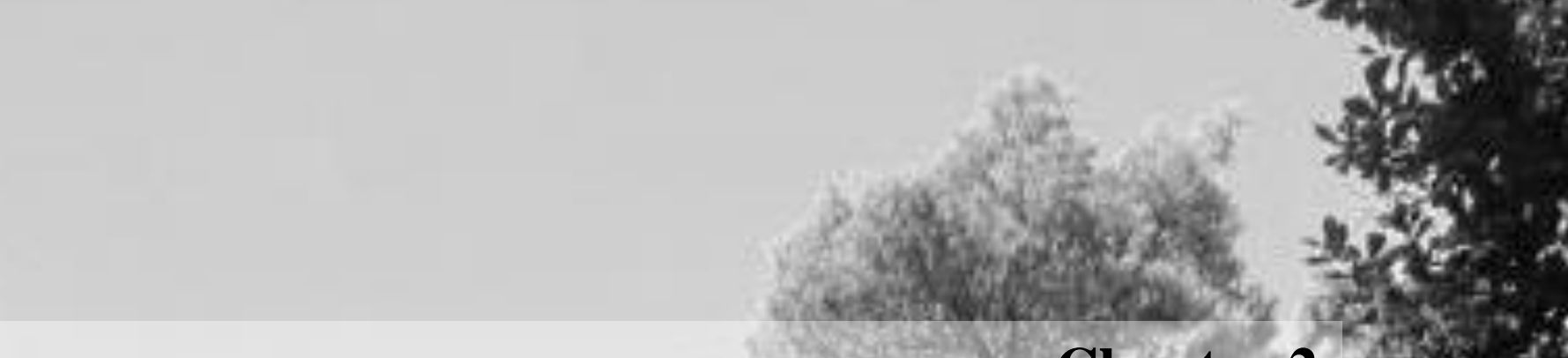

\section{Chapter 2}

Overyielding of temperate mixed forests occurs in evergreendeciduous but not in deciduous-deciduous species mixtures over time in the Netherlands

over time in the Netherlands
Huicui Lu, Godefridus M. J. Mohren, Jan den Ouden, Venceslas Goudiaby, Frank J. Sterck
Published in Forest Ecology and Management, 376, 321-332(2016)

Published in Forest Ecology and Management, 376, 321-332 (2016)

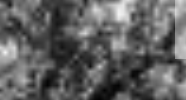

Based
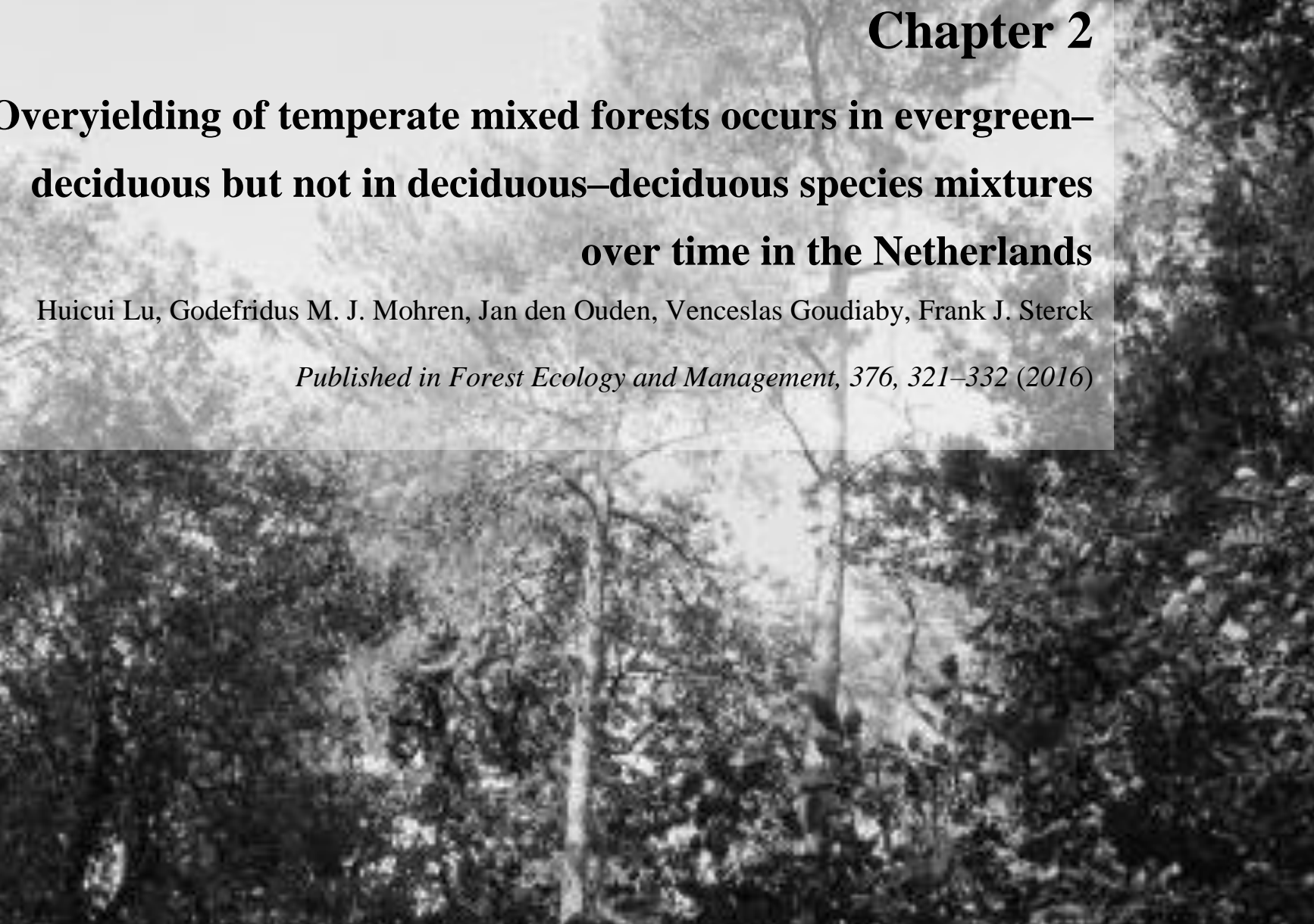

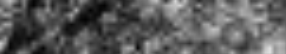

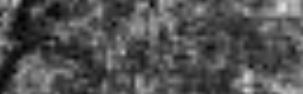

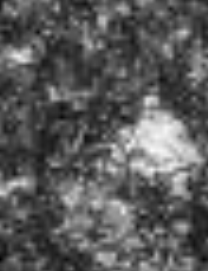

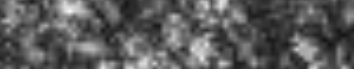

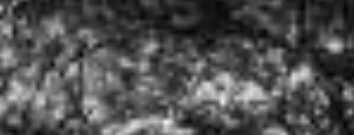

ondos.

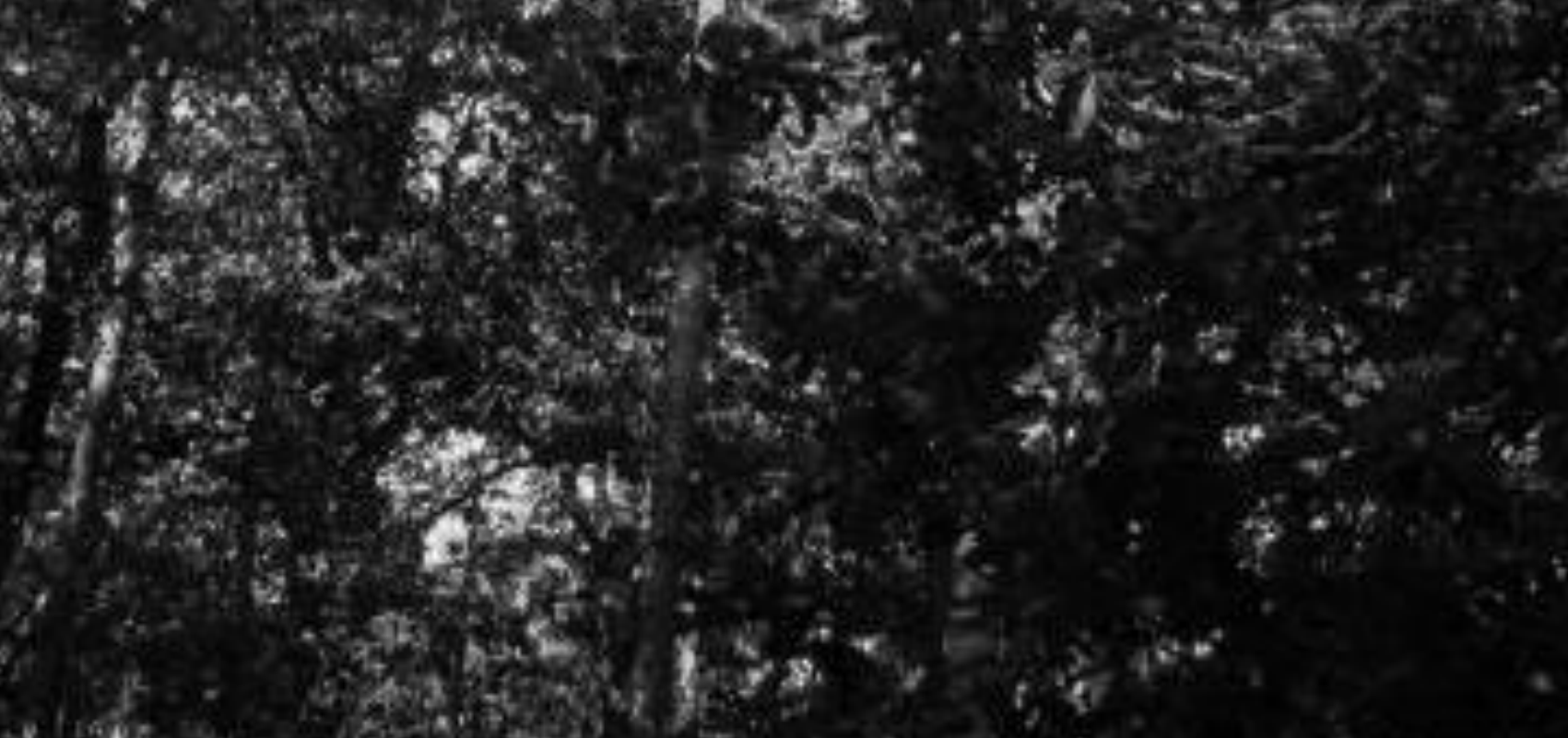




\begin{abstract}
Recent studies show that mixed species forests sometimes have higher stand productivity than monospecific forests, which we refer to as overyielding. Yet, results for temperate forests are ambiguous, possibly because forests differ in local site conditions, thinning history and forest age. In line with the niche complementarity hypothesis, we expect stronger overyielding for forests with species differing in both leaf phenology (evergreen or deciduous) and shade tolerance. We also hypothesise that overyielding will decrease with stand development because of decreasing resource availability. We compared 4 two-species mixtures with their corresponding monospecific stands from long-term field measurements in the Netherlands. The mixtures were Douglas-fir (Pseudotsuga menziesii (Mirb.) Franco)-common beech (Fagus sylvatica L.), Scots pine (Pinus sylvestris L.)-pedunculate oak (Quercus robur L.), pedunculate oak-common beech, and pedunculate oak-silver birch (Betula pendula Roth). Overyielding was observed in 2 of the 4 mixtures: Douglas-fir-common beech mixtures had $35.9 \%$ and $36.7 \%$ higher volume growth relative to Douglas-fir and common beech monocultures, respectively; Scots pine-pedunculate oak mixtures had $20.3 \%$ and $31.2 \%$ higher volume growth relative to Scots pine and pedunculate oak monocultures, respectively, on average over time. Furthermore, overyielding was relatively constant for the two mixtures through stand development. This result was robust after accounting for possible effects of site quality and thinning history, where site quality contributed independently to stand productivity and thinning history had no effect. No significant overyielding effects were observed for the two deciduous mixed stands, i.e. pedunculate oak-common beech and pedunculate oak-silver birch. Mixing tree species in temperate forests resulted in overyielding for evergreen-deciduous species mixtures, but not for deciduous-deciduous species mixtures. This indicates that leaf phenology contributes to overyielding effects. Overyielding was higher in the Douglas-fir-common beech mixtures than the Scots pine-pedunculate oak mixtures, which coincides with a stronger contrast in shade tolerance between Douglas-fir and common beech and thus stronger complementarity. Our results support the complementarity hypothesis and imply that such mechanisms are maintained with stand development. It therefore appears that mixing evergreen with deciduous species with contrasting shade tolerance is a valid management strategy for increasing diversity and productivity of temperate forests in the Netherlands.
\end{abstract}

Keywords: Mixture; Monoculture; Niche complementarity; Productivity; Stand development; Volume growth 


\section{Introduction}

Over the past decade, forest stands dominated by single species (monospecific stands or monocultures) have been converted to stands co-dominated by multiple species (mixed stands, or mixtures) in Europe, as mixed stands are considered more resistant and resilient to disturbances than monocultures (Bravo-Oviedo et al., 2014; Gazol and Camarero, 2016) and may provide higher levels of multiple ecosystem services (Gamfeldt et al., 2013). Both theory and data suggest that mixed stands can be more productive than monocultures, which is also referred to as overyielding (Morin et al., 2011; Zhang et al., 2012; Vilà et al., 2013; Jucker et al., 2014b; Zhang and Chen, 2015); however, the evidence for overyielding is mixed since other studies document that mixtures are not more productive than monospecific stands (Bouillet et al., 2013; Epron et al., 2013; Forrester and Albrecht, 2014). It could be that overyielding effects in existent forests are masked by other factors, such as variable soil conditions, forest management history and competitive interactions (Pretzsch et al., 2015a), which all vary across plots and change with stand age.

A possible key mechanism contributing to overyielding is complementary resource use in which divergent crown architectures, crown phenology and root distributions may play a main role (Forrester and Albrecht, 2014; Pretzsch et al., 2014; Pretzsch et al., 2015b). In mixtures, tree species with divergent architectures may occupy different spaces and partition light capture. When young growing stands close their canopy, trees of light-demanding species may transmit sufficient light through their canopy, so that trees of shade-tolerant species can survive and grow in their shade, leading to greater use of a limited resource such as light (complementarity). Several studies have reported mixtures where species differ in shade tolerance were more productive than monocultures (Morin et al., 2011; Jucker et al., 2014a; de-Dios-García et al., 2015; Toïgo et al., 2015). Such overyielding may even be strengthened when tree species in mixtures also differ in their crown phenology, such as deciduous and evergreen species, and thus in their light capture over a year. Another frequently mentioned mechanism underlying overyielding is mixing species with shallow roots and those with deep roots, which enhances the acquisition of nutrients and water (Forrester et al., 2010; Reyer et al., 2010; Brassard et al., 2013; Pretzsch et al., 2013b). Yet, there is still little evidence that mixtures where species differ in shade tolerance, leaf phenology, or root distributions will overyield (Forrester and Pretzsch, 2015). Moreover, most of existing studies compared the effect of species mixing on overyielding under different site quality and climatic conditions (the spatial mixture effect), and some studies documented that overyielding happened on poor soils and underyielding on rich soils because of complementarity effect (Pretzsch et al., 2013a; Pretzsch et al., 2015b; Toïgo et al., 2015). Little information is available for long-term mixture effect (the temporal mixture effect) in forests, as most previous studies did not account for stand age.

Stand productivity decreases after canopy closure when leaf area index peaks, probably because the increasing costs of maintaining living wood and hydraulic limitations reduce the 
net primary productivity (Ryan et al., 1997). When trees grow taller and gradually occupy more space, both below-ground and above-ground, mixing effect may shift and overyielding may become weaker which might result from changes in resource capture and interspecific interactions among species with stand development (Cavard et al., 2011). Long-term repeated measurements from the same plots to study the effect of species mixing provide information about how species interactions change as stands develop (Forrester and Pretzsch, 2015). Previous findings show that aboveground wood production is more stable through time in mixed-species stands than pure stands (Cardinale et al., 2007; Jucker et al., 2014b; Drössler et al., 2015). However, mixing effect with stand development on productivity is still hardly known because most studies used protocols that removed possible stand age impacts, using for example dominant height and quadratic mean diameter or quadratic mean diameter at age of 50 and 100 years from yield table as surrogates of age (Pretzsch et al., 2010; Condés et al., 2013; Pretzsch et al., 2015b). This approach masks possible age effects on overyielding, which might result from changes in resource capture and interspecific interactions among species with stand development. A further complication to testing and understanding of overyielding in mixed forests is forest management history such as thinning. Yet, in the European context, species interactions are continuously affected by forest management practices. Apart from stand age, forest management history is thus considered a key factor, and accounted for by using protocols that calculated productivity either in fully stocked stands (Pretzsch et al., 2013a; Pretzsch et al., 2015b), or by removing stands that were managed in the last five years from the analysis to minimize possible management effects (Jucker et al., 2014b; Toïgo et al., 2015). Therefore, by using these protocols to remove impacts of stand age and forest management, these studies may mask possible trends in age effects and thinning regime on productivity and, indirectly, possible overyielding.

In this study, we asked what is the effect of species mixture on stand productivity and dynamics over time. First, in line with the niche complementarity hypothesis (Kelty, 1992; Tilman et al., 2001), we expect that mixing tree species that differ in both leaf phenology and shade tolerance would overyield most strongly because of complementary resource use by the different species. Everything else being equal, evergreen-deciduous species mixed stands may thus be more productive than deciduous-deciduous species mixed stands, and overyielding impacts are expected to increase with increasing differences in shade tolerance (or light requirements) between the species in the mixed forest. Second, we expect overyielding to decrease with stand development because fully growing stands take all resource and limit resource partitioning. However, in thinned stands, resource partition may maintain with age and thus offset trends in overyielding. We evaluated our hypotheses by comparing 4 two-species mixtures (Douglas-fir (Pseudotsuga menziesii (Mirb.) Franco)common beech (Fagus sylvatica L.), Scots pine (Pinus sylvestris L.)-pedunculate oak (Quercus robur L.), pedunculate oak-common beech, and pedunculate oak-silver birch (Betula pendula Roth)) with the respective monocultures of the same species from 410 permanent field plots in Dutch forests. In this study, we use the term overyielding to refer to 
higher production in mixed stands relative to the corresponding pure stands, without taking the species proportions explicitly into account. This definition of overyielding is in agreement with some studies (Jucker et al., 2014b), but not with studies that account for species proportions in mixed stands (Kelty, 1992; Condés et al., 2013; Pretzsch et al., 2013a).

\section{Methods}

\section{Study site and species}

We used the growth and yield data, maintained by the Forest Ecology and Forest Management Group of Wageningen University (FEM), which are derived from permanent field plots in the Netherlands, to investigate the effect of species mixing on stand productivity and dynamics with stand development. The database includes 135 mixed-species and 1311 monospecific stands all over the Netherlands (see Appendix 2.1 for a description of FEM growth and yield database from permanent field plots). The Netherlands has a moderate maritime climate created by predominant southwest winds, and the mean annual temperature is $10.8^{\circ} \mathrm{C}$ with cool winter (average temperature in December-February is $2.5^{\circ} \mathrm{C}$ ) and mild summer (average temperature in June-August is $15.9^{\circ} \mathrm{C}$ ). The mean annual rainfall is around $800 \mathrm{~mm}$ and is evenly distributed throughout the year (KNMI, 2015).

In this study, we compared the productivity in Douglas-fir (Pseudotsuga menziesii (Mirb.) Franco)-common beech (Fagus sylvatica L.), Scots pine (Pinus sylvestris L.)-pedunculate oak (Quercus robur L.), pedunculate oak-common beech, and pedunculate oak-silver birch (Betula pendula Roth) mixtures with their corresponding monospecific stands. The stands comprised plots surveyed up to 15 times. The oldest records date back to 1929 and the most recent one to 2011. Stand ages ranged from 6 to 265 years. The measurement intervals varied from 1 to 16 years, depending on the age of the trees (Table 2.1). All trees with sufficient height (circa>1.3 m) were measured for their diameter at breast height $(\mathrm{dbh})$. Tree variables, e.g. dbh and height, were measured for almost all trees in each survey. For the few missing trees, we used models to estimate dbh and height (see Appendix 2.1). 
Table 2.1 Stand and plot characteristics for this study.

\begin{tabular}{|c|c|c|c|c|c|c|c|c|c|c|}
\hline Species & $\begin{array}{l}\text { Number } \\
\text { of plots }\end{array}$ & Plot size (ha) & $\begin{array}{l}\text { Survey interval } \\
\text { (years) }\end{array}$ & $\begin{array}{l}\text { Number of } \\
\text { surveys }\end{array}$ & $\begin{array}{l}\text { Age span } \\
\text { (years) }\end{array}$ & $\begin{array}{l}\text { Survey } \\
\text { duration } \\
\text { (years) }\end{array}$ & $\begin{array}{l}\text { Stand density } \\
\text { (trees/ha) }\end{array}$ & $\begin{array}{l}\text { Thinning history } \\
\text { (\%/years) }\end{array}$ & $\begin{array}{l}\text { Leaf } \\
\text { phenology }\end{array}$ & $\begin{array}{l}\text { Difference of two species studied } \\
\text { in shade tolerance (Niinemets and } \\
\text { Valladares, 2006) }\end{array}$ \\
\hline \multicolumn{11}{|l|}{ Pure stands } \\
\hline Douglas-fir & 114 & $0.008-0.290$ & $1-16$ & $3-17$ & $6-130$ & 1929-2011 & $63-5781$ & 2.294 & E & \\
\hline Common beech & 39 & $0.008-0.198$ & $2-7$ & $3-9$ & $16-176$ & 1960-1999 & $60-3671$ & 1.452 & $\mathrm{D}$ & \\
\hline Scots pine & 72 & $0.008-0.156$ & $3-6$ & $3-8$ & $16-150$ & 1954-1999 & $129-14450$ & 1.625 & E & \\
\hline Pedunculate oak & 72 & $0.008-0.255$ & $2-8$ & $3-16$ & $9-150$ & $1947-2004$ & $80-13356$ & 1.555 & $\mathrm{D}$ & \\
\hline Silver birch & 22 & $0.008-0.090$ & $2-8$ & $3-4$ & $7-125$ & 1984-1999 & $224-2927$ & 1.040 & $\mathrm{D}$ & \\
\hline \multicolumn{11}{|l|}{ Mixed stands } \\
\hline Douglas-fir-Beech & 17 & $0.032-0.315$ & $2-10$ & $1-6$ & $11-108$ & 1984-2003 & $84-6012$ & 0.908 & E-D & 1.78 \\
\hline Pine-Oak & 30 & $0.016-0.400$ & $2-8$ & $1-15$ & $12-160$ & 1949-2004 & $152-13789$ & 1.854 & $\mathrm{E}-\mathrm{D}$ & 0.78 \\
\hline Oak-Beech & 18 & $0.008-0.198$ & $4-7$ & $3-4$ & $19-265$ & 1984-1999 & $106-2753$ & 0.702 & $\mathrm{D}-\mathrm{D}$ & 2.11 \\
\hline Oak-Birch & 26 & $0.008-0.072$ & $4-7$ & $3-4$ & $10-86$ & 1984-1999 & 293-2195 & 0.757 & $\mathrm{D}-\mathrm{D}$ & 0.42 \\
\hline
\end{tabular}

Data are from minimum to maximum. Thinning history (mean value) was described as the average volume percentage that is removed from the stand on an annual basis, see Appendix 2.6. E: evergreen; D: deciduous 


\section{Plot selection}

In order to compare productivity in pure and mixed stands, we selected pure stands among permanent field plots where the corresponding species represented $90 \%$ of the stand basal area. Mixed stands are defined as stands in which the two species of interest together represented at least $80 \%$ of the total stand basal area, and the sum of the basal area of other species was lower than that of each of the two species studied (see Appendix 2.4 for a description of species basal area proportion per survey of per plot in mixed stands). Finally, we obtained 319 plots for pure stands and 91 plots for mixed stands and the plots were distributed all over the Netherlands (Figure 2.1). More plots were on poor sandy soil and relatively deep groundwater tables than on rich or wet soils according to the existing Dutch soil classification systems (Bose et al., 2014) .

\section{Statistical analysis}

\section{Mixing effect on stand productivity}

We tested whether the productivity of the mixed stands differs from each of the corresponding monocultures by using linear mixed-effects models (Eq.(1)).

$$
\begin{aligned}
\ln (P A I V)= & \beta_{0}+\beta_{1} \times \text { age }+\beta_{2} \times \text { stand }+\beta_{3} \times \text { age } \times \text { stand }+\beta_{4} \times H_{\mathrm{dom}}+\beta_{5} \times \text { thinning history } \\
& +\beta_{6} \times \text { plot }+\varepsilon
\end{aligned}
$$

where PAIV is the periodic annual volume increment $\left(\mathrm{m}^{3} \mathrm{ha}^{-1} \mathrm{year}^{-1}\right)$ (log-transformed); age is the stand age (years); stand is the dummy variable for mixed stands and the corresponding 2 pure stands; $H_{\mathrm{dom}}$ is the dominant height $(\mathrm{m})$, using as a proxy for site quality; thinning history is the average volume percentage that is removed from the stand on an annual basis (Appendix 2.6, Thinning history in mixtures and corresponding monocultures); $\varepsilon$ is the model residuals. We used volume growth as a measure of productivity, since it accounts for tree basal area and height which could change after species mixing because of different light requirement. We considered age, stand, $H_{\mathrm{dom}}$, and thinning history as fixed factors and plot as random factor to account for the repetitive measurement in the plots.

In order to compare stand productivity, we selected the same time span for every species combination in mixtures and their corresponding monocultures. All analyses were performed in R 3.2.0 (R Core Team, 2015). We used the lmer() function of the lme4 package (Bates et al., 2013) to analyse the relationship between PAIV and stand age in mixtures and monocultures. The default behaviour of $\operatorname{lmer(})$ to optimise the maximum likelihood criterion (ML) was used (Pinheiro and Bates, 2000). Normality and homogeneity of the model residuals were checked by visual inspections of diagnostic plots of residuals against fitted values (Figure. B2) (Zuur et al., 2009). All linear mixed-effects models were tested with random intercept, and with random intercept and slope to see whether stand age had a significant effect on PAIV. For each test, the model giving the lowest Akaike Information Criteria (AIC) was chosen, and we computed estimated p-values. We used r.squaredGLMM() 
function of the MuMIn package (Barton, 2013) to compare $\mathrm{R}^{2}$ (conditional) in logarithmic transformation models.

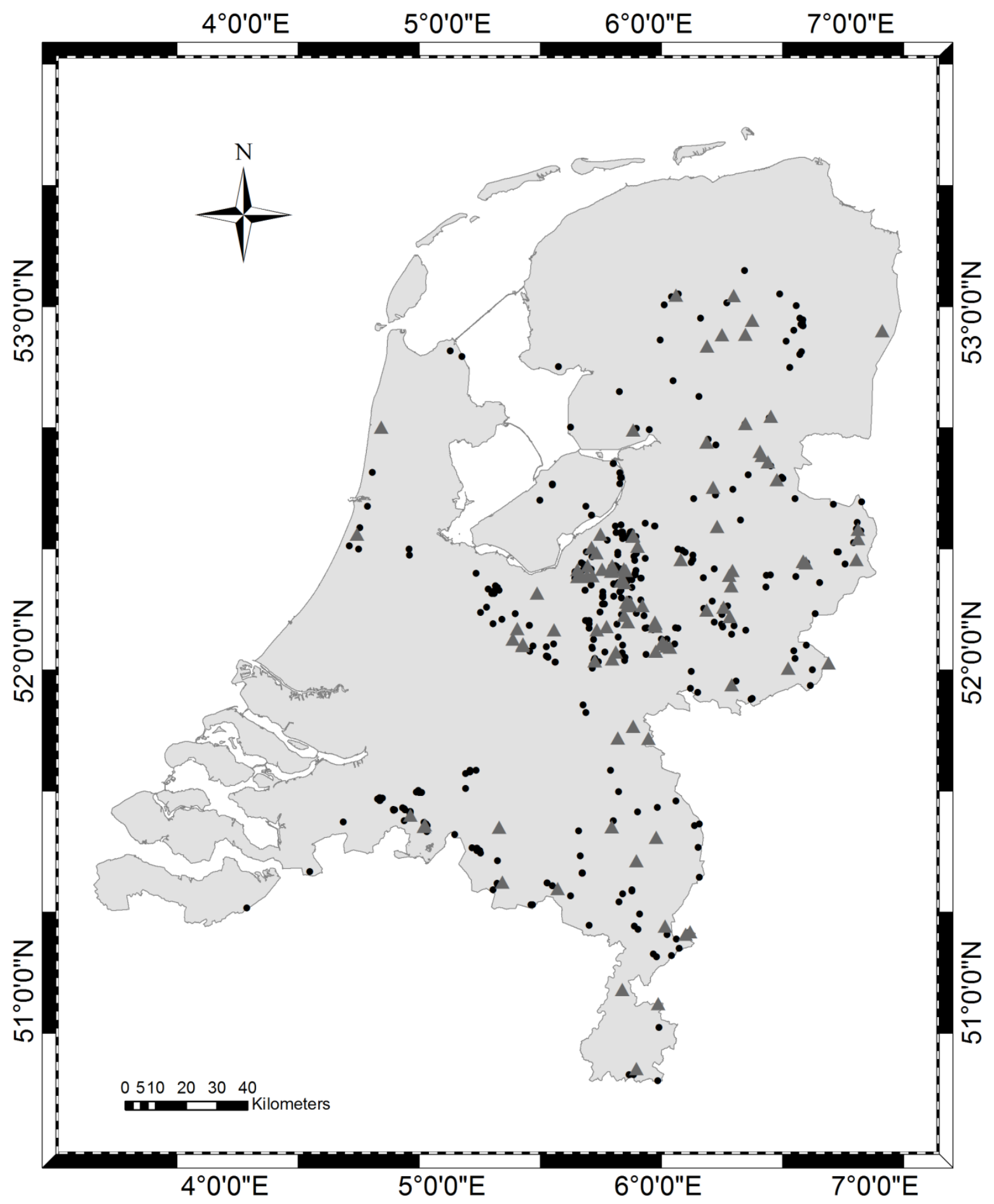

Figure 2.1 Distribution of the study plots from permanent fields in the Netherlands. Black dots are monocultures, grey triangles are mixtures. 
Table 2.2 Coefficients (Est.), standard errors (SE) and $P$-values $(P)$ of Eq.1 for log-transformed periodic annual volume increment (PAIV) in monocultures and mixtures, and possible factors site quality (expressed by $H_{\text {dom }}$ ) and thinning history. We used mixtures as a reference when we ran the linear mixed-effects models.

\begin{tabular}{|c|c|c|c|c|c|c|c|c|c|c|c|c|c|c|c|}
\hline \multicolumn{4}{|c|}{ Douglas-fir-common beech } & \multicolumn{4}{|c|}{ Scots pine-pedunculate oak } & \multicolumn{4}{|c|}{ Pedunculate oak-common beech } & \multicolumn{4}{|c|}{ Pedunculate oak-silver birch } \\
\hline Fixed effects & Est. & SE & $P$ & Fixed effects & Est. & SE & $P$ & Fixed effects & Est. & SE & $P$ & Fixed effects & Est. & SE & $P$ \\
\hline Douglas-fir-Beech & 3.0023 & 0.1564 & $<10^{-3}$ & Pine-Oak & 2.0311 & 0.1245 & $<10^{-3}$ & Oak-Beech & 2.4949 & 0.1920 & $<10^{-3}$ & Oak-Birch & 1.4050 & 0.2137 & $<10^{-3}$ \\
\hline Age & -0.0123 & 0.0027 & $<10^{-3}$ & Age & -0.0118 & 0.0016 & $<10^{-3}$ & Age & -0.0084 & 0.0022 & $<10^{-3}$ & Age & -0.0167 & 0.0040 & $<10^{-3}$ \\
\hline Douglas-fir & -0.3827 & 0.1574 & 0.0156 & Scots pine & -0.0541 & 0.1266 & 0.6695 & Pedunculate oak & -0.6307 & 0.1825 & $<10^{-3}$ & Pedunculate oak & 0.2839 & 0.2084 & 0.1761 \\
\hline Common beech & -0.5950 & 0.1784 & $<10^{-3}$ & Pedunculate oak & -0.4140 & 0.1253 & 0.0011 & Common beech & -0.0855 & 0.2042 & 0.6760 & Silver birch & 0.0021 & 0.2447 & 0.9931 \\
\hline $\mathrm{H}_{\mathrm{dom}}$ & 0.0096 & 0.0063 & 0.1251 & $\mathrm{H}_{\mathrm{dom}}$ & 0.0253 & 0.0063 & $<10^{-3}$ & $\mathrm{H}_{\mathrm{dom}}$ & -0.0037 & 0.0074 & 0.6202 & $\mathrm{H}_{\mathrm{dom}}$ & 0.0442 & 0.0105 & $<10^{-3}$ \\
\hline Thinning history & 0.0018 & 0.0081 & 0.8255 & Thinning history & -0.0109 & 0.0077 & 0.1584 & Thinning history & -0.0041 & 0.0134 & 0.7601 & Thinning history & -0.0150 & 0.0127 & 0.2393 \\
\hline AgexDouglas-fir & 0.0011 & 0.0026 & 0.6645 & Age $\times$ Scots pine & -0.0024 & 0.0018 & 0.1799 & Agexpedunculate oak & 0.0025 & 0.0020 & 0.2213 & Agexpedunculate oak & -0.0004 & 0.0041 & 0.9146 \\
\hline Agexcommon beech & 0.0061 & 0.0030 & 0.0427 & Agexpedunculate oak & 0.0020 & 0.0017 & 0.2283 & Agexcommon beech & 0.0057 & 0.0024 & 0.0183 & Agexsilver birch & -0.0094 & 0.0055 & 0.0863 \\
\hline \multicolumn{4}{|l|}{ Random effects } & \multicolumn{4}{|l|}{ Random effects } & \multicolumn{4}{|l|}{ Random effects } & \multicolumn{4}{|l|}{ Random effects } \\
\hline Name & Variance & Std. dev. & & Name & Variance & Std. dev & & Name & Variance & Std. de & & Name & Variance & Std & lev. \\
\hline plot (Intercept) & 0.0597 & 0.2444 & & plot (Intercept) & 0.0286 & 0.1691 & & plot (Intercept) & 0.0794 & 0.2818 & & plot (Intercept) & 0.0762 & 0.27 & \\
\hline Residual & 0.1616 & 0.4020 & & Residual & 0.1473 & 0.3837 & & Residual & 0.1557 & 0.3947 & & Residual & 0.1231 & 0.35 & \\
\hline
\end{tabular}

$\mathrm{H}_{\mathrm{dom}:}$ dominant height. 
Table 2.3 Coefficients (Est.), standard errors (SE) and $P$-values $(P)$ of final models for log-transformed periodic annual volume increment (PAIV) in different monocultures and mixtures. We used mixtures as a reference when we ran the linear mixed-effects models.

\begin{tabular}{|c|c|c|c|c|c|c|c|c|c|c|c|c|c|c|c|}
\hline \multicolumn{4}{|c|}{ Douglas-fir-common beech } & \multicolumn{4}{|c|}{ Scots pine-pedunculate oak } & \multicolumn{4}{|c|}{ Pedunculate oak-common beech } & \multicolumn{4}{|c|}{ Pedunculate oak-silver birch } \\
\hline Fixed effects & Est. & SE & $\boldsymbol{P}$ & Fixed effects & Est. & SE & $P$ & Fixed effects & Est. & SE & $\boldsymbol{P}$ & Fixed effects & Est. & SE & $P$ \\
\hline Douglas-fir-Beech & 2.9651 & 0.0906 & $<10^{-3}$ & Pine-Oak & 1.9500 & 0.0934 & $<10^{-3}$ & Oak-Beech & 2.4585 & 0.1732 & $<10^{-3}$ & Oak-Birch & 1.4540 & 0.1417 & $<10^{-3}$ \\
\hline Age & -0.0072 & 0.0010 & $<10^{-3}$ & Age & -0.0120 & 0.0009 & $<10^{-3}$ & Age & -0.0090 & 0.0019 & $<10^{-3}$ & Age & -0.0178 & 0.0023 & $<10^{-3}$ \\
\hline Douglas-fir & -0.3070 & 0.0780 & $<10^{-3}$ & Scots pine & -0.1850 & 0.0566 & 0.0012 & Pedunculate oak & -0.6319 & 0.1796 & $<10^{-3}$ & Pedunculate oak & 0.2557 & 0.0805 & 0.0022 \\
\hline \multirow[t]{4}{*}{ Common beech } & -0.3126 & 0.0758 & $<10^{-3}$ & Pedunculate oak & -0.2711 & 0.0496 & $<10^{-3}$ & Common beech & -0.0879 & 0.2009 & 0.6620 & Silver birch & -0.3532 & 0.1026 & $<10-3$ \\
\hline & & & & $\mathrm{H}_{\mathrm{dom}}$ & 0.0298 & 0.0061 & $<10^{-3}$ & & & & & $\mathrm{H}_{\mathrm{dom}}$ & 0.0438 & 0.0104 & $<10^{-3}$ \\
\hline & & & & & & & & Age $\times$ pedunculate oak & 0.0026 & 0.0020 & 0.1981 & & & & \\
\hline & & & & & & & & Age $\times$ common beech & 0.0057 & 0.0024 & 0.0175 & & & & \\
\hline \multicolumn{4}{|l|}{ Random effects } & \multicolumn{4}{|l|}{ Random effects } & \multicolumn{4}{|l|}{ Random effects } & \multicolumn{4}{|l|}{ Random effects } \\
\hline Name & Variance & Std. & & Name & Variance & Std. & & Name & Variance & Std. dev. & & Name & Variance & Std. dev. & \\
\hline plot (Intercept) & 0.0614 & 0.247 & & plot (Intercept) & 0.0253 & 0.158 & & plot (Intercept) & 0.0714 & 0.2672 & & plot (Intercept) & 0.0662 & 0.2572 & \\
\hline Residual & 0.1615 & $0.402-2$ & & Residual & 0.1509 & 0.388 & & Residual & 0.1550 & 0.3937 & & Residual & 0.1234 & 0.3513 & \\
\hline
\end{tabular}

$\mathrm{H}_{\text {dom: }}$ dominant height. 


\section{Results}

In line with our first hypothesis, the two evergreen-deciduous mixtures showed overyielding over the time period studied. The Douglas-fir-beech mixtures produced between $35.9 \%$ and $36.7 \%$ more stem volume per hectare per year compared to Douglas-fir and beech monocultures, respectively (Figure 2.2a, Table 2.3), and the pine-oak mixtures produced between $20.3 \%$ and $31.2 \%$ more stem volume per hectare per year compared to pine and oak monocultures, respectively (Figure 2.2b, Table 2.3). However, the other two deciduousdeciduous mixtures, oak-beech and oak-birch, did not show any significant overyielding (Figure 2.2c,d and Table 2.3).

Moreover, oak-beech mixtures were more productive than oak monocultures, but they did not differ in stand productivity (i.e. PAIV) from beech monocultures in the young stands (Table 2.3), and their production was in-between the two monocultures at later ages. Oakbirch mixtures had a higher PAIV than birch monocultures, and they also had a lower PAIV than oak monocultures (Table 2.3). These results were robust for possible effects of site quality and thinning history: site quality contributed positively to PAIV and thinning history had no significant effect on PAIV, but did not affect possible overyielding effects (Table 2.2 and Table 2.3).

In contrast to our second hypothesis, the observed overyielding was constant with stand development (Figure 2.2) and did not result in divergent patterns in standing volume over time (Figure 2.3). Changes in overyielding with age were similar across mixed-species stands and corresponding pure stands, as illustrated by lack of significant age $\times$ stand interaction effects (Table 2.3).

Age trends in stand productivity did not run parallel to age trends in standing volume. Overall, individual forest stands developed faster in volume per year than expressed by longterm based trends in volume increment, but faced drops in volume in years of thinning (Figure 2.3). Apparently, the drops in standing volume were compensated later by higher volume increment rates in-between thinnings. 

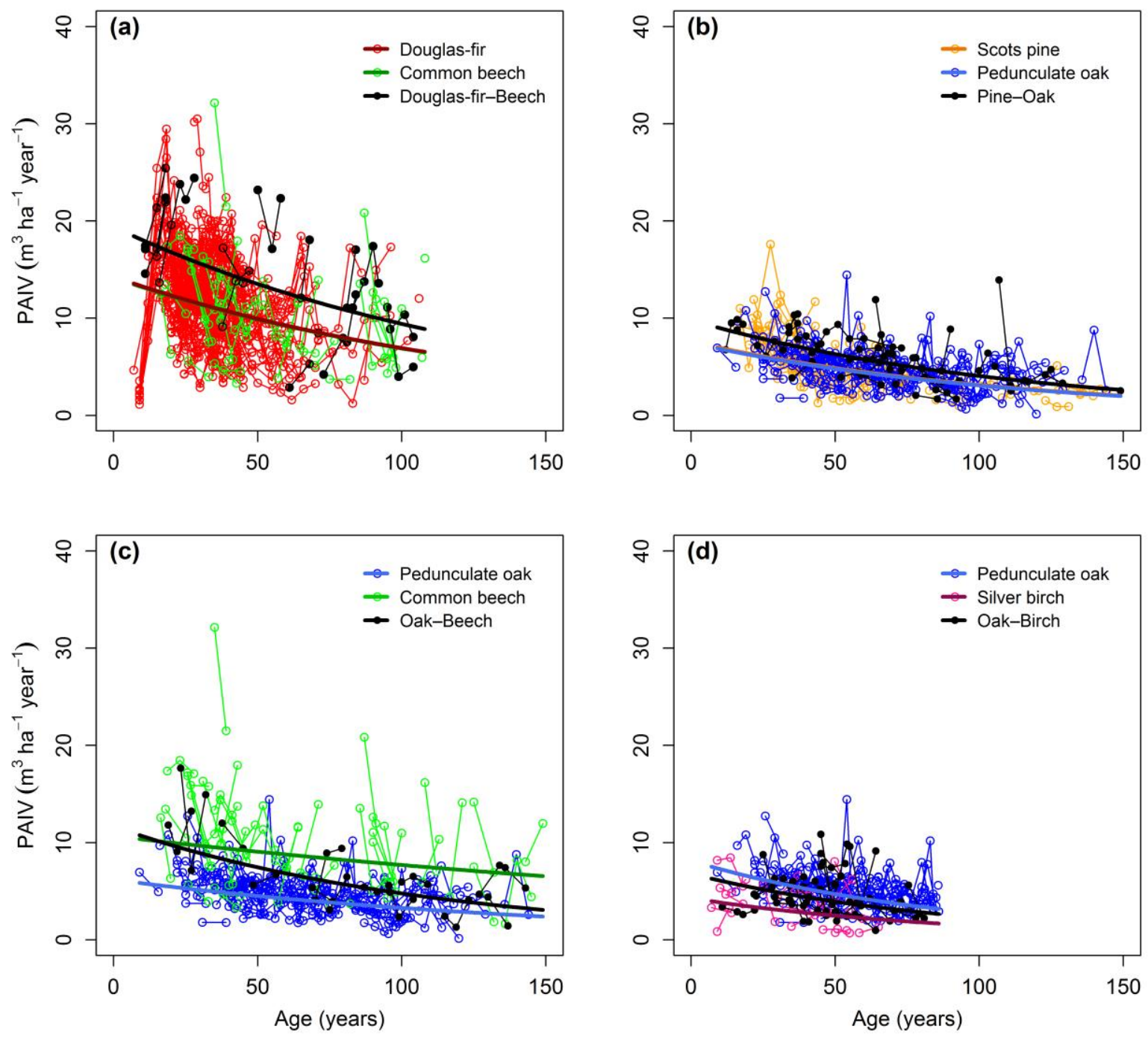

Figure 2.2 Periodic annual volume increment (PAIV) in mixtures and corresponding monocultures over time.

(a) PAIV in Douglas-fir and beech monocultures and Douglas-fir-beech mixtures, respectively. (b) PAIV in pine and oak monocultures and pine-oak mixtures, respectively. (c) PAIV in oak and beech monocultures and oakbeech mixtures, respectively. (d) PAIV in oak and birch monocultures and oak-birch mixtures, respectively. The dots connected by same colour, solid thin lines are PAIV from one permanent field plot, which was repeatedly measured. The solid bold lines are regression lines with fitted final linear mixed-effects models without dominant height effect from Table 2.3. 

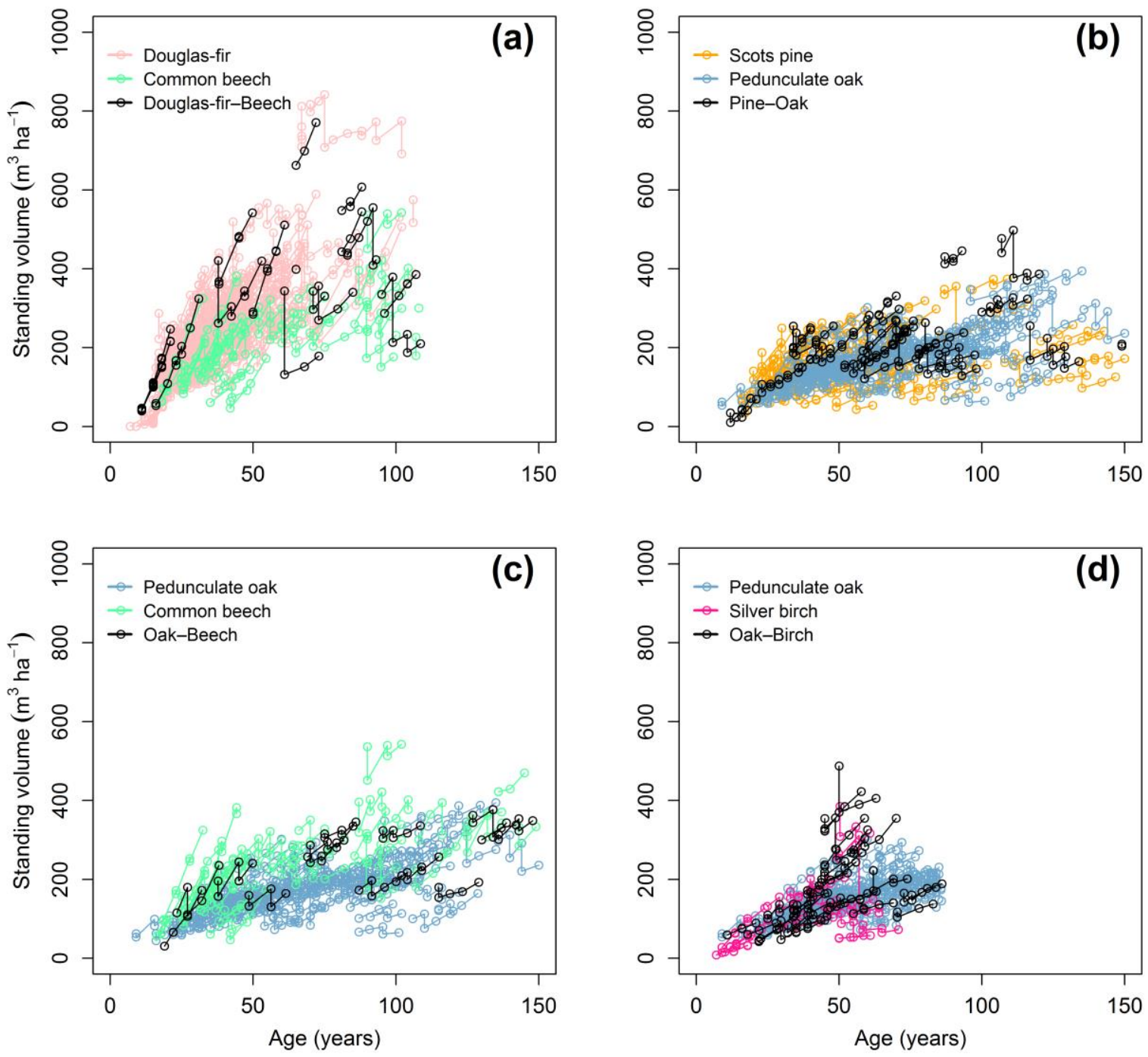

Figure 2.3 Standing volume over time in mixed stands and corresponding monocultures.

(a) Standing volume in Douglas-fir and beech monocultures and Douglas-fir-beech mixtures, respectively.

(b) Standing volume in pine and oak monocultures and pine-oak mixtures, respectively. (c) Standing volume in oak and beech monocultures and oak-beech mixtures, respectively. (d) Standing volume in oak and birch monocultures and oak-birch mixtures, respectively. The dots connected by same colour, solid lines are observations before and after thinning from one permanent field plot, which was repeatedly measured.

\section{Discussion}

We studied the effect of species mixing on stand productivity of permanent field plots in temperate forests in the Netherlands. We showed that stand productivity consistently decreased with age, and that mixing species led to overyielding in evergreen-deciduous species mixtures across all stand ages but not in deciduous-deciduous mixtures. Moreover, these results were robust as they were not affected by possible effects of site conditions and thinning histories. Next, we compare our results with the reported results on other evergreen- 
deciduous and deciduous-deciduous mixtures in other conditions, and speculate on different possible mechanisms underlying overyielding.

We expected that tree species mixtures that consist of evergreen and deciduous species and of species that differ in shade tolerance would show overyielding because of complementary resource use by the two different species. As expected, the evergreendeciduous species mixtures showed overyielding, relative to the respective monospecific stands. The stronger overyielding in Douglas-fir-beech relative to pine-oak mixtures may be attributed to the greater difference in shade tolerance. Both deciduous-deciduous species mixtures did not significantly overyield, probably because complementary resource use was limited by synchronization in leaf phenology. Second, we hypothesised that overyielding through complementary resource use would decrease with stand development. This hypothesis, however, was not confirmed by our results: overyielding was constant over the whole studied stand ages. This contradicts a previous simulation study in which overyielding occurred only in the first 10 years (Bartelink, 2000). Instead, the lack of age $\times$ stand interaction effects suggests that the same level of overyielding was maintained in the two evergreen-deciduous mixtures over the whole range of observed stand ages ( 6-150 years). Possibly, the intensive thinning regimes in Dutch forests (Appendix 2.7) maintain the available resource levels relatively high at any forest age, and may thus enhance the possibilities for complementary resource use over the whole range of stand ages studied.

We also found that stand productivity decreased with stand age in all studied forest stands (Figure 2.2). At first sight, this result seems to differ from findings that emphasize that stand productivity generally peaks at low stand ages after stand closure (e.g. 10 years), and then goes down gradually (Ryan et al., 1997). Yield tables also show such an intermediate peak in productivity (Jansen et al., 1996). Our dataset, however, was strongly biased towards stand ages after full stand closure, with most plots older than 15 years and some more than 150 years (Table 2.1). Over this age range, the different monocultures and mixtures decreased in stand productivity with increasing stand age (Figure 2.2).

In our analysis, we tested whether the trends in stand productivity and overyielding could partially be attributed to two possible factors. First, the large variation in productivity across forest sites may be attributed to differences in site quality, e.g. poor versus rich soils. As the stress-gradient hypothesis addresses, there is a transition from competition in favourable environments to facilitation in harsh environments (Bertness and Callaway, 1994). Therefore, stand productivity and overyielding may be dependent on the different species interactions. Soil fertility is known to be related to soil texture and access to soil water (De Kovel et al., 2000), but is complex to quantify because soils are notoriously heterogeneous and the role of limited resources is still debated and largely hypothetical. For this reason, foresters use dominant height (the height of the largest tree for a given stand age) as a proxy for site quality (Condés et al., 2013; Forrester et al., 2013b). Our analyses showed, as expected, positive effects of site quality on stand productivity, when using dominant height as a proxy for site quality (Table 2.3). However, site quality did not explain the observed overyielding in the two 
evergreen-deciduous species mixtures. Second, through thinning, forest managers keep the increase in standing volume at low levels and forest stands therefore never reached the expected equilibrium state of low net productivity. The variation in thinning history across plots did not significantly influence the stand productivity in the years after thinning (Table 2.2). Overall, the observed overyielding in 2 of the 4 mixtures was unaffected by site quality and thinning history, and was maintained over the full range of observed stand ages.

Our observation that overyielding occurs in evergreen-deciduous species mixtures but not in deciduous-deciduous species mixtures is partially supported in the literature. For example, Toigo et al. (2015) showed that most evergreen-deciduous species mixtures tended towards overyielding (but not always significant), but not deciduous-deciduous species mixtures (sessile oak-common beech). However, some studies did show overyielding (Condés et al., 2013; Dirnberger and Sterba, 2014; Pretzsch et al., 2015b) for evergreendeciduous species mixtures while other findings are not in line with this (Del Río and Sterba, 2009; Toïgo et al., 2015), thus also contrasting our result. Douglas-fir-beech overyielding was confirmed by one study in the Netherlands (Hendriks and Bianchi, 1995), which supports the idea that differences in leaf phenology and shade tolerance (Table 2.1 and Appendix 2.3) may contribute to overyielding of this mixture. Moreover, overyielding of the mixture was explained by more hidden causes of complementary resource use by, e.g. differential roots distributions (Hendriks and Bianchi, 1995; Reyer et al., 2010). However, whether overyielding for this species combination is maintained over broader climate gradients is not clear, since all of these studies referred to the temperate forests of the Netherlands. Pine-oak overyielding is in line with a modelling approach study for only one site of France (Perot and Picard, 2012), but is not consistent with an empirical study from French inventory data (Toïgo et al., 2015). Possibly, the small overyielding effects in this species combination (our results) are confounded when comparing forests over broad climate gradient, as done by Toigo et al. (2015). In our and Perot \& Picard's study (Perot and Picard, 2012), climate variation was rather limited, which may allow for showing actual overyielding in those forests. Most of other evergreen-deciduous species mixtures showed overyielding, e.g. Scots pine-common beech (Condés et al., 2013; Pretzsch et al., 2015b), Norway spruce-common beech (Pretzsch and Schütze, 2009; Dirnberger and Sterba, 2014; Toïgo et al., 2015) and silver fir-common beech (Toïgo et al., 2015). However, combinations of different pine with oak species showed very contrasting results: from lack of overyielding in central-north Spanish and French forests (Del Río and Sterba, 2009; Toïgo et al., 2015) to 48\% overyielding in central Spanish forests (Jucker et al., 2014a). However, conclusions on mechanisms remain speculative because there might be more mechanisms operating than differences in leaf phenology or shade tolerance. For instance, evergreen-deciduous species mixtures may benefit from increased atmospheric deposition of limited nutrients (André et al., 2008; Pretzsch et al., 2013a), more litter fall and accelerated nutrient turnover (Richards et al., 2010) and have more stable growth over time (Jucker et al., 2014b), which has been mentioned as alternative mechanisms contributing to overyielding. It appears that we cannot easily generalize overyielding resulting from mixing 
evergreen-deciduous species, partially because of interaction effects of climate or soil or due to differences in thinning history. But we can conclude that overyielding probably occurs in evergreen-deciduous species mixtures at a local scale.

With respect to deciduous-deciduous species mixtures, some studies did not find overyielding (Toïgo et al., 2015), which agrees with our results. However, others reported overyielding in oak-beech mixtures (Pretzsch et al., 2013a), but only in relatively poor site conditions (dominant height below $25 \mathrm{~m}$ at age 100 years) whereas underyielding occurred in relatively rich sites (dominant height between $25 \mathrm{~m}$ and $35 \mathrm{~m}$ at age 100 years). They argue that the overyielding on poor soils resulted from effective complementary resource use, e.g. differences in root distributions or shade tolerance (Pretzsch et al., 2013a), whereas such complementary resource use is less likely to occur on richer soils. Since the dominant height of our oak-beech mixed stands is in-between these forests on relatively poor and rich sites (Appendix 2.5), the lack of any significant overyielding seems in line with the site quality of our study stands. As documented from previous findings, beech may be a more successful competitor for aboveground and belowground resources than oak (Rewald and Leuschner, 2009; Longuetaud et al., 2013); therefore, overyielding of beech could be balanced by underyielding of oak in our study. Another explanation is that the dominant height differences between the species explain the lack of overyielding. Beech is more shade tolerant, but it was dominant (taller trees) over oak (shorter trees) in most of our oak-beech mixtures, so that shade tolerance differences, with the more light demanding oak in the understory, cannot directly contribute to overyielding. The other deciduous-deciduous species mixtures, oakbirch, did not show any overyielding either. This agrees with those species being rather similar in leaf phenology and shade tolerance (Table 2.1 and Appendix 2.3). Yet, the results on overyielding in deciduous-deciduous species mixtures are scarce, still ambiguous and context-dependent.

\section{Conclusions}

We can conclude that our results imply strong contributions of differences in leaf phenology in combination with contrasting shade tolerance to overyielding. Remarkably, overyielding in evergreen-deciduous species mixtures was maintained with stand development. Overall, our studies suggest that, relative to monospecific stands, mixtures of evergreen-deciduous tree species that differ in shade tolerance can be a good option for increasing diversity and productivity of temperate forests.

\section{Acknowledgements}

We thank Hans Jansen for compiling data and Leo Goudzwaard for data collection. We would also like to thank Lourens Poorter, Monique Weemstra for discussions and Mart-Jan Schelhaas for providing Dutch soil classification systems. We are grateful to Masha van der 
Sande, Merel Jansen, Peter Groenendijk and Danaë Rozendaal for their assistance with data analysis. H.C.L. acknowledges the financial support from the China Scholarship Council (No. 201306600022). The manuscript also benefited from the constructive comments and suggestions by anonymous reviewers.

\section{Data Accessibility}

FEM growth and yield data for this study are archived at the EASY online archiving system of the Dutch Data Archiving and Networked Services (DANS):

DOI for Douglas-fir monocultures: http://dx.doi.org/10.17026/dans-x9t-rxd7.

DOI for Common beech monocultures: http://dx.doi.org/10.17026/dans-zfh-yght.

DOI for Scots pine monocultures: http://dx.doi.org/10.17026/dans-zkq-r6yc.

DOI for Pedunculate oak monocultures: http://dx.doi.org/10.17026/dans-2ck-zpgk.

DOI for Silver birch monocultures: http://dx.doi.org/10.17026/dans-zth-5df8.

DOI for Mixed-species stands: http://dx.doi.org/10.17026/dans-z5m-kp67. 


\section{Appendix}

Appendix 2.1 Permanent field sites and data collection

\section{Stand history}

The data used in this study are part of FEM growth and yield database, which belongs to Forest Ecology and Forest Management Group, Wageningen University. The dataset is a collection of growth and yield data from even-aged monocultures, even-aged mixed-species forest plots. They were established from saplings at earliest 1920 year and had been repeatedly measured for several times since then. In total, there are 1311 pure stand plots and 135 mixed-species stand plots.

\section{Missing tree diameter and height calculation}

Most of diameter at breast height (dbh) (91.3\%) and height (65.3\%) of trees were measured. Some trees were not measured, probably omitted or marked for harvesting (but was not harvested during measurements). We used models to estimate tree dbh and height for unmeasured trees (for details, see Data Accessibility).

\section{Dominant height}

Each plot was divided into one or more subplots. The mean height of the thickest trees in the subplots was dominant height for monocultures. For mixed stands, the dominant height depended on the larger dominant height of mixing species.

\section{Individual tree volume calculation}

We used Eq.(A1) to estimate tree volume (over stem bark) for the trees which both dbh and height were measured.

$v=e^{\mathrm{c} 3} * d b h^{\mathrm{c} 1} * h^{\mathrm{c} 2}$

with $d b h$ in $\mathrm{cm}, h$ in $\mathrm{m}$ and $v$ in $\mathrm{dm}^{3}$.

Then we got the relationship between tree volume and dbh (for calculation details, see online data in Data Accessibility). We applied this to estimate volume for all the trees of this study. For the parameters $c_{1}, c_{2}, c_{3}$, they are species-specific and we list here (Appendix 2.2) the main species we studied, cited from Jansen (Jansen et al., 1996).

Appendix 2.2 Species-specific parameters for individual tree volume calculation based on Eq.(A1).

\begin{tabular}{lllll}
\hline & & \multicolumn{3}{l}{ Parameter } \\
\cline { 3 - 5 } Species & Common name & $\mathbf{c}_{\mathbf{1}}$ & $\mathbf{c}_{\mathbf{2}}$ & $\mathbf{c}_{\mathbf{3}}$ \\
\hline Pseudotsuga menziesii & Douglas-fir & 1.90053 & 0.80762 & -2.43151 \\
Fagus sylvatica & Common beech & 1.86116 & 1.04313 & -3.05257 \\
Pinus sylvestris & Scots pine & 1.82075 & 1.07427 & -2.88085 \\
Quercus robur & Pedunculate oak & 1.82628 & 1.11342 & -3.04885 \\
Betula pendula & Silver birch & 1.54291 & 1.24235 & -2.66506 \\
\hline
\end{tabular}


Appendix 2.3 Shade and drought tolerance indices (Niinemets and Valladares, 2006) for species studied.

\begin{tabular}{llll}
\hline Species & Common name & Shade tolerance index & Drought tolerance index \\
\hline Pseudotsuga menziesii & Douglas-fir & $2.78 \pm 0.18$ & $2.62 \pm 0.41$ \\
Fagus sylvatica & Common beech & $4.56 \pm 0.11$ & $2.40 \pm 0.43$ \\
Pinus sylvestris & Scots pine & $1.67 \pm 0.33$ & $4.34 \pm 0.47$ \\
Quercus robur & Pedunculate oak & $2.45 \pm 0.28$ & $2.95 \pm 0.31$ \\
Betula pendula & Silver birch & $2.03 \pm 0.09$ & $1.85 \pm 0.21$ \\
\hline
\end{tabular}

Appendix 2.4 Species basal area proportion per survey of per plot in mixed stands. The dots represent the plot selection criteria used. Dots that are and are not on the grey diagonal line stand for where the two species studied represent $100 \%$ and $80-100 \%$ of the basal area, respectively.
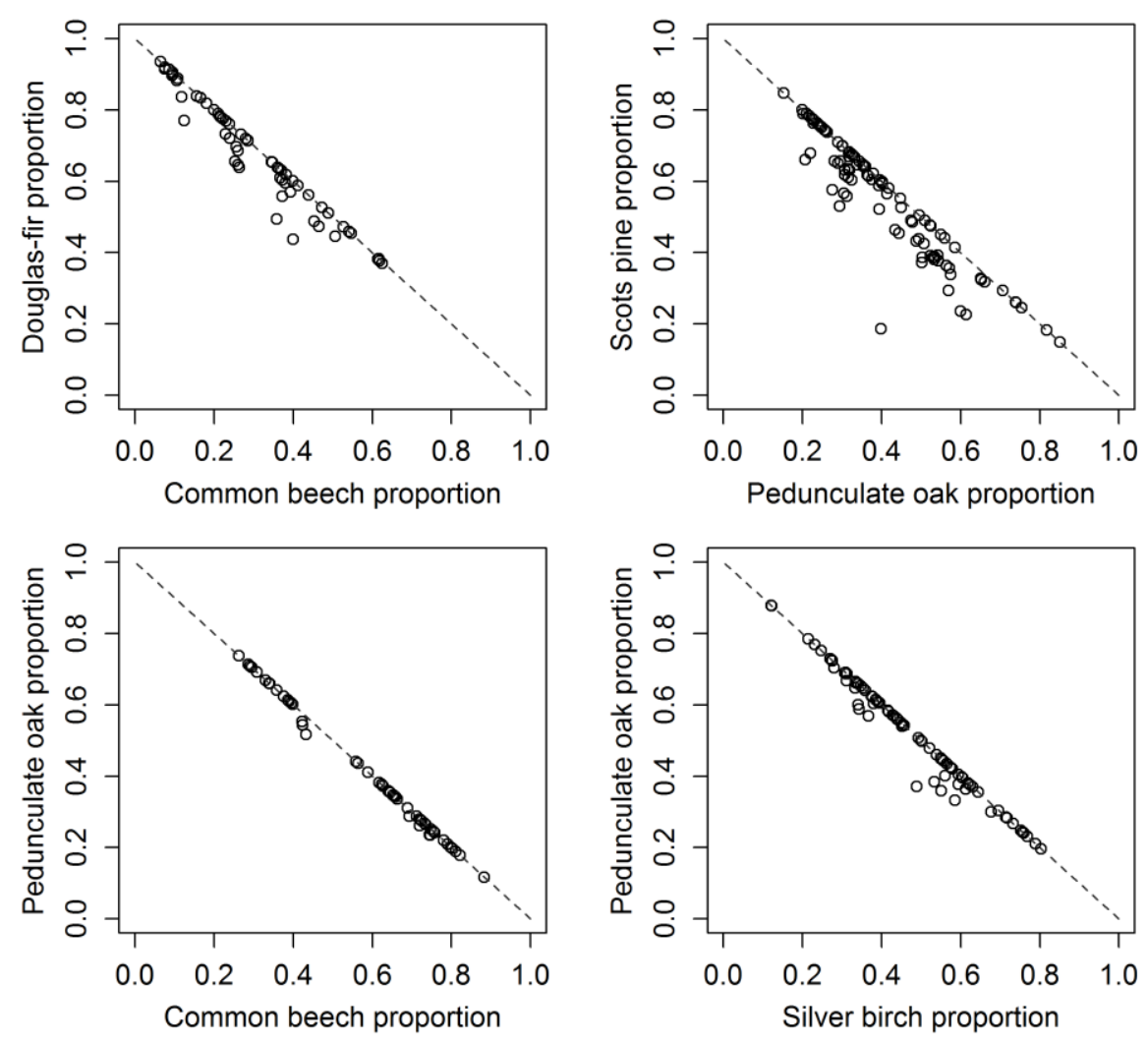
Appendix 2.5 Dominant height over time in oak-beech mixtures and their corresponding monocultures. Vertical dashed red line means dominant height at 100 years.

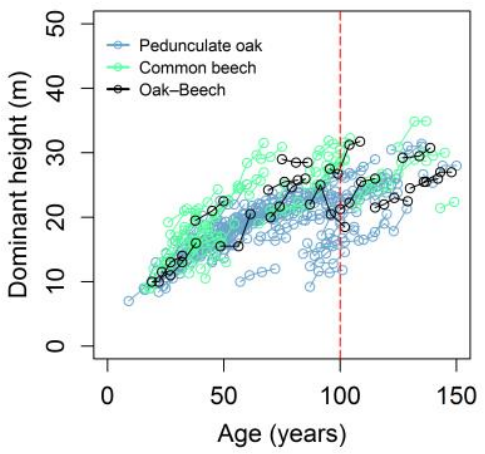

Appendix 2.6: Thinning history in mixtures and respective monocultures.

In this study, thinning was considered a potential factor influencing the standing volume. We used the following equations (Eq.(A2), Eq.(A3), Eq.(A4), and Eq.(A5)) to calculate the percent of volume removed and thinning interval.

Volume removed percent $=$ volume of thinned $/$ standing volume before thinning

Thinning frequency $=$ times of thinning $/$ times of measurement $\times$ mean measurement interval

Thinning interval $=1 /$ thinning frequency

Thinning history $=$ Volume removed percent $/$ Thinning interval

We used Kruskal-Wallis and Scheffe's test for volume removed percent and thinning interval.

Appendix 2.7 Volume removed percent and thinning intervals in monocultures and mixtures. (a) Volume removed percent. (b) Thinning intervals. Values with the different letters denote significant difference among stands at $\mathrm{a}=0.05$ based on Scheffe's test.
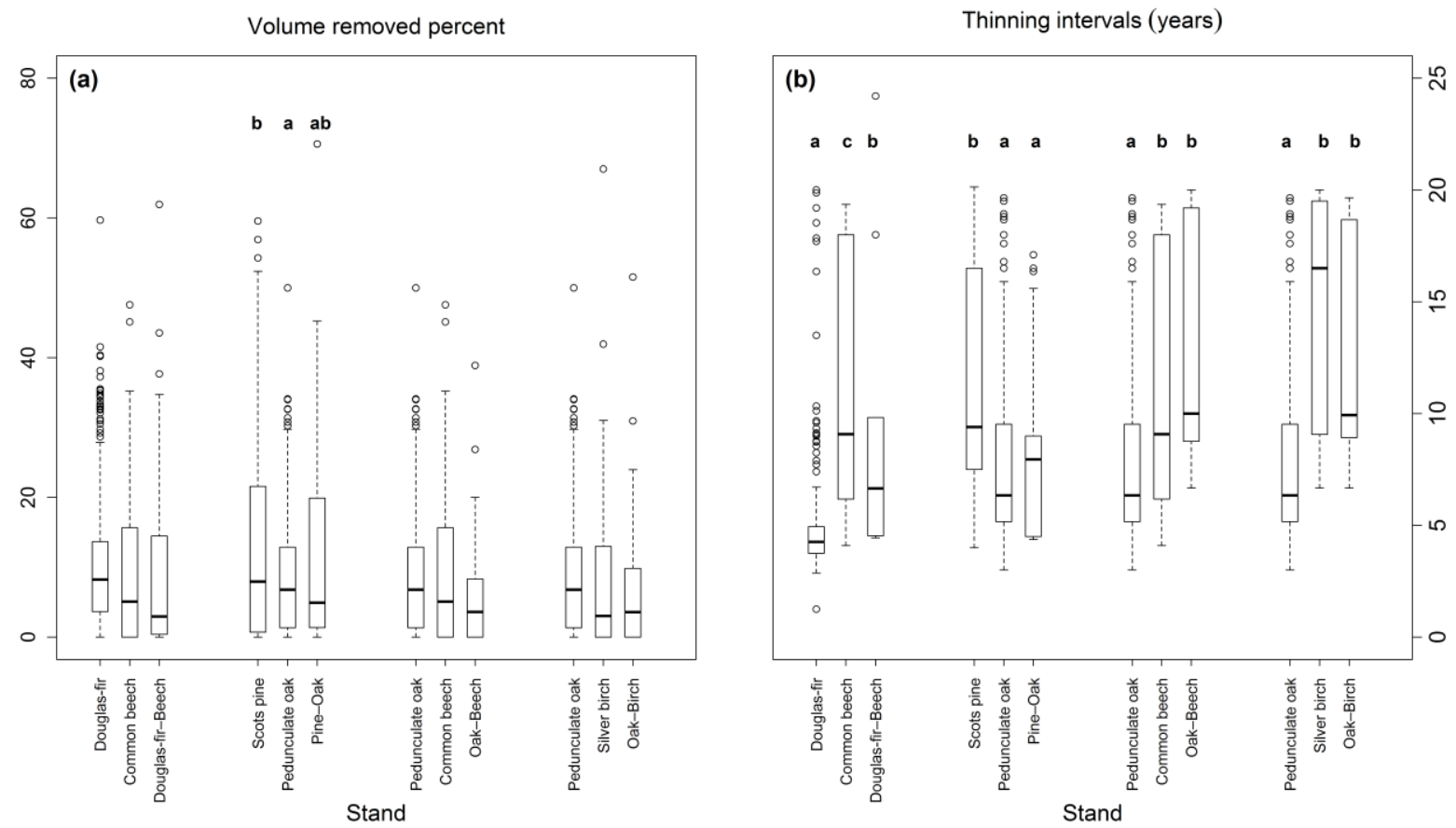
For each of the four species combinations, there was no significant difference in volume removed percent in monocultures in comparison to mixtures. With respect to thinning intervals, all the four species combinations differed significantly between monocultures and mixtures $(P<0.05)$.

Appendix 2.8 Residuals vs. predicted log-transformed PAIV over time for different species combinations based on final models in Table 2.3. (a) Douglas-fir and beech monocultures and Douglas-fir-beech mixtures. (b) Pine and oak monocultures and pine-oak mixtures. (c) Oak and beech monocultures and oak-beech mixtures. (d) Oak and birch monocultures and oak-birch mixtures.
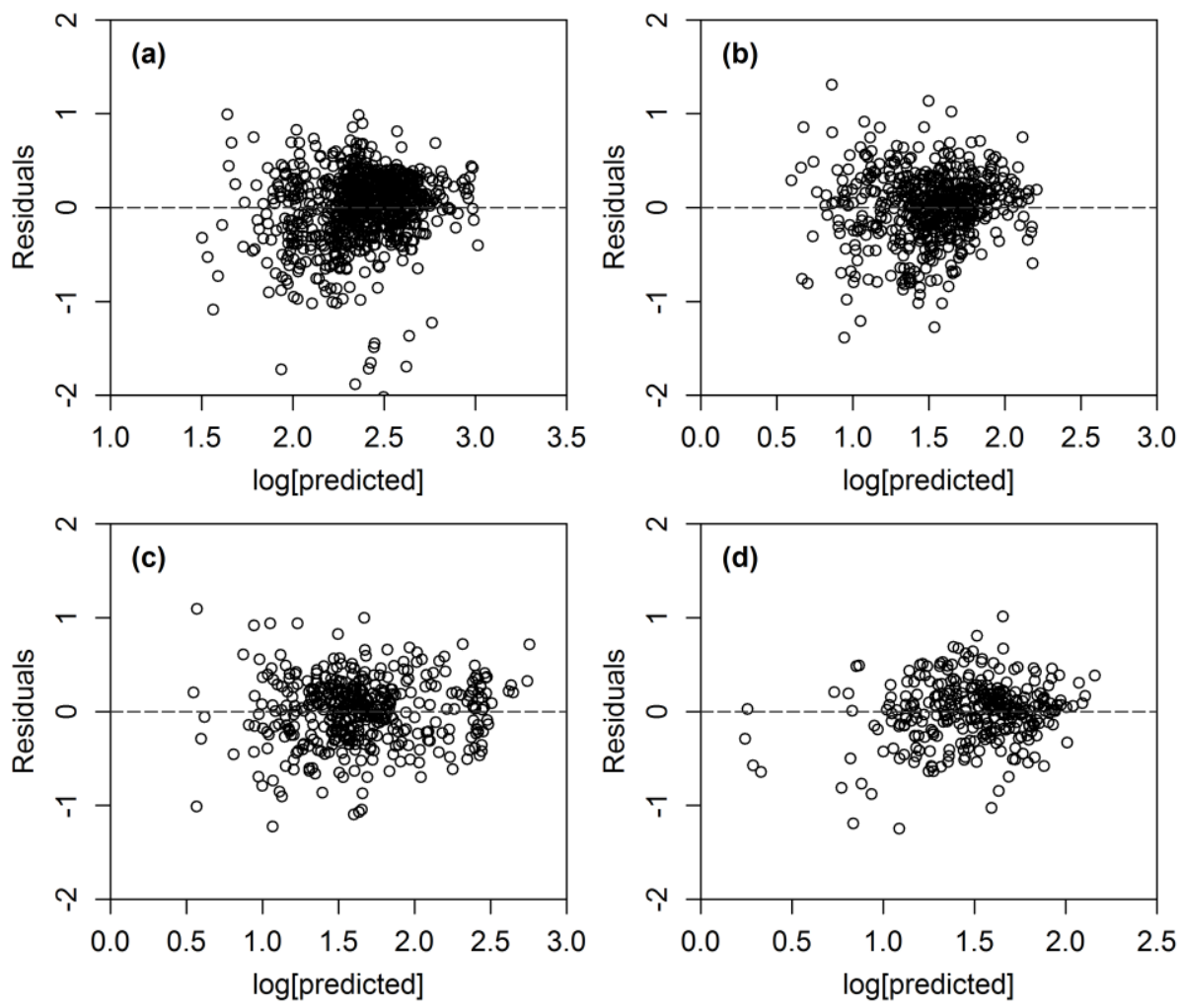
当局者迷，旁观者清

一中国俗语

Lookers-on see more than players.

-Chinese proverb 


\section{Abstract}

A growing number of studies provide evidence that mixed-species forests often have higher stand productivity than monospecific forests, which is referred to as overyielding. In this study, we explored how the combination of species and soil conditions affect overyielding in mixed Dutch forests. Firstly, we hypothesised that the fast-growing light-demanding species dominates the slow-growing shade-tolerant species in mixed-species stands, and that the overyielding is caused by higher exposure of fast-growing species, in combination with complementary light use of the suppressed slow-growing species. Secondly, we expected that this overyielding will be stronger at poor soils than at rich soils, since facilitation or complementary soil resource use is often favoured at poor soils as suggested by the stressgradient hypothesis. Alternatively, overyielding would be stronger at rich soils, because the species interactions result in a reduction in competition for light and thus higher complementarity. We evaluated our hypotheses by analysing five species: Douglas-fir (Pseudotsuga menziesii (Mirb.) Franco), common beech (Fagus sylvatica L.), Scots pine (Pinus sylvestris L.), pedunculate oak (Quercus robur L.), and silver birch (Betula pendula Roth) growing in Douglas-fir-common beech, Scots pine-pedunculate oak , pedunculate oakcommon beech, and pedunculate oak-silver birch mixtures from 398 permanent field plots all over the Netherlands. We found that the Douglas-fir-common beech and Scots pinepedunculate oak mixtures always showed overyielding. This overyielding was largely attributed to the fast-growing Douglas-fir in the former mixture and to the slow-growing shade-tolerant pedunculate oak in the latter mixture, respectively. In both cases, overyielding was stronger at poor soils than at rich soils. The pedunculate oak-common beech mixtures overyielded at poor soils and underyielded at rich soils, which was attributed to the response of the common beech. Overyielding was not observed for the pedunculate oak-silver birch mixtures, irrespective of soil conditions. The results do not support our first hypothesis since overyielding was not always driven by fast-growing light-demanding species. Overyielding was stronger for evergreen-deciduous species combinations, suggesting that differences in leaf phenology are a major driver of overyielding. Secondly, our results imply that overyielding is much stronger at poor soils than at rich soils, which is in line with the prediction of the stress-gradient hypothesis. We conclude that the growth of one species benefits from the admixture species, particularly in evergreen-deciduous species mixtures and that soils affect the extent of overyielding as studied in the Netherlands.

Keywords: Species mixture effect; Niche complementarity; Productivity; Soil;

Volume growth. 


\section{Introduction}

Forest management practices often have turned traditional monospecific stands into mixed stands in Europe over the last decades (Bravo-Oviedo et al., 2014), not only because mixed stands increase biodiversity and ecosystem services of forests (van der Plas et al., 2016), but also because they can be more stable, resilient and productive than monospecific stands (Vilà et al., 2013; Jucker et al., 2014b; Lu et al., 2016; Thurm et al., 2016b; Del Río et al., 2017). The phenomenon of a higher production in mixed stands compared to pure stands is also referred to as overyielding.

A mechanism that is often proposed for explaining overyielding is niche complementarity in resource use by the different species. Divergence in shade tolerance, crown architecture, crown phenology and root distribution may play a main role in this (Kelty, 1992; Tilman et al., 2001; Forrester and Albrecht, 2014; Pretzsch et al., 2014; Pretzsch et al., 2015b). If two species in the mixture differ both in shade tolerance and in leaf phenology, trees of fastgrowing, light-demanding species may transmit sufficient light through their canopy to allow shade-tolerant species to grow underneath, and total leaf life span may be elongated, leading to greater light use over a whole year. Such overyielding would be stronger if the two species also differ in root depths, for example shallow-rooted species mixed with deep-rooted species. In this case, the total acquisition of soil water and nutrients in a forest could be raised (Forrester et al., 2010; Reyer et al., 2010; Brassard et al., 2013; Pretzsch et al., 2013b). However, complementary resource use may decline over time when trees of both species grow taller and occupy more space, both aboveground (Cavard et al., 2011) and belowground (Ma and Chen, 2017). Such a decline was however not observed in temperate Dutch forests, probably because forest management (notably thinning) keeps stands below a maximum stand basal area and density, and reduces competition and allows for complementary resource use (Lu et al., 2016). Yet, it remains largely unclear how different tree species contribute to overyielding of mixed forest stands, and whether such overyielding is affected by soil fertility.

Some studies found that in two-species mixed stands, both species contributed to overyielding (Del Río and Sterba, 2009; Condés et al., 2013; Pretzsch et al., 2013a) while others reported that only one species was responsible for overyielding (Vallet and Pérot, 2011; Huber et al., 2014; Toïgo et al., 2015; Thurm and Pretzsch, 2016). These contrasting results may be due to differences in species composition, with different or similar traits between the species, and to other factors affecting species interactions, such as site conditions with different growth-limiting factors. In a previous study, we found that differences in the leaf phenology between evergreen and deciduous species and, to a lesser extent, shade tolerance are important factors for overyielding ( $\mathrm{Lu}$ et al., 2016). In general, more shade-tolerant species tend to be slower growing than light-demanding species, leading to a stand with different canopy layers. Owing to size-asymmetric competition for light, trees of fast-growing species will rapidly win the height growth competition with trees of slow-growing species, but the slow-growing species may persist in the understory because they are more shade 
tolerant (Oliver and Larson, 1996; Jucker et al., 2014a). Since trees of slower growing species remain shorter, trees of faster growing species encounter more free space aboveground, their crowns occupy more space and full growth rates that may exceed those of trees in monospecific stands, where more individuals of the same fast-growing species compete for the same space. In contrast, the trees of the slow-growing species are shaded by the individuals of the fast-growing species in the mixtures, and will therefore show slower growth rates than trees in monospecific stands. In other words, the overyielding is not only because trees of slow-growing species occupy space that cannot be occupied by trees of the fastgrowing species, but also because trees of fast-growing species show higher growth rates in mixtures than in monocultures of the same species. We therefore expect that dominant, fastgrowing species will overyield, and that suppressed, more slowly growing species will actually underyield when comparing to single species stands.

This overyielding effect may vary on different site conditions. There are two dominant viewpoints describes this changes. The stress-gradient hypothesis states that species interactions shift from competition in favourable environments to facilitation in harsh environments (Bertness and Callaway, 1994). Following this, overyielding would be stronger on poor sites than on rich sites, because species facilitate each other to improve the soil resource availability. Several studies found overyielding on poor sites and underyielding on rich sites (Pretzsch et al., 2013a; Pretzsch et al., 2015b; Toïgo et al., 2015). However, the resource-ratio hypothesis states that competition for light on rich soils switches to competition for soil resources on poor soils (Tilman, 1985). On rich soils where soil water and nutrients supplies are adequate, stands can develop large leaf areas but competition for light will also increase, so overyielding would be stronger if the mixed species have complementary light use (Forrester, 2014). On poor soils, limited availability of nutrients or water will limit growth and trees in mixtures are then expected to compete more fiercely for belowground resources. Yet, when this results in less leaf production and lower light interception, this may leave less room for light complementarity and positive mixture effects would lessen (Tilman, 1985; Jucker et al., 2014a). Indeed, several studies report that overyielding increased under better site conditions (Forrester et al., 2013a; Jucker et al., 2014a; Sterba et al., 2014; Thurm and Pretzsch, 2016), because trees in mixtures invested more into stem growth (Thurm et al., 2016a) and crown development (Dieler and Pretzsch, 2013; Jucker et al., 2014a; Williams et al., 2017) than in monocultures. Thus, the impact of soil on overyielding is still ambiguous and debated.

In this study, we investigated how overyielding depends on the combination of mixed species and on the type of soils in Dutch forests. First, We hypothesized that the faster growing and more light-demanding species would dominate the slower growing and more shade-tolerant species in mixed-species stands, and that the resulting stratified canopies and the subsequent partitioning of the light gradient would cause overyielding by complementary light use. Second, we expected that this overyielding effect would be stronger on poor soils than on rich soils, according to the stress-gradient hypothesis, because one species improves 
the soil resource availability for the other species or allows for complementary soil resource use. Alternatively, following the resource-ratio hypothesis, the overyielding would be stronger on rich soils, owing to that rich soils allow for a denser forest canopy with possibilities for complementary light use, particularly when species differ in shade tolerance or leaf phenology. We evaluated our hypotheses by analysing five species (Douglas-fir (Pseudotsuga menziesii (Mirb.) Franco), common beech (Fagus sylvatica L.), Scots pine (Pinus sylvestris L.), pedunculate oak (Quercus robur L.), and silver birch (Betula pendula Roth)) growing in Douglas-fir-common beech, Scots pine-pedunculate oak, pedunculate oak-common beech, and pedunculate oak-silver birch mixtures and their respective monocultures from 398 permanent field plots all over forest area of the Netherlands.

\section{Methods}

\section{Study site and species}

We compared the growth of the species in mixtures with their respective monocultures using long-term measurements from permanent field plots in the Netherlands, maintained by the Forest Ecology and Forest Management Group of Wageningen University. In this study, we analysed the species mixture effect on stand productivity on different soils for five tree species: Douglas-fir (Pseudotsuga menziesii (Mirb.) Franco), common beech (Fagus sylvatica L.), Scots pine (Pinus sylvestris L.), pedunculate oak (Quercus robur L.), and silver birch (Betula pendula Roth) growing in monocultures and mixtures of Douglas-fir-common beech, Scots pine-pedunculate oak, pedunculate oak-common beech, and pedunculate oak-silver birch. Hereafter, the five species and monocultures are written as Douglas-fir, beech, pine, oak and birch, and the four mixtures accordingly as Douglas-fir-beech, pine-oak, oak-beech and oak-birch, respectively. There are 314 plots of pure stands and 84 plots of mixed stands with stand ages ranging from 10 to 150 years. Most plots were regularly thinned. For information on plot distributions and thinning history, see Lu et al (2016).

The study plots were located throughout the Netherlands. Dutch climate is moderate maritime with a mean annual temperature of $10.8{ }^{\circ} \mathrm{C}$ with cool winters (average temperature in December-February of $2.5^{\circ} \mathrm{C}$ ) and mild summers (average temperature in June-August of $15.9^{\circ} \mathrm{C}$ ). The mean annual rainfall is around $800 \mathrm{~mm}$ and is evenly distributed throughout the year (KNMI, 2015). Plot characteristics and stand variables for monocultures and mixtures are shown in Table 3.1. For more detailed data and stand description, see Lu et al. (2016).

\section{Plot soil information}

Soil data were taken from the ISRIC-World Soil Information SoilGrids $250 \mathrm{~m}$ database (http://www.isric.org/explore/soilgrids). SoilGrids250m provides global predictions for standard soil properties at seven standard depths $(0,5,15,30,60,100$ and $200 \mathrm{~cm})$ at $250 \mathrm{~m}$ resolution. The soil properties include sand content, silt content, clay content, $\mathrm{pH}$ (in $\mathrm{H}_{2} \mathrm{O}$ ), soil organic carbon (ORC), cation-exchange capacity (CEC), bulk density and coarse 
fragments (Hengl et al., 2016). First, we calculated the average value by taking the average of the predictions at the upper and lower boundary of the depth intervals $(0-5 \mathrm{~cm}, 5-15 \mathrm{~cm}, 15-$ $30 \mathrm{~cm}, 30-60 \mathrm{~cm}, 60-100 \mathrm{~cm}, 100-200 \mathrm{~cm}$ ), resulting in values for 6 layers for each soil property. For the $\mathrm{pH}$, all average values were very similar to the first layer value $(0-5 \mathrm{~cm})$ since $\mathrm{pH}$ was highly correlated among all over the 6 layers, therefore we simply used the value of the first layer in our analysis. For soil property characteristics in the studied plots, see Appendix 3.1. Second, we calculated weighted averages according to layer thickness for sand content, silt content, clay content, bulk density and coarse fragments over the 6 layers, assuming that this represents average soil properties as experienced by the tree roots. For ORC and CEC, we took the weighted average from the top 2 layers since most of soil organic matter is in these layers. Since we expected the soil properties to be strongly correlated (see Appendix 3.2), we did a principal component analysis (PCA) based on the weighted averaged values of the 7 soil properties and first layer value of $\mathrm{pH}$ to determine the major soil gradients in our dataset. In the end, we linked the first and second principal components (PC1 and PC2) from the PCA with species growth efficiency (see Model framework for further details) in our study plots to evaluate the impact of soils on overyielding in different mixtures. 
Table 3.1 Stand variables by species for this study.

\begin{tabular}{|c|c|c|c|c|c|c|c|c|c|c|c|c|c|c|c|c|c|c|}
\hline \multirow{3}{*}{ Variables } & \multirow{3}{*}{ Value } & \multirow{2}{*}{\multicolumn{5}{|c|}{ Pure stands }} & \multicolumn{12}{|c|}{ Mixed stands } \\
\hline & & & & & & & \multicolumn{3}{|c|}{ Douglas-fir-Beech } & \multicolumn{3}{|c|}{ Pine-Oak } & \multicolumn{3}{|c|}{ Oak-Beech } & \multicolumn{3}{|c|}{ Oak-Birch } \\
\hline & & Douglas-fir & Beech & Pine & Oak & Birch & Total & Douglas-fir & Beech & Total & Pine & Oak & Total & Oak & Beech & Total & Oak & Birch \\
\hline No. plots & & 110 & 38 & 72 & 72 & 22 & 16 & 16 & 16 & 28 & 28 & 28 & 14 & 14 & 14 & 26 & 26 & 26 \\
\hline \multirow[t]{2}{*}{ Survey duration (years) } & Min & 1937 & 1960 & 1954 & 1947 & 1984 & 1984 & 1984 & 1984 & 1949 & 1949 & 1949 & 1984 & 1984 & 1984 & 1984 & 1984 & 1984 \\
\hline & $\operatorname{Max}$ & 2000 & 1994 & 1994 & 1999 & 1994 & 2000 & 2000 & 2000 & 2000 & 2000 & 2000 & 1994 & 1994 & 1994 & 1994 & 1994 & 1994 \\
\hline \multirow{4}{*}{ Age span (years) } & Mean & 36 & 64 & 58 & 67 & 51 & 55 & 55 & 55 & 66 & 66 & 66 & 83 & 83 & 83 & 45 & 46 & 45 \\
\hline & $\mathrm{SD}$ & 15 & 35 & 31 & 27 & 32 & 31 & 31 & 31 & 30 & 30 & 30 & 37 & 37 & 37 & 16 & 16 & 16 \\
\hline & Min & 12 & 16 & 16 & 16 & 10 & 11 & 11 & 11 & 12 & 12 & 12 & 19 & 19 & 19 & 11 & 11 & 11 \\
\hline & Max & 113 & 149 & 144 & 144 & 145 & 104 & 104 & 104 & 149 & 149 & 149 & 143 & 143 & 143 & 81 & 81 & 81 \\
\hline \multirow[t]{4}{*}{ Stand density (trees ha ${ }^{-1}$ ) } & Mean & 1146 & 899 & 822 & 579 & 845 & 998 & 505 & 483 & 914 & 491 & 409 & 579 & 236 & 337 & 905 & 490 & 377 \\
\hline & SD & 889 & 955 & 883 & 646 & 561 & 1126 & 611 & 523 & 1334 & 654 & 835 & 654 & 236 & 434 & 458 & 307 & 281 \\
\hline & Min & 64 & 110 & 104 & 80 & 196 & 84 & 42 & 28 & 152 & 22 & 65 & 116 & 46 & 11 & 294 & 56 & 42 \\
\hline & $\operatorname{Max}$ & 4570 & 4528 & 7675 & 5810 & 2683 & 3523 & 1716 & 1874 & 7134 & 2613 & 5000 & 2735 & 1026 & 1710 & 2195 & 1282 & 1098 \\
\hline \multirow{4}{*}{$\begin{array}{l}\mathrm{D}_{\mathrm{g}} \\
(\mathrm{cm})\end{array}$} & Mean & 21 & 26.5 & 21.7 & 25.1 & 18.5 & 31 & 38 & 24.7 & 24.8 & 27.4 & 24.2 & 32 & 29.1 & 35.9 & 18.5 & 18.8 & 21 \\
\hline & SD & 11 & 13.2 & 8.2 & 9.7 & 8.7 & 16.3 & 19.7 & 15 & 9.2 & 11.4 & 9.2 & 13.5 & 12.6 & 18.3 & 6.1 & 7.3 & 7.6 \\
\hline & Min & 1.9 & 8.2 & 5.1 & 4.5 & 6.6 & 5.9 & 8 & 2.8 & 3.3 & 3.1 & 2.6 & 7.5 & 6.2 & 8.8 & 8.7 & 8.2 & 7.6 \\
\hline & $\operatorname{Max}$ & 72.1 & 52 & 43.7 & 57.7 & 42.9 & 58 & 64.3 & 51.4 & 39.6 & 57.2 & 42.7 & 52.9 & 47 & 91 & 32.2 & 35.2 & 38.1 \\
\hline \multirow{4}{*}{$\begin{array}{l}\mathrm{H}_{\text {dom }} \\
(\mathrm{m})\end{array}$} & Mean & 18.2 & 21 & 15 & 18.6 & 15.7 & 24.2 & 24.5 & 20 & 18 & 18 & 16.8 & 21.8 & 20.1 & 21.4 & 17.7 & 16.1 & 18 \\
\hline & $\mathrm{SD}$ & 6.5 & 6.3 & 3.6 & 4.3 & 4.7 & 9.6 & 9.8 & 9.1 & 5 & 4.9 & 5 & 5.9 & 6.6 & 5.7 & 3.9 & 3.8 & 4.3 \\
\hline & Min & 4.2 & 9 & 5 & 8.4 & 6.3 & 6.2 & 6.2 & 4.1 & 6.5 & 6.2 & 5 & 10 & 5 & 10 & 7 & 6 & 7 \\
\hline & Max & 40.1 & 34.9 & 26.5 & 31 & 24 & 39.1 & 39.1 & 32 & 27.4 & 26.7 & 25.5 & 31.2 & 29.2 & 31.2 & 26 & 23 & 26 \\
\hline \multirow{4}{*}{$\begin{array}{l}\text { SDI } \\
\left(\text { stem ha }^{-1}\right)\end{array}$} & Mean & 551 & 507 & 439 & 383 & 371 & 529 & 341 & 188 & 453 & 262 & 191 & 433 & 179 & 254 & 464 & 251 & 213 \\
\hline & SD & 112 & 150 & 142 & 74 & 128 & 164 & 132 & 109 & 118 & 112 & 82 & 95 & 77 & 112 & 174 & 140 & 100 \\
\hline & Min & 72 & 227 & 187 & 169 & 137 & 179 & 150 & 30 & 164 & 45 & 71 & 239 & 78 & 87 & 182 & 74 & 50 \\
\hline & $\operatorname{Max}$ & 1026 & 974 & 809 & 595 & 726 & 920 & 619 & 543 & 748 & 468 & 396 & 655 & 338 & 491 & 1125 & 664 & 553 \\
\hline \multirow{4}{*}{$\begin{array}{l}\text { PAIV } \\
\left(\mathrm{m}^{3} \mathrm{ha}^{-1} \text { year }^{-1}\right)\end{array}$} & Mean & 12.1 & 10.1 & 5.2 & 4.8 & 3.3 & 14.4 & 11.3 & 2.9 & 6 & 3.5 & 2.4 & 6.7 & 2 & 4.6 & 4.8 & 3.1 & 1.6 \\
\hline & SD & 4.7 & 5 & 2.7 & 2 & 2 & 6.1 & 6.4 & 1.8 & 2.6 & 2.5 & 1.2 & 3.7 & 1.3 & 3.2 & 2.3 & 1.8 & 1.1 \\
\hline & Min & 1.2 & 1.7 & 0.9 & 0.1 & 0.7 & 2.9 & 1.5 & 0.5 & 1.7 & 0.2 & 0.6 & 1.3 & 0.3 & 0.6 & 1 & 0.4 & 0.1 \\
\hline & $\operatorname{Max}$ & 30.5 & 32.1 & 17.6 & 14.4 & 8.5 & 25.4 & 24.3 & 9.1 & 13.9 & 9.1 & 7.7 & 17.6 & 4.8 & 13.1 & 10.8 & 8.4 & 4.8 \\
\hline \multirow[t]{3}{*}{ Species proportion } & Mean & & & & & & & 0.7 & 0.3 & & 0.6 & 0.4 & & 0.4 & 0.6 & & 0.5 & 0.5 \\
\hline & Min & & & & & & & 0.3 & 0.1 & & 0.2 & 0.2 & & 0.2 & 0.2 & & 0.2 & 0.1 \\
\hline & Max & & & & & & & 0.9 & 0.7 & & 0.8 & 0.8 & & 0.8 & 0.8 & & 0.9 & 0.8 \\
\hline
\end{tabular}

$\mathrm{D}_{\mathrm{g}}$ : quadratic mean diameter; $\mathrm{H}_{\mathrm{dom}}$ : dominant height; SDI: Reineke stand density index; PAIV: periodic annual volume increment; Species proportion: proportion in basal area (the species basal area/the total stand basal area). 


\section{Model framework}

To explore the influence of admixture species on productivity at different soil fertilities, we developed a model framework as shown in the following equations which were earlier applied by Condés et al. (Condés et al., 2013). We used the species growth efficiency as dependent variable in order to compare the tree species growth in monospecific and mixed stands. The species growth efficiency $I V_{P i}$ was defined as the periodic annual volume increment of the species $i$ in $\mathrm{m} 3 \mathrm{ha}^{-1}$ divided by the species proportion $P_{i}$ using Eq. (1), that is up-scaled to the hectare.

$I V_{P i}=P A I V_{i} / P_{i}$

where $I V_{P i}$ is the growth efficiency of species $i\left(\mathrm{~m}^{3} \mathrm{ha}^{-1} \mathrm{year}^{-1}\right) ; P A I V_{i}$ is the periodic annual volume increment of species $i\left(\mathrm{~m}^{3} \mathrm{ha}^{-1}\right.$ year $\left.^{-1}\right) ; P_{i}$ is the proportion of species $i$ (dimensionless). Species proportion $P_{i}$ was derived from the absolute stand density index (SDI) by species using Eq. (2).

$P_{i}=S D I_{i} /\left(S D I_{i}+S D I_{j}\right)$

where $P_{i}$ is the proportion of species $i$ in mixed stands, $j$ is the admixture species; species proportion $P_{i}$ equals 1 in monocultures.

Tree species growth in a pure and mixed stand depends on stand density expressing the amount of resources used by trees in relation to the resource availability of a site (Dean and Baldwin, 1996). As species can have different capacities to occupy the site, i.e. different maximum or potential densities, species proportion should be estimated by using relative densities (proportion of the maximum density) in order to correct this difference (Del Río et al., 2015). Since species-specific maximum density boundary lines are not available in the Netherlands, and considering that there was frequent thinning in the plots and stands were never fully stocked (Lu et al., 2016), we used absolute SDI by species by Eq. (3) (Reineke, 1933 ) instead of relative SDI to estimate species proportion and stand density.

$S D I=N *\left(25 / d_{g}\right)^{E}$

where $S D I$ is the stand density index $\left(\right.$ stem $\left.\mathrm{ha}^{-1}\right) ; N$ is the number of trees per hectare; $d_{g}$ is the quadratic mean diameter $(\mathrm{cm}) ; E$ is the generic value proposed by Reineke $E=-1.605$ for all studied species because, as abovementioned, no species-specific boundary line values are given in the Netherlands. The SDI thus increases with $N$ and $d_{g}$ and reflects the increasing competition when trees grow bigger.

The developed growth models predict the growth efficiency of one species in pure and mixed stands and is an expression of stand age, quadratic mean diameter, dominant height, 
absolute SDI, the species proportion of the admixture species in mixed stands ( 1 for pure stands), and soil type and its interactions with species proportion as in Eq. (4).

$$
\begin{aligned}
\log \left(I V p_{i}\right)= & a_{0}+a_{1} \times \log \left(\text { age }_{i}\right)+a_{2} \times \log \left(\text { dg }_{i}\right)+a_{3} \times \log \left(\text { Hdom }_{i}\right)+a_{4} \times \log (S D I) \\
& +a_{5} \times P C_{1}+a_{6} \times P C_{2}+\sum_{j} b_{1 j} \times P_{j}+\sum_{j} b_{2 j} \times P_{j} \times P C_{1} \\
& +\sum_{j} b_{3 j} \times P_{j} \times P C_{2}+\varepsilon_{i}
\end{aligned}
$$

where $I V_{P i}$ is the growth efficiency $\left(\mathrm{m}^{3} \mathrm{ha}^{-1}\right.$ year $\left.^{-1}\right)$ (log-transformed) of species $i$; age is the stand age (years); $d g$ is the quadratic mean diameter $(\mathrm{cm}) ; H d o m$ is the dominant height $(\mathrm{m})$; $S D I$ is the stand density index $\left(\right.$ stem $\left.\mathrm{ha}^{-1}\right) ; P_{j}$ is the species proportion of the admixture species $j$ in the mixed stands; $P C 1$ and $P C 2$ are the first and second principal components from the PCA of soil properties; $\varepsilon_{i}$ is the model residuals. In the equation, age and Hdom were included to explain the influence of age and site quality on growth. SDI explained the stand density effect on growth. $d g$ might reflect the silvicultural history of the stand for a given age, Hdom and SDI. In order to study the influence of soils on overyielding, we included PC1 and PC2 from the PCA of soil properties as a co-variable in Eq. (4) for each species in pure and mixed stands and its interaction with species proportion. In addition, considering stronger species interactions could be found in more dense stands (Condés et al., 2013), we did not consider the interaction between stand density index and species proportion, since most of the plots were regularly thinned and the stand density was low.

All analyses were performed in R 3.2.0 (R Core Team, 2015). For the Eq. (4), we used Generalized Least Squares (the gls() function) of the nlme package (Bates et al., 2013) to analyse the growth efficiency for each species in mixtures and monocultures. The model of gls() includes autocorrelation considering the time-series data. We applied each individual "plot" in the autocorrelation since each plot was repeatedly measured over time (Lu et al., 2016) and the previous growth was correlated with the next period. We applied a mix of procedures of stepwise regression and manual insertion and/or deletion of variables in the model (Condés and Sterba, 2008). We inspected the variance inflation factors (VIF) by using vif() function of the car package (Fox and Weisberg, 2010) to check collinearity among the variables, and manually removed variables with VIF larger than 10 (Zuur et al., 2010). The default behaviour of $\mathrm{gls}()$ to optimise the maximum likelihood criterion (ML) was used (Pinheiro and Bates, 2000). Normality and homogeneity of the model residuals were checked by visual inspections of diagnostic plots of residuals against fitted values (Zuur et al., 2009). For each test, the model selection was based on the lowest Akaike Information Criteria (AIC) and biological plausibility of the results, and contained only independent variables that are significant ( $p<0.05$ ). McFadden pseudo $R^{2}$ was used for gls() to get $R^{2}$ (McFadden, 1974) for the final model of each species. 


\section{Results}

A principle component analysis shows that eight soil properties strongly covary (Figure 3.1), and that the first principal component PC1 explains $42 \%$ of the variance and the second principal component $\mathrm{PC} 230 \%$. PC1 was positively associated with silt, clay content and $\mathrm{pH}$, but negatively with sand content. The negative correlation with bulk density was low, but this soil property was not significantly correlated with any of the other soil properties (Appendix 3.2). The correlations between sand, silt, clay and $\mathrm{pH}$ were in line with their projection on PC1. Here we interpret PC1 with a gradient of increasing nutrient and water availability as driven by soil texture over the whole soil profile $(0-200 \mathrm{~cm})$. PC2 was positively correlated with coarse fragments, soil organic carbon (ORC) and cation-exchange capacity (CEC), with the latter two soil properties measured over the top layers (depth $0-15 \mathrm{~cm}$ ). PC2 reflects the accumulation of soil organic matter, which was strongly linked to CEC. Here PC2 is interpreted as a gradient of increasing nutrient availability (CEC as an indicator), increased released nutrients from decomposition of ORC, and increased water availability, given that ORC increases water retention. In short, PC1 is thus interpreted as a parent material driven fertility gradient, and PC2 as an organic material driven fertility gradient.

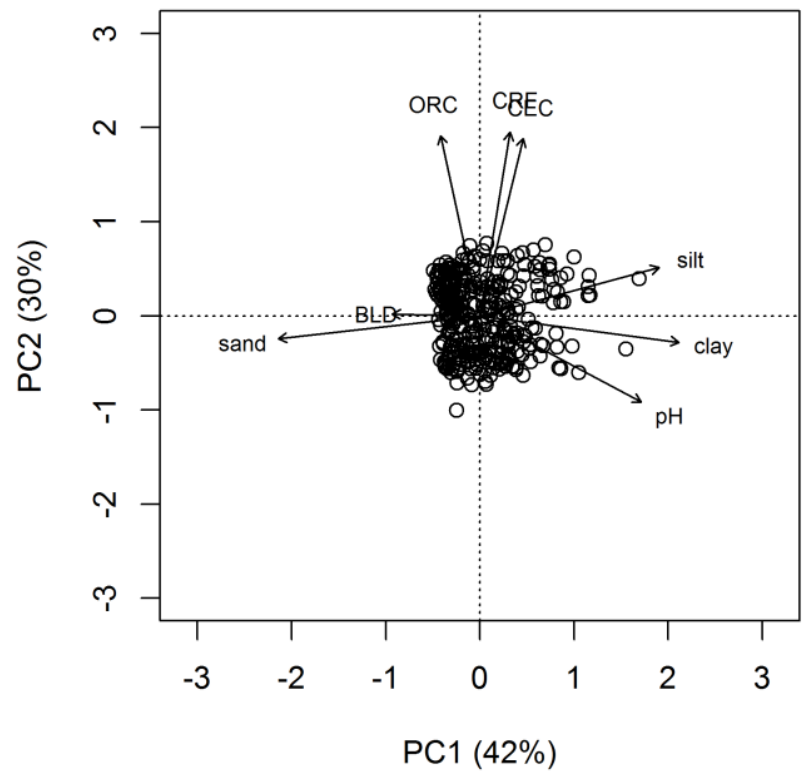

Figure 3.1 Principal component analysis of soil properties used in this study. Clay, sand and silt represent clay content, sand content and silt content, respectively; ORC: soil organic carbon; CEC: cation-exchange capacity; CRF: coarse fragments; BLD: bulk density. Dots are individual plots in this study.

Species growth efficiency was estimated using the mean values of stand variables observed in the plots (Table 3.1) and for difference proportions of the different species (Figure 3.2) or a proportion of $50 \%$ for each species in the mixtures (Figure 3.3). Based on our assumption for the first and second PC axes, growth efficiencies for poor sites were 
simulated using $\mathrm{PC} 1=-0.3$ and $\mathrm{PC} 2=-0.3$ and for rich sites using $\mathrm{PC} 1=0.3$ and $\mathrm{PC} 2=0.3$, which was within the range of predicted values for the different plots (Figure 3.1). See Appendix 3.4 and Appendix 3.5 for poor and rich soils for each axis separately Mixture effects on yield and growth efficiency varied in some cases between poor and rich sites (Figure 3.2 and 3.3). Particularly in the Douglas-fir-beech mixtures, Douglas-fir overyielded more strongly on poor sites than on rich sites (Figure 3.2a,b, Figure 3.3a,b). In the same mixtures, beech overyielded on the poor soils but underyielded on the rich soils (Figure 3.2a,b, Figure 3.3c,d). Yet the responses of beech were inferior to those of Douglas-fir. Douglas-fir-beech mixed stands thus achieved overall higher production than pure stands, with a stronger on poor soils. Qualitatively, a similar pattern was observed for pine-oak mixtures, but this overyielding effect was in general weaker compared to the Douglas-firbeech mixtures. In these mixtures, oak overyielded rather similarly on poor and rich soils (Figure 3.2c,d, Figure 3.3g,h), whereas pine overyielded on poor sites but underyielded on rich soils (Figure 3.2c,d, Figure 3.3e,f). The responses of oak were superior to those of pine, and overall mixed stands achieved higher levels of productivity than pure stands. Interestingly, oak-beech mixtures exhibited overyielding on poor soils due to a positive mixture effect on beech, and underyielding on rich soils because of a negative mixture effect on beech (Figure 3.2e,f, Figure 3.3c,d). However, oak was not affected by the admixture species beech and had similar growth efficiency with that in pure stands (Figure 3.2e,f, Figure $3.3 \mathrm{~g}, \mathrm{~h}$ ). No overyielding was observed in oak-birch mixtures since there was null mixture effect on both species, regardless of poor and rich soils (Figure 3.2g,h, Figure 3.3g,h,i,j). 
un $\quad$ Table 3.2 Coefficients (Est.), standard errors (SE) and $P$-values $(P)$ of final models a for all species based on first and second principal component PC1 and PC2 from principal component analysis only significant variables were shown.

\begin{tabular}{|c|c|c|c|c|c|c|c|c|c|c|c|c|c|c|c|}
\hline & \multicolumn{3}{|c|}{ Douglas-fir } & \multicolumn{3}{|c|}{ Common beech } & \multicolumn{3}{|c|}{ Scots pine } & \multicolumn{3}{|c|}{ Pedunculate oak } & \multicolumn{3}{|c|}{ Silver birch } \\
\hline & Est. & $\mathbf{S E}$ & $P$ & Est. & SE & $P$ & Est. & SE & $P$ & Est. & $\mathbf{S E}$ & $P$ & Est. & SE & $P$ \\
\hline (Intercept) & 1.6791 & 0.4869 & 0.0000 & 0.8675 & 0.7884 & 0.2723 & 0.0355 & 0.6457 & 0.9561 & -0.0684 & 0.5430 & 0.8999 & -0.6097 & 1.2163 & 0.6169 \\
\hline $\ln ($ age $)$ & -0.4062 & 0.1372 & 0.0032 & -0.4594 & 0.1199 & 0.0000 & -0.5570 & 0.1303 & 0.0000 & -0.4022 & 0.0916 & 0.0000 & -0.5455 & 0.1701 & 0.0016 \\
\hline $\ln \left(d_{g}\right)$ & -0.4796 & 0.1508 & 0.0015 & $\mathrm{n} . \mathrm{s}$ & & & -0.8537 & 0.1866 & 0.0000 & -0.5545 & 0.1212 & 0.0000 & $\mathrm{n} . \mathrm{s}$ & & \\
\hline $\ln \left(\mathrm{H}_{\mathrm{dom}}\right)$ & 0.5601 & 0.2138 & 0.0090 & 0.3689 & 0.1623 & 0.0239 & 1.1095 & 0.2031 & 0.0000 & 1.0552 & 0.1588 & 0.0000 & n.s & & \\
\hline $\ln (\mathrm{SDI})$ & 0.3128 & 0.0679 & 0.0000 & 0.3244 & 0.1182 & 0.0065 & 0.5388 & 0.0942 & 0.0000 & 0.3092 & 0.0831 & 0.0000 & 0.6141 & 0.2191 & 0.0057 \\
\hline$P_{\text {beech }}$ & 1.1421 & 0.2481 & 0.0000 & & & & & & & n.s & & & & & \\
\hline $\mathrm{P}_{\text {pine }}$ & & & & & & & & & & 0.5725 & 0.0988 & 0.0000 & & & \\
\hline$P_{\text {Douglas-fir }}$ & & & & n.s & & & & & & & & & & & \\
\hline $\mathrm{P}_{\mathrm{oak}}$ & & & & n.s & & & $\mathrm{n} . \mathrm{s}$ & & & & & & n.s & & \\
\hline $\mathrm{P}_{\text {birch }}$ & & & & & & & & & & n.s & & & & & \\
\hline $\mathrm{PC} 1$ & & & & 0.2036 & 0.0971 & 0.037 & & & & & & & & & \\
\hline PC2 & 0.1864 & 0.0693 & 0.0073 & & & & & & & -0.1570 & 0.0627 & 0.0126 & & & \\
\hline $\mathrm{P}_{\text {beech }}: \mathrm{PC} 1$ & -2.1742 & 0.7072 & 0.0022 & & & & & & & & & & & & \\
\hline $\mathrm{P}_{\text {oak }}: \mathrm{PC} 1$ & & & & & & & -0.8753 & 0.2994 & 0.0037 & & & & & & \\
\hline $\mathrm{P}_{\text {Douglas-fir }}: \mathrm{PC} 2$ & & & & -0.8018 & 0.3031 & 0.0087 & & & & & & & & & \\
\hline $\mathrm{P}_{\text {oak }}: \mathrm{PC} 2$ & & & & -2.4702 & 0.6119 & 0.0000 & & & & & & & & & \\
\hline
\end{tabular}

${ }^{\text {a }}$ Eq. (4): $\ln \left(I V_{P i}\right)=a_{0}+a_{1} \times \ln \left(a g e_{i}\right)+a_{2} \times \ln \left(d_{g i}\right)+a_{3} \times \ln \left(H_{d o m i}\right)+a_{4} \times \ln \left(S D I_{i j k}\right)+a_{5} \times P_{i j k}+a_{6} \times P C 1+a_{7} \times P C 2+a_{8} \times P_{i j k} \times P C 1+a_{9} \times P_{i j k} \times P C 2+\varepsilon_{i}$, where IV $\mathrm{P}_{\mathrm{P} i}$ is the growth efficiency of species $i$ expressed by the periodic annual volume increment of one species up-scaled to the hectare; age is the stand age (years); dg is the quadratic mean diameter ( $(\mathrm{cm}) ; \mathrm{H}_{\mathrm{dom}}$ is the dominant height ( $\mathrm{m}$ ); SDI is the stand density index (stem $\left.\mathrm{ha}^{-1}\right)$; $\mathrm{P}_{i j k}$ is the species proportion of the admixture species $j$ or $k$ in the mixed stands; soil is the PC1 and PC2 values shown in Figure 3.1. n.s: not significant. 


\section{Poor soil}
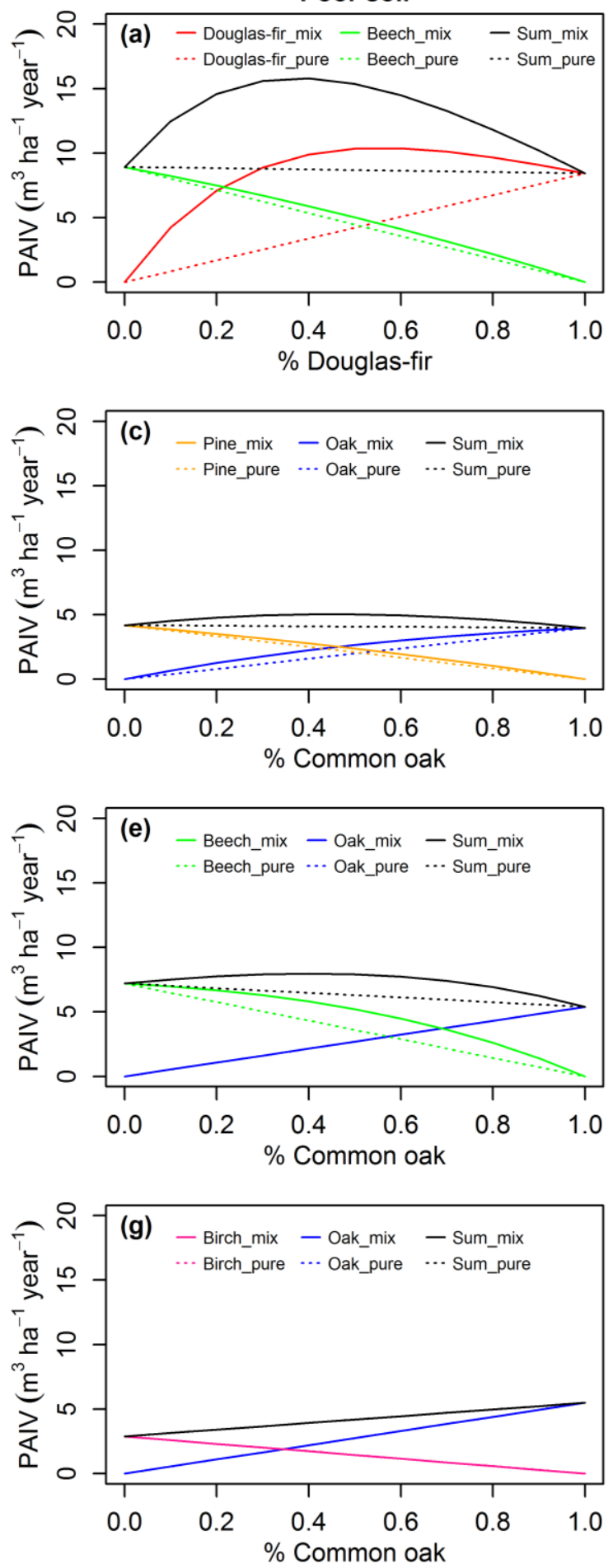

Rich soil
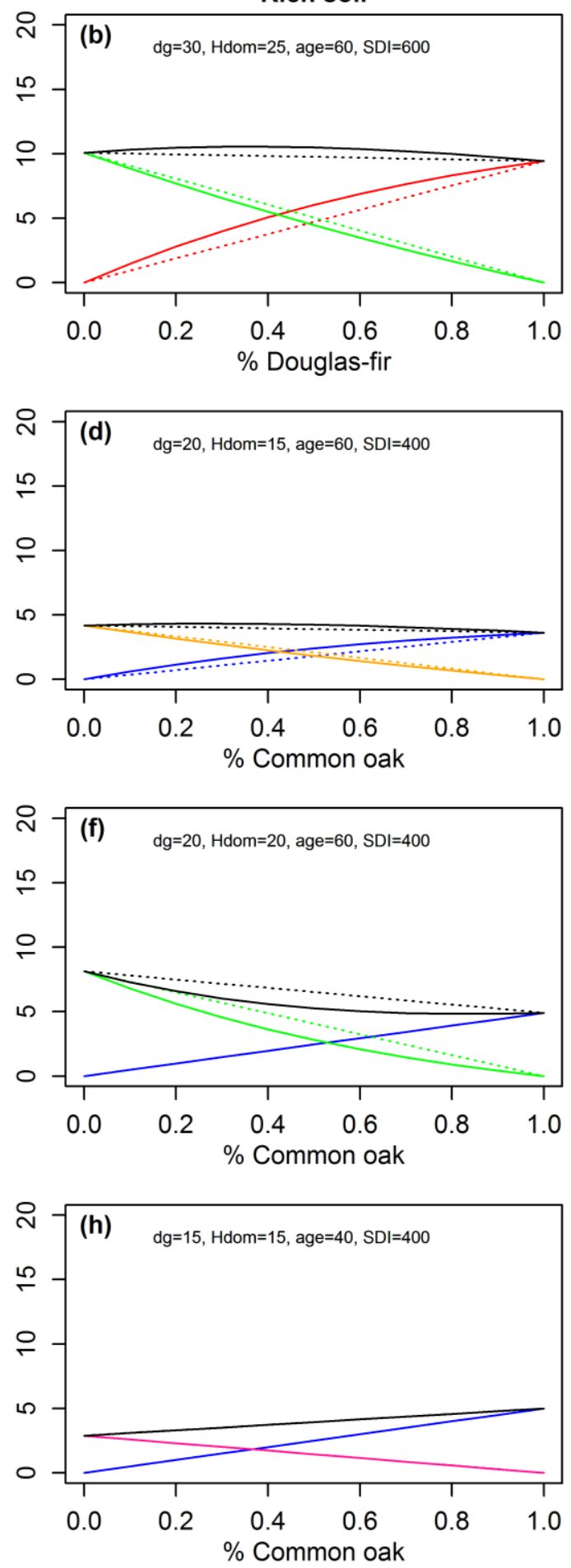

Figure 3.2 Periodic annual volume increment (PAIV) in mixed and pure stands at poor (left panel) and rich soils (right panel), given the admixture proportion, mean values of quadratic mean diameter $\left(\mathrm{d}_{\mathrm{g}}\right)$, dominant height $\left(\mathrm{H}_{\mathrm{dom}}\right)$, age, stand density index (SDI). Poor soils where defined as PC1=-0.3 and PC2=-0.3, and rich soils as $\mathrm{PC} 1=0.3$ and $\mathrm{PC} 2=0.3$. (a) Douglas-fir and beech growing in pure and Douglas-fir-beech mixed stands. (b) Pine and oak growing in pure and pine-oak mixed stands. (c) Oak and beech growing in pure and oak-beech mixed stands. (d) Oak and birch growing in pure and oak-birch mixed stands. 
These results for the different mixtures were largely in line with the results for the different species in those mixtures (Figure 3.2), and were supported by the statistical models where the growth efficiency of Douglas-fir, beech and pine were influenced by soils and the interactions of the admixed species proportion with soils (Table 3.2). The negative impact of PC1: $P_{\text {beech }}$ supported the conclusion that overyielding of Douglas-fir in mixed stands with beech increased with lower fertility as driven by the texture of the parent material (Table 3.2, Figures 3.2, 3.3). For beech, the interaction effect of PC2: $\mathrm{P}_{\text {oak }}$ had a stronger negative effect

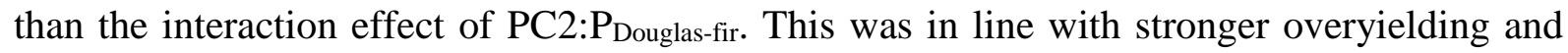
underyielding impacts of beech in mixtures with oak than with Douglas-fir, and implies that this overyielding is particularly related to the organic material in the top soil layers. For pine, the negative effect of $\mathrm{P}_{\text {oak }}: \mathrm{PC} 1$ confirmed that overyielding of pine increased with lower fertility in pine-oak mixtures (Table 3.2; Figures 3.2 and 3.3). PC1 had a positive effect on the growth efficiency of beech, while PC2 had a negative effect on the growth efficiency of oak. In addition, both stand age and quadratic mean diameter had negative effects on species growth efficiency, whereas dominant height and stand density index had positive effects (Table 3.2). The fitting statistics and the graphs for residuals vs. predicted of the final model of each species are shown in Table 3.3 and in Appendix 3.3, respectively. There was no bias of the models for the studied species, but the accuracy of predictions was better for pine than for other species.

Table 3.3 $n$ : number of trees; ME: mean error; MAE: mean absolute error; RMSE: root mean standard error and adjusted coefficients of determination $R^{2}$ for the final growth models of the five species studied.

\begin{tabular}{llllll}
\hline Species & $\boldsymbol{n}$ & ME & MAE & RMSE & $\boldsymbol{R}^{2}$ \\
\hline Douglas-fir & 790 & -0.0060 & 0.3093 & 0.1694 & 0.3096 \\
Common beech & 248 & -0.0022 & 0.3553 & 0.0645 & 0.2746 \\
Scots pine & 320 & 0.0004 & 0.3275 & 0.0171 & 0.4283 \\
Pedunculate oak & 631 & 0.0046 & 0.3133 & 0.1296 & 0.1906 \\
Silver birch & 160 & -0.0031 & 0.5665 & 0.0880 & 0.2034 \\
\hline
\end{tabular}



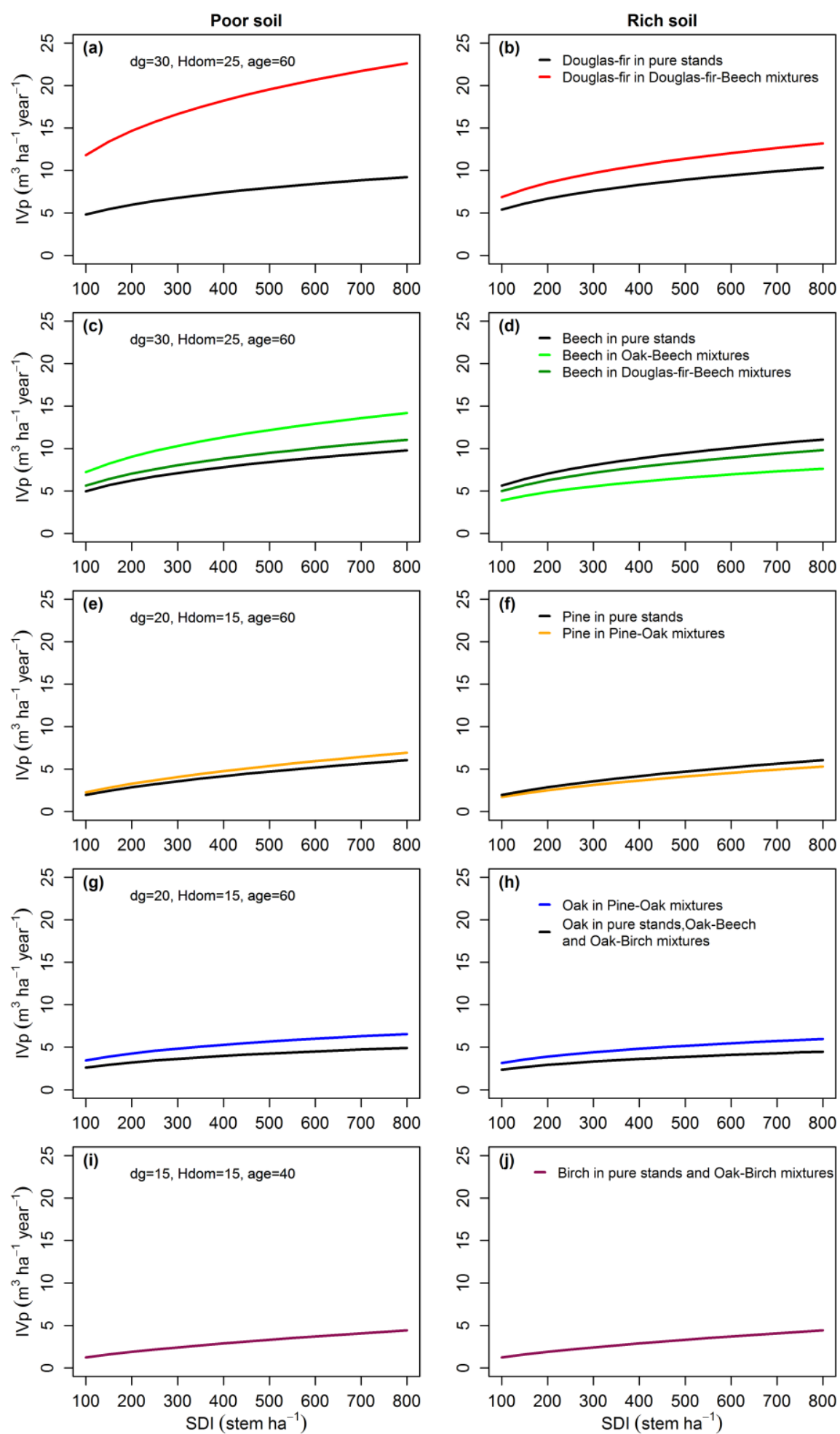

Figure 3.3 Growth efficiency $\left(\mathrm{IV}_{\mathrm{P}}\right)$ of one species in mixed versus pure stands changes with stand density index (SDI) on poor soils where $\mathrm{PC} 1=-0.3$ and $\mathrm{PC} 2=-0.3$ (left panel), and on rich soils where $\mathrm{PC} 1=0.3$ and $\mathrm{PC} 2=0.3$ (right panel), depending on quadratic mean diameter $\left(\mathrm{d}_{\mathrm{g}}\right)$, dominant height $\left(\mathrm{H}_{\mathrm{dom}}\right)$ and age. $(\mathrm{a}-\mathrm{b})$ Douglas-fir in pure and Douglas-fir-beech mixed stands. (c-d) Beech in pure, Douglas-fir-beech and oak-beech mixed stands. (e-f) Pine in pure and pine-oak mixed stands. (g-h) Oak in pure, pine-oak, oak-beech and oak-birch mixed stands. (i-j) Birch in pure and oak-birch mixed stands. A proportion of 50\% has been used for each species in the mixed stands. 


\section{Discussion}

We studied how soil fertility influenced the species mixture effect on species-specific productivity in four two-species mixed stands. In a previous study based on the same plots, we reported that there was overyielding for Douglas-fir-beech and pine-oak mixtures (Lu et al., 2016), but not for oak-beech and oak-birch mixtures. Here, we show what species actually contributed to overyielding, and how this overyielding changed with soil fertility. The principal component analysis (PCA) on eight soil properties indicated two major axes of soil fertility, explaining $72 \%$ of the variance amongst soil variables. The first PCA axis is interpreted as a soil fertility axis driven by the parent material, and the second PCA axis interpreted as a soil fertility axis driven by organic matter. We use these two major axes of soil fertility in our dataset to discuss our hypotheses on species and soil impacts on overyielding in mixtures.

In the first hypothesis, we expected that the faster growing and more light-demanding species would dominate the slower growing and more shade-tolerant species in mixed-species stands, and that the resulting stratified canopies and the subsequent partitioning of the light gradient would cause overyielding by complementary light use. We found that mainly more fast-growing Douglas-fir caused overyielding in Douglas-fir-beech mixtures, and that generally more slower growing light-demanding oak and beech contributed to overyielding of pine-oak and oak-beech mixtures, respectively. Surprisingly, fast-growing light-demanding birch did not cause overyielding in oak-birch mixtures. The results led us to reject the first hypothesis because it was not always the fast-growing light-demanding species that caused overyielding. Overall, large differences in leaf phenology and shade tolerance between the two species in the two evergreen-deciduous species mixtures might explain the strong overyielding, as hypothesised and observed in an earlier study (Lu et al., 2016). This is also consistent with one long-standing observation that mixing fast-growing light-demanding species with slow-growing shade-tolerant species enhanced forest productivity (Kelty, 1989). Second, in accordance with the stress-gradient hypothesis, we expected that the overyielding effect would be stronger on poor soils than on rich soils, as poor soils are supposed to allow for complementarity because of a reduction in competition for soil resource. Alternatively, following the resource-ratio hypothesis, overyielding might be stronger on rich soils because of a reduction in competition for light. Overall, the overyielding was stronger on poor soils than on rich soils for all the species and mixtures. Therefore, our results are in line with the prediction from the stress-gradient hypothesis but not with those from the resource-ratio hypothesis. The general pattern of higher overyielding on poor than rich soils was suggested to arise from species interactions that reduced competition for, or improved the availability of soil nutrients and water. Next, we discuss each mixture at poor and rich soils.

For Douglas-fir-beech mixtures, on poor soils, the overyielding of Douglas-fir was stronger and accompanied by some overyielding of beech, thus leading to higher total overyielding of the mixtures. On rich soils, Douglas-fir overyielded to a smaller degree and 
beech even showed underyielding, thereby reducing overyielding of the mixtures (Figure 3.2a,b; Figure. 3.3a,b,c,d). Overall, these findings are in agreement with the previous findings that reported that Douglas-fir-beech mixtures showed overyielding and the overyielding was driven by an increase in Douglas-fir growth in Germany (Thomas et al., 2015; Thurm and Pretzsch, 2016; Thurm et al., 2016b). However, in contrast with their findings of stronger overyielding on better sites, we found less overyielding on richer soils due to a negative effect of Douglas-fir on beech growth. Possible mechanisms for the higher overyielding on poor soils might result from partitioning resources above or belowground, or both. With respect to aboveground complementary, Douglas-fir, which is the evergreen and more light-demanding species, wins the height battle from beech, a deciduous species which is considered more shade-tolerant. The differences in phenology and the formation multiple layers of canopy may lead to greater crown complementarity in mixtures than in monospecific stands (Williams et al., 2017). This is supported by results showing height stratification with a dominant Douglasfir and a suppressed beech in our mixed stands (Appendix 3.6), as well as in previous studies (Thomas et al., 2015; Thurm and Pretzsch, 2016). Second, belowground complementarity in soil resource acquisition may occur when species differ in root distributions. It is supposed that Douglas-fir has shallow roots dominating the top soil and beech has deep roots spreading into deeper soil layers in the Netherlands (Hendriks and Bianchi, 1995), as well as that Douglas-fir is capable of sending roots deep into the soil and even into rock crevices (Thomas et al., 2015). The complementary use of rooting space and soil water in the mixtures highlights the importance of mixed forest in adapting forest management to climate change (Reyer et al., 2010).

On poor soils, tree growth is expected to be more limited by belowground resources than light, as suggested by the resource-ratio hypothesis (Tilman, 1985). Due to the contrasting rooting systems of the two species, there is probably a reduction in competition for soil resources. First, this may promote Douglas-fir growth by better access to soil nutrients because the uppermost soil layer is the dominant area of decomposition and mineralization of organic matter on poor soils (Thomas et al., 2015), which was supported by the positive effect of the second PCA soil fertility axis PC2 driven by organic matter on Douglas-fir growth efficiency (Table 3.2). Second, there could also be a hydraulic lift of water by deeper rooting beech in favour of Douglas-fir (Bolte and Villanueva, 2006), as confirmed by the positive effect of first PCA soil fertility axis PC1 driven by parent material on beech growth efficiency. Third, intrinsic water use efficiency of Douglas-fir is larger than beech and Douglas-fir can translate into a higher carbon gain of the needles per unit water than beech (Thomas et al., 2015), which is an advantage for Douglas-fir during drought. In the end, the soil resources might be better exploited. This consequence would in turn allow for some aboveground light complementarity, given that poor site conditions were not harsh enough to limit tree growth in Dutch climate context. Therefore, complementary in the use of both soil resources and light could explain stronger overyielding on poor soils than on rich soils. This suggests not only 
complementarity in soil resource use as described by the stress-gradient hypothesis, but also implies complementarity in light use on low fertility soils.

On rich soils, the increased nutrient and water availability enables trees to develop high leaf areas and light is considered a major limiting resource. Douglas-fir had similar growth on rich soils as on poor soils and led to total stand overyielding. The underyielding for beech could be attributed to Douglas-fir suppressing beech stronger on rich soils by producing a more and denser leaf area. Additionally, there could be strong intra-specific competition for beech at below-ground, as detected during beech seedling stage (Fruleux et al., 2016). These results are opposite to the findings that stronger overyielding occurs on more favourable conditions (Thurm et al., 2016a; Thurm and Pretzsch, 2016). In these studies, it is argued that trees allocate more carbon to height growth to keep their crown in the canopy to reduce the increased light competition on benign conditions, while trees invest more carbon to root growth due to higher competition for soil resources under harsher conditions, supporting the resource-ratio hypothesis. Yet, our results imply that Douglas-fir and beech have stronger complementary use of both soil resources and light on poor soils, and that the two species face stronger competition for light on rich soils. To better test those ideas, we call for studies that actually present root and leaf distribution data for mixed stands on poor and rich soils.

Overyielding was also observed in pine-oak mixtures and was mainly driven by slowgrowing shade tolerant oak. Overyielding was rather weak on rich soils compared with the one on poor soils, which is in line with the stress-gradient hypothesis. The positive mixture effect on oak was similar on poor and rich soils, but pine overyielded on poor soils while it underyielded on rich soils (Fig.2c,d; Fig.3e,f,g,h). This underyielding of pine on rich soils was supported by the decreased pine growth with the interactions of increasing first PCA soil

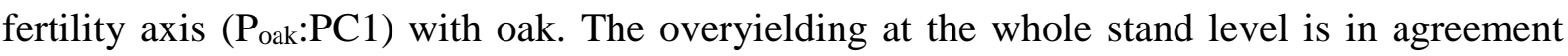
with the results reported in an earlier study for the same stands ( $\mathrm{Lu}$ et al., 2016), and the results of similar pine-oak mixed stands from other areas in Europe (Brown, 1992; Del Río and Sterba, 2009; Perot and Picard, 2012). Literature also shows that oak often drives the overyielding in this mixture, and not Scots pine (Toïgo et al., 2015). On poor soils, the two species may benefit from complementary soil resource use. Relative deep-rooted oak is more likely to "pump" water to shallow-rooted pine (Brown, 1992), resulting in high water use efficiency in the mixtures. This enhanced soil water availability could enable the complementary light use of these two species differing in light requirements, causing greater overyielding on poor soils. On rich soils, the lower overyielding, caused by underyielding of pine, could be explained by low complementarity of light use, as suggested by the similar heights of both species in the mixtures (Appendix 3.6). Improvement of oak height and absence of suppression by pine was also observed in experiment by Brown, 1992 (1992).

While oak-beech mixtures did not show any overyielding when soil variation was not accounted for (Lu et al., 2016), our analysis revealed that these mixtures overyielded on poor soils and underyielded on rich soils (Figure 3.3e,f). These trends were fully attributed to beech, as oak performed similar in mixed and pure stands (Figure 3.2e,f; Figure 3.3c,d,g,h). 
These results contrast with our first hypothesis, given that beech is the slow-growing shadetolerant species in the understory and the more slower growing light-demanding oak in the overstory. However, in reality, beech trees grew faster than oak trees and occupied the upper layer (Appendix 3.4c). Our results confirm our second hypothesis, which predicted that overyielding would be stronger on a poorer soil and are in line with some earlier studies on this mixture (Pretzsch et al., 2013a). Possibly the overyielding on poor soils results from hydraulic redistribution by deep-rooted oak, which thus increases water availability for relatively high proportion of superficial roots of beech. A more efficient use of below-ground resources was speculated for the oak-beech mixtures, which allows for a better exploration of the soil profile (Manso et al., 2015). This was also detected in a seedling experiment where oak facilitated beech seedlings under water limiting sites (Fruleux et al., 2016). However, on rich soils, trees of these two species may not benefit from complementarity effect in light because they had similar dominant heights, suggesting that their crowns are at similar vertical positions and may not effectively partition the light environment (Appendix 3.4c). Another reason, as reported in previous studies, is that beech may be a more successful competitor for above and belowground resources than oak (Rewald and Leuschner, 2009; Lebourgeois et al., 2013). Thus strong intra-specific competition for beech led to underyielding of beech and even caused underyielding of the total stand (Fruleux et al., 2016).

Overyielding was not observed in oak-birch mixtures and the neutral mixture effect of both oak and birch was similar, irrespective of site conditions (Table 3.2; Figure 3.2g,h; Figure $3.3 \mathrm{~g}, \mathrm{~h}, \mathrm{i}, \mathrm{j})$. The results do not support our first hypothesis, since the fast-growing lightdemanding birch did not overyield. These results are in accordance with our previous study that no significant overyielding was observed for this mixture as the two species are rather similar in leaf phenology and shade tolerance ( $\mathrm{Lu}$ et al., 2016). The result is also in line with the study that birch was unaffected by mixture effect and soils (Göransson et al., 2016). The neutral mixture effect on both poor and rich soils indicates that soils are not the limiting factor for this mixture. Birch is a light-demanding, early successional species with fast juvenile growth (Fischer et al., 2002) and dominates the upper tree layer (Appendix 4.4d). Therefore, the two species in the mixture mainly compete light. Apparently, birch and oak did not benefit from complementary use of resource on poor and rich soils, which may partly be attributed to their similar phenology and shade tolerance. 


\section{Conclusions}

Our results show that mixing species sometimes led to overyielding, but this overyielding was attributed to one or two species and not always driven by fast-growing light-demanding species. Differences in leaf phenology are a major driver for overyielding. Overyielding was stronger on poor soils than on rich soils in the Netherlands, probably because of stronger complementarity use of resources both below and aboveground.

\section{Acknowledgements}

We thank Hans Jansen for compiling data and Leo Goudzwaard for data collection. H.C.L. acknowledges the financial support from the China Scholarship Council (No. 201306600022), and she also thanks the COST Action FP1206 EuMIXFOR for funding the STSM-FP120633579 and STSM-FP1206-34833, and the Short Scientific Visits Grant from European Forest Institute. 


\section{Appendix}

Appendix 3.1 Soil properties of SoilGrids250m used in this study.

\begin{tabular}{llll}
\hline Soil variable name & Units & Range & Mean \\
\hline Sand content (gravimetric) & $\mathrm{kg} / \mathrm{kg}$ & $38.2-89.5$ & 80.0 \\
Silt content (gravimetric) & $\mathrm{kg} / \mathrm{kg}$ & $6.1-48.5$ & 13.1 \\
Clay content (gravimetric) & $\mathrm{kg} / \mathrm{kg}$ & $2.7-21.7$ & 7.0 \\
$\mathrm{pH}\left(\mathrm{H}_{2} \mathrm{O}\right.$ solution) & & $4.7-6.3$ & 5.2 \\
Soil organic carbon (dry combustion) & $\mathrm{g} / \mathrm{kg}$ & $28.0-179.0$ & 86.9 \\
Cation-exchange capacity (fine earth fraction) & $\mathrm{cmol}+/ \mathrm{kg}$ & $8.5-28$ & 17.6 \\
Bulk density (fine earth fraction) & $\mathrm{kg} / \mathrm{m}^{3}$ & $1215-1506$ & 1435 \\
Coarse fragments (volumetric) & $\mathrm{cm}^{3} / \mathrm{cm}^{3}$ & $2.0-16.4$ & 7.2 \\
\hline
\end{tabular}

Appendix 3.2 Results of the correlation analysis based on the 8 soil properties used in this study and eigenvalues of the soil properties on the two main principal components. Clay, sand, silt, $\mathrm{pH}$, bulk density and coarse fragments took weighted average value over 6 soil layers, while ORC and CEC took from weighted average value from top 2 soil layers. Clay, sand and silt represent clay content, sand content and silt content, respectively; BLD: bulk density; CRF: coarse fragments; ORC: soil organic carbon; CEC: cation-exchange capacity. Pearson pairwise correlation coefficients are given $(* P<0.05 ; * * P<0.01 ; * * * P<0.001)$.

\begin{tabular}{|c|c|c|c|c|c|c|c|c|c|c|}
\hline & clay & sand & silt & pH & BLD & CRF & ORC & CEC & $\begin{array}{l}\text { PC1 } \\
(42 \%)\end{array}$ & $\begin{array}{l}\text { PC2 } \\
(30 \%)\end{array}$ \\
\hline clay & & & & & & & & & 2.487 & -0.33089 \\
\hline sand & $-0.8506^{* * *}$ & & & & & & & & -2.5209 & -0.28529 \\
\hline silt & $0.6706^{* *}$ & $-0.9589 * * *$ & & & & & & & 2.2377 & 0.60158 \\
\hline pH & $0.8022 * * *$ & $-0.5554^{* *}$ & 0.3526 & & & & & & 2.0138 & -1.07832 \\
\hline BLD & -0.3453 & 0.2048 & -0.1082 & -0.4396 & & & & & -1.0964 & 0.02202 \\
\hline CRF & -0.0507 & -0.2817 & 0.4339 & -0.3418 & 0.0396 & & & & 0.3774 & 2.2949 \\
\hline ORC & -0.2045 & 0.1499 & -0.0954 & -0.3487 & -0.0551 & 0.5307 & & & -0.4925 & 2.25184 \\
\hline CEC & 0.1526 & -0.1808 & 0.1791 & -0.0193 & -0.1810 & $0.5898^{*}$ & $0.7261 *$ & & 0.5403 & 2.21378 \\
\hline
\end{tabular}


Appendix 3.3 Residuals vs. predicted values for the final model of each species.
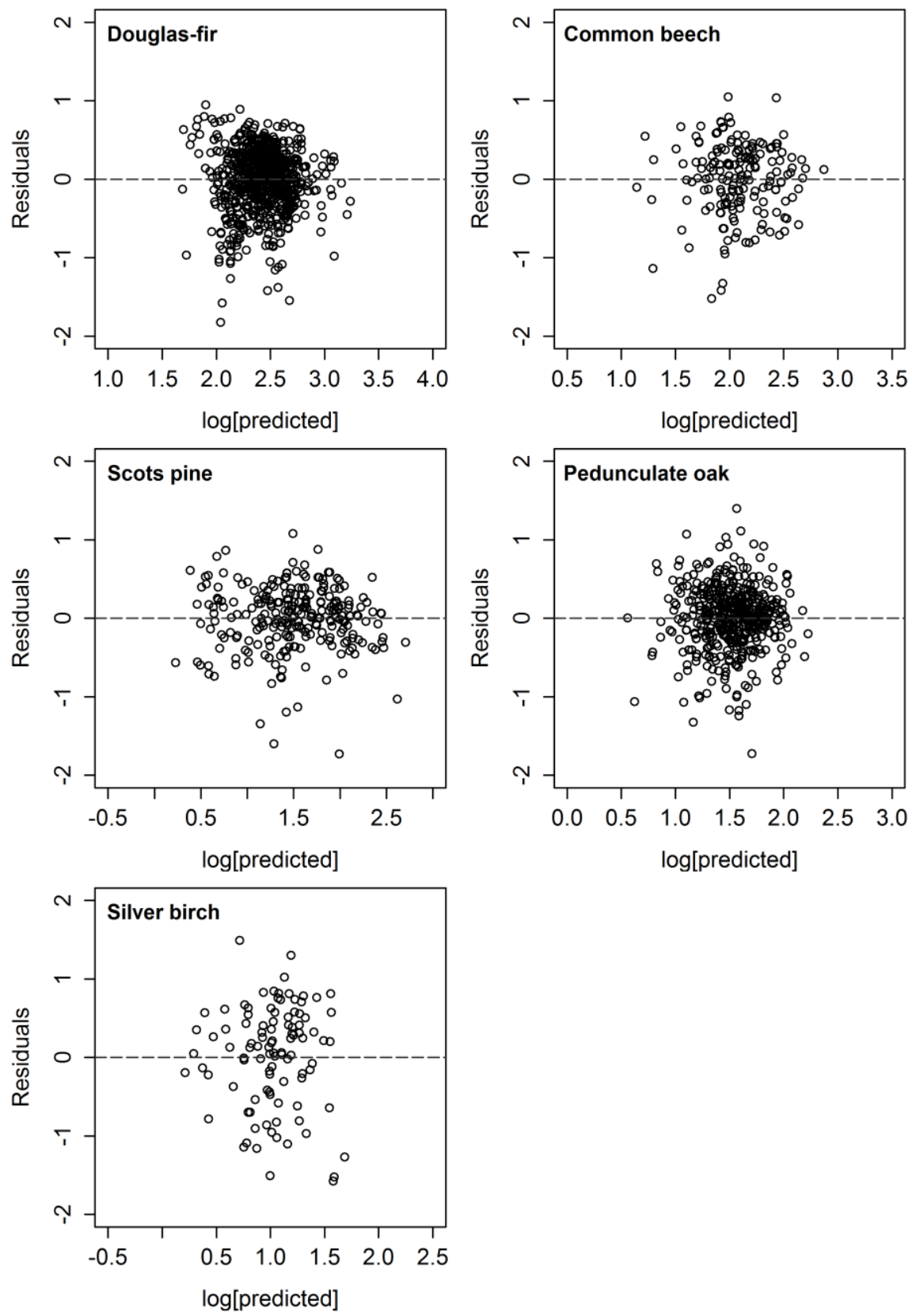
Appendix 3.4 Periodic annual volume increment (PAIV) in mixed and pure stands changes with one admixture proportion, depending on mean values of quadratic mean diameter $\left(\mathrm{d}_{\mathrm{g}}\right)$, dominant height $\left(\mathrm{H}_{\mathrm{dom}}\right)$, age, stand density index (SDI) on poor soils where $\mathrm{PC} 1=0, \mathrm{PC} 2=-0.3$ and $\mathrm{PC} 2=0, \mathrm{PC} 1=-0.3$, and on rich soils where $\mathrm{PC} 1=0, \mathrm{PC} 2=0.3$ and $\mathrm{PC} 2=0, \mathrm{PC} 1=0.3$. (a-d) Douglas-fir and beech growing in pure and Douglas-fir-beech mixed stands. (e-h) Pine and oak growing in pure and pine-oak mixed stands. (i-1) Oak and beech growing in pure and oak-beech mixed stands. (m-p) Oak and birch growing in pure and oak-birch mixed stands.
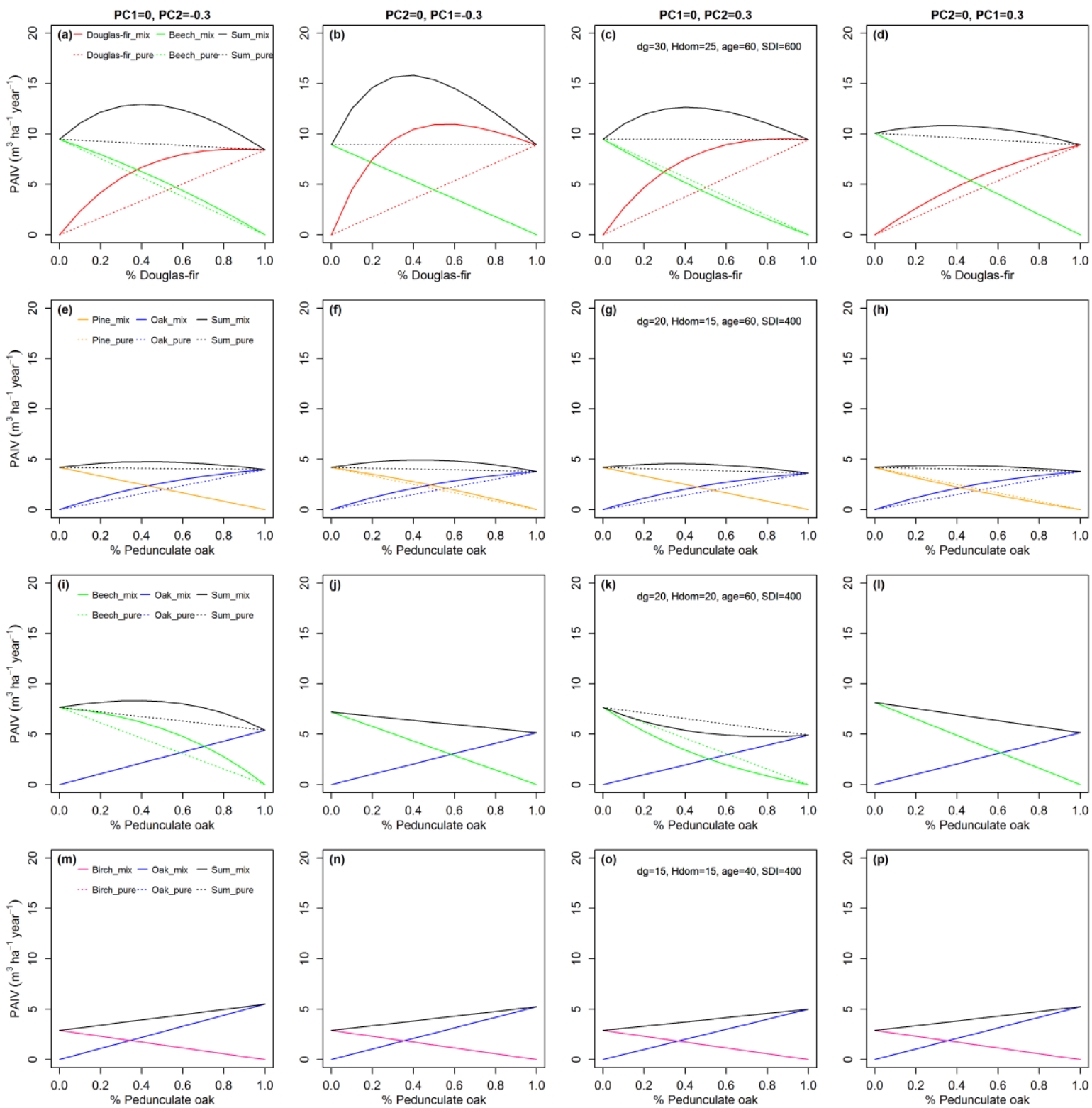
Appendix 3.5 Growth efficiency $\left(\mathrm{IV}_{\mathrm{P}}\right)$ of one species in mixed versus pure stands changes with stand density index (SDI), depending on quadratic mean diameter $\left(\mathrm{d}_{\mathrm{g}}\right)$, dominant height $\left(\mathrm{H}_{\mathrm{dom}}\right)$ and age on poor soils where $\mathrm{PC} 1=0, \mathrm{PC} 2=-0.3$ and $\mathrm{PC} 2=0, \mathrm{PC} 1=-0.3$ on rich soils where $\mathrm{PC} 1=0, \mathrm{PC} 2=0.3$ and $\mathrm{PC} 2=0, \mathrm{PC} 1=0.3$.

(a-d) Douglas-fir in pure, Douglas-fir-beech mixed stands. (e-h) Beech in pure, Douglas-fir-beech and oakbeech mixed stands. (i-l) Pine in pure, pine-oak mixed stands. (m-p) Oak in pure, pine-oak, oak-beech and oakbirch mixed stands. (q-t) Birch in pure, oak-birch mixed stands. A proportion of $50 \%$ has been used for each species in the mixture.
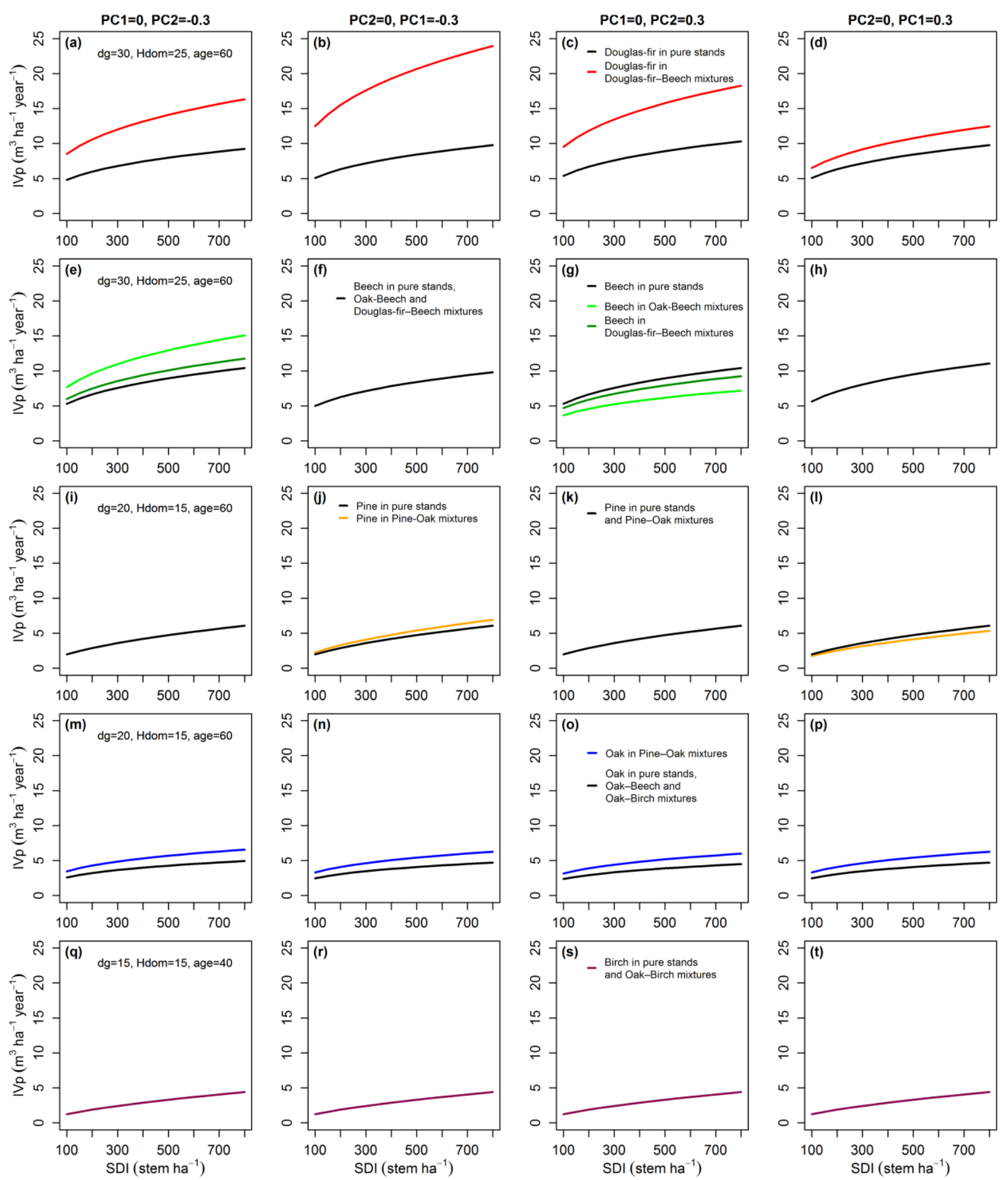
Appendix 3.6 Dominant height of total stand and by each species in mixtures. (a) Douglas-fir-beech mixed stands. (b) pine-oak mixed stands. (c) oak-beech mixed stands. (d) oak-birch mixed stands. Solid lines are moving average for dominant height of the total mixed-species stands and each species.
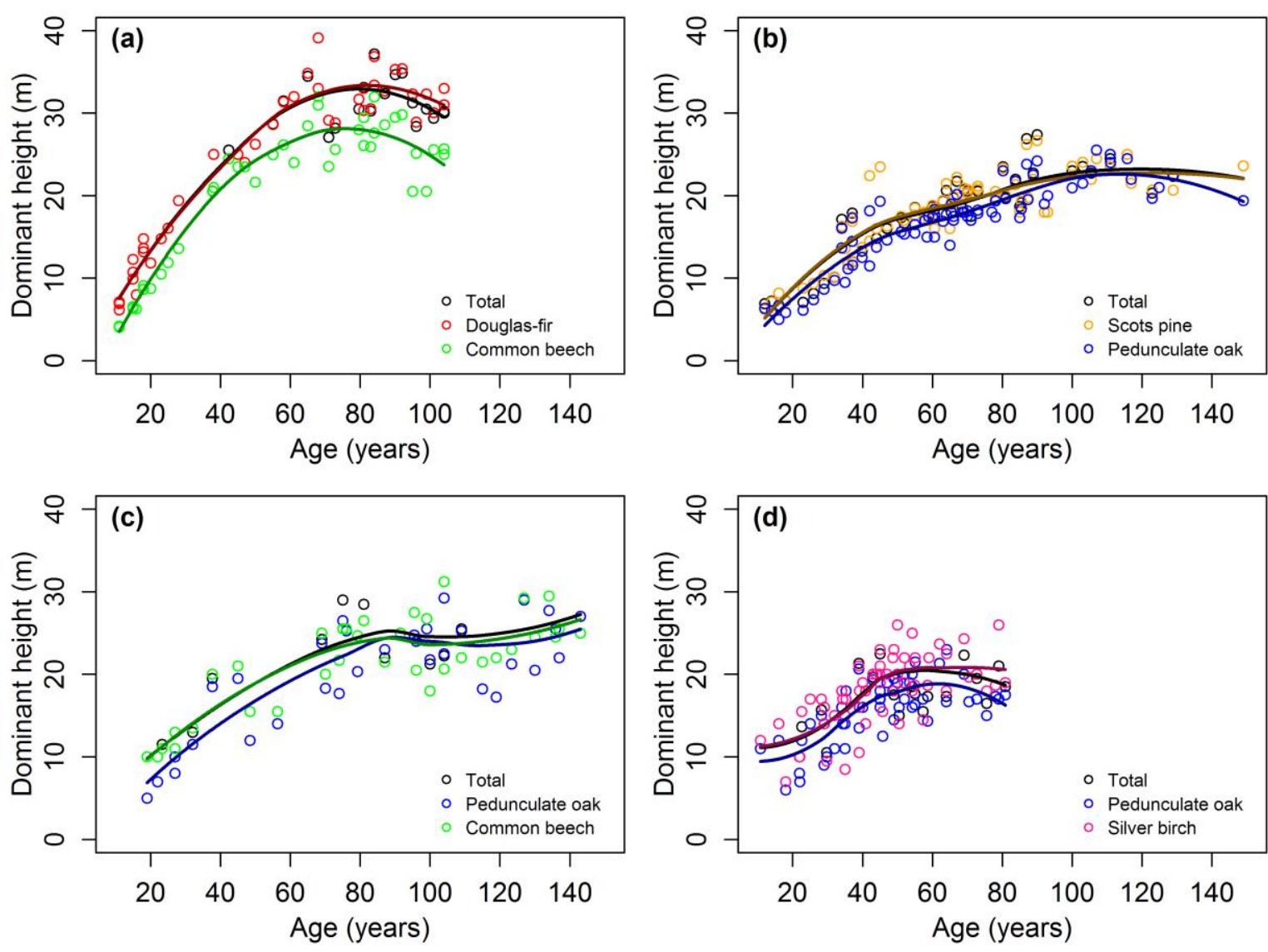
有则改之，无则加勉

一中国俗语

Correct mistakes if you have committed them and guard against them if you have not.

-Chinese proverb 



\section{Abstract}

Intra-specific competition is acknowledged to frequently have a more pronounced effect on tree growth than inter-specific competition, particularly when niche complementarity results in competitive reduction. This positive species interaction can happen both above and belowground. The aboveground competition for light is often considered size-asymmetric, while the belowground competition for soil resources is mainly size-symmetric. We hypothesised that (1) intra-specific competition is stronger than inter-specific competition and competitive reduction is larger at less fertile soils, in accordance with the stress-gradient hypothesis; (2) when light is the most important growth limiting factor in Dutch forests, sizeasymmetric competition is more relevant for tree growth than size-symmetric competition; (3) given that forests develop a denser canopy at high fertility soils, size-asymmetric competition will be greater at high fertility soils, in accordance with the resource-ratio hypothesis, and this in turn may imply a higher probability of complementarity for light than for soil resources. To test the hypotheses, we used individual tree models to understand the effect of competitive interactions on tree basal area growth along a soil fertility gradient. To examine whether individual tree growth is better explained by size-asymmetric or size-symmetric competition, the models considered competition with all individuals (as a proxy of size-symmetry, expressed by Reineke's stand density index, SDI) or only larger individuals (as a proxy of size-asymmetry, SDI of large trees). We applied the models to three tree species: pedunculate oak (Quercus robur L.), silver birch (Betula pendula Roth) and Scots pine (Pinus sylvestris L.) in three two-species mixtures from Dutch national forest inventory data. In pedunculate oaksilver birch mixtures, both oak and birch growth benefitted from the presence of the other species, and this positive effect was not influenced by soils. In Scots pine-pedunculate oak mixtures, neither pine nor oak growth were influenced by the presence of the other species, regardless of the low and high soil fertility. Finally, in Scots pine-silver birch mixtures, birch always benefited from the presence of pine in larger size classes, although the benefit was greater on rich soils. We conclude that intra-specific competition was not necessarily stronger than inter-specific competition and this competitive reduction was less seen at lower soil fertility and dependent on species mixtures, which is not in line with the stress-gradient hypothesis. Moreover, size-asymmetric competition for light was more associated with tree basal area growth than size-symmetric competition for soil resources, suggesting that light is the most limiting resource. Competition for light was generally much stronger at high fertility soils, supporting the resource-ratio hypothesis. Our analysis revealed that species mixing can increase tree growth by alleviating competition for light between neighbouring species, thereby driving species and stand overyielding.

Keywords: Individual tree model; Intra- and inter-specific competition; Size-asymmetric and size-symmetric competition; Species interactions; Tree basal area growth. 


\section{Introduction}

Mixed-species forests are often more productive than monoculture forests, a phenomenon which is often referred to as overyielding. One key mechanism that may explain such overyielding is niche complementarity (Kelty, 1992; Tilman, 1999). This means that two species take resources from different locations or time, thus reducing competition. This is often referred to as competitive reduction. This competitive reduction can apply to light or to soil resources, and in both cases can be affected by soil fertility.

Individual tree growth in mixed-species stands is determined by light and soil resources, as well as by species composition and interactions between trees of the same and different species. Interactions between species growing in mixtures are often described in terms of competition, competitive reduction and facilitation (Vandermeer, 1989). Competitive reduction and facilitation often occur simultaneously and their effects are difficult to separate, and these two are collectively described as complementarity (Loreau and Hector, 2001) and usually result in overyielding of mixtures (Forrester, 2014). The species interactions are linked to the intra- and inter-specific competition (Harper, 1977). Existing studies show that inter-specific competition is often lower than intra-specific competition because of niche complementarity (Loreau, 2004; Pretzsch et al., 2013b; Del Río et al., 2014a). Moreover, the larger intra- than inter-specific competition can occur both aboveground and belowground.

The intra- and inter-specific competition can be identified related to the mode of competition: size-asymmetric or size-symmetric. Size-asymmetric competition takes place when trees compete for light, as larger individuals often benefit disproportionately and suppress the growth of their smaller neighbours accordingly. Size-symmetric competition is generally linked to belowground competition for mineral nutrients and water (Hara, 1993; Schwinning and Weiner, 1998). In temperate forests, competition for light is often more relevant for tree growth than competition for soil resources, and species complementarity leads to more tree growth because inter-specific is lower than intra-specific competition (Del Río et al., 2014a; Condés and Del Río, 2015). This may however depend on the site, stand age and species composition (Cavard et al., 2011; Coates et al., 2013; Toïgo et al., 2015). As a stand develops, complementary resource use may decline as the trees of both species grow taller and occupy more space, both aboveground and belowground. This is in line with the observation that competition increases with increasing stand development (Cavard et al., 2011; Del Río et al., 2014b). However, this increased competition over time may not be apparent in Dutch forests, where frequent forest management (thinning) keeps stands below a maximum stand basal area and density, therefore possibly reducing competition and allowing for complementary resource use (Lu et al., 2016).

Across a soil fertility gradient, two dominant hypotheses address possible changes in the strength of species interactions. The stress-gradient hypothesis predicts that facilitation or complementary resource use is more frequent at less fertile soils whereas competition occurs at more fertile soils (Bertness and Callaway, 1994). As a consequence, competitive reduction 
should be greater with decreasing soil fertility through facilitation or complementary resource use by which one species may effectively improve the soil resource availability for the other. However, the resource-ratio hypothesis states that competition for light is more prevalent at high fertility soils, while competition for soil resources is predominant at low fertility soils. According to the resource-ratio hypothesis, competition for light should be stronger when soil fertility is higher. Size-symmetric competition is more common and stronger on poor sites where nutrients or water limit growth, so that trees in mixtures compete more fiercely for below-ground resources (Forrester, 2014; Jucker et al., 2014a). One study identified a transition from size-asymmetric to size-symmetric competition along the gradient from fertile to poor sites (Pretzsch and Biber, 2010). Other studies show that inter-specific competition had a positive effect on tree growth at dryer sites relative to intra-specific competition (Condés and Del Río, 2015). One study found that competition for soil resources increased in one experiment on poor soils (Baribault and Kobe, 2011), while another found that it decreased (Trinder et al., 2012). Our study shows stronger competition for soil resources on low fertile soils (chapter 3). Yet other studies have shown that competitive interactions varied across a soil fertility gradient, depending on the species composition and the main type of competition: above or belowground competition in a sub-boreal forest (Coates et al., 2013). Therefore, the relationships between mode of competition, inter-specific competition and environmental conditions in terms of their influence on tree growth are still poorly understood.

To gain a deeper understanding of the relationship between stand density and productivity, Harry et al. (1964) introduced the idea of 'crowding'. However, crowding changes with tree size and the average distance between trees (Assmann, 1970; Zeide, 2005). A meaningful alternative to crowding is Reineke's stand density index (SDI) (Reineke, 1933). This index relates the actual stand density to a theoretical maximum stocking density and is independent of age, diameter, site quality, and other variables (Zeide, 2005). Tree species mixing can increase the maximum stand density (Pretzsch and Biber, 2016), and changes in stand density often modify the way in which species interact on growth (Condés et al., 2013; Forrester et al., 2013a). Stand density should therefore usually be taken into account when interpreting the mixing effect. The SDI is usually applied to express competition for belowground resources, while for the SDI of larger trees than the target tree is used to express competition for aboveground resources. Both have often been used in growth models to express sizesymmetric and size-asymmetric competition (Weiskittel et al., 2011; Del Río et al., 2014a). Individual tree growth models consider tree competition, taking into account resource partitioning, and are more site-sensitive (Pretzsch and Biber, 2010), therefore providing a sound approach for studying species competition in mixed-species stands.

In our previous studies, we showed that inter-specific differences in leaf phenology and shade tolerance are important drivers of overyielding in mixed forests (in chapter 2, Lu et al., 2016), and that overyielding in these forests is stronger at low fertility soils (chapter 3 ), providing evidence in favour of the stress-gradient hypothesis. These results were obtained for a relatively small dataset of well-controlled research plots. In this study, we expanded the 
analysis to the overall Dutch forest to see if the same patterns occur in practical forestry. We used the Dutch national forest inventory data, which are representative for the Dutch forests as a whole and contain a larger number of mixed plots. In this study, we considered the underlying tree-tree interactions and explored whether reduced competition for light or soil resources contributed to overyielding. We therefore addressed the following questions: (1) Is inter-specific competition smaller than intra-specific competition and is this competitive interaction influenced by soils? (2) Which mode of competition is more associated with tree growth: size-asymmetric or size-symmetric competition? and (3) Is the mode of competition influenced by soils? We hypothesised that (1) intra-specific competition is stronger than interspecific competition, with more competitive reduction on poor soils, in accordance with the stress-gradient hypothesis, (2) when light is the most important growth limiting factor in Dutch forests, size-asymmetric competition (for light) is more relevant for tree growth than size-symmetric competition (for soil resources), and (3) given that forests develop a denser canopy on rich soils, the resource-ratio hypothesis would predict that size-asymmetric competition is greater on rich soils than on poor soils, and in turn this may allow for more complementary light use than soil resource use. To deepen our understanding of how competitive interactions between trees vary with soil fertility, we combined the effects of competition that depends on site conditions in individual tree models for mixtures of pedunculate oak (Quercus robur L.)-silver birch (Betula pendula Roth), Scots pine (Pinus sylvestris L.)-pedunculate oak, and Scots pine-silver birch, using Dutch national forest inventory data. We analysed which mode of competition is more relevant for tree growth by incorporating into the approach the effects of site condition variables, size-asymmetric and size-symmetric competition, intra- and inter-specific competition, as well as the interactions among them.

\section{Methods}

\section{Study area}

The study was conducted in the Netherlands, where only about $11 \%$ of the land area is occupied by forest (Schelhaas et al., 2014). The Netherlands has a moderate maritime climate created by predominant southwestern winds, with a mean annual temperature of $10.8^{\circ} \mathrm{C}$. It has cool winters (average temperature in December-February is $2.5^{\circ} \mathrm{C}$ ) and mild summers (average temperature in June-August is $15.9^{\circ} \mathrm{C}$ ). The mean annual rainfall is around $800 \mathrm{~mm}$ and is evenly distributed throughout the year (KNMI, 2015).

\section{Dutch National Forest Inventory data}

Data from the $5^{\text {th }}$ and $6^{\text {th }}$ Dutch National Forest Inventory (NFI) (Dirkse et al., 2007; Schelhaas et al., 2014) were used. The $5^{\text {th }}$ inventory was carried out between 2001 and 2005 , and the $6^{\text {th }}$ between 2012 and 2013. Applying a $1 \times 1 \mathrm{~km}$ grid system across the Netherlands, one sample point was randomly chosen per grid cell. If the plot centre was marked as forest 
on the map, a circular sample plot was set for that location. The plot radius was chosen to include about 20 trees per plot, with a minimum of 5 metres and a maximum of 20 metres. Within each plot, all trees were measured that had a diameter at breast height (DBH) of at least $5 \mathrm{~cm}$, and their species identity and status (standing, lying or hanging, dead or alive) were recorded. The age of the plot was obtained from forest databases or maps.

\section{Plot selection}

To understand the interaction between species and to disentangle possible causes of interspecific competition in mixed stands, we studied three two-species mixtures using Dutch NFI data. The mixtures were pedunculate oak (Quercus robur L.)-silver birch (Betula pendula Roth), Scots pine (Pinus sylvestris L.)-pedunculate oak, and Scots pine-silver birch. Henceforth, the three species and three mixtures are written as oak, birch and pine, and oakbirch, pine-oak and pine-birch, respectively. Mixed stands were defined as stands in which the proportion of the two species of interest together represented more than $90 \%$ of the total plot basal area, and in which the proportion of each species was greater than 5\%. Moreover, to avoid possible thinning effects on species interactions, mixed stands were further selected using the criteria that the proportion of harvested basal area between the two surveys was less than $5 \%$ of the total plot basal area at the start of the studied growth period. As a result, we obtained 145 plots with two-species stands (Table 4.1). A description of the individual tree data at the beginning of the studied growth period (the $5^{\text {th }}$ survey) for different species in each mixture is given in Table 4.2.

\section{Soil data}

Soil data were taken from the ISRIC-World Soil Information SoilGrids250m database (http://www.isric.org/explore/soilgrids). SoilGrids250m provides global predictions for standard numeric soil properties at seven standard depths $(0,5,15,30,60,100$ and $200 \mathrm{~cm})$ at a $250 \mathrm{~m}$ resolution across the Netherlands. The soil properties include sand content, silt content, clay content, $\mathrm{pH}$ (in $\mathrm{H}_{2} \mathrm{O}$ ), soil organic carbon (ORC), cation-exchange capacity (CEC), bulk density and coarse fragments (Hengl et al., 2016). First, we calculated the average value by taking the average of the predictions for the upper and lower boundaries of the depth intervals $(0-5 \mathrm{~cm}, 5-15 \mathrm{~cm}, 15-30 \mathrm{~cm}, 30-60 \mathrm{~cm}, 60-100 \mathrm{~cm}, 100-200 \mathrm{~cm})$, resulting in values for six layers for each soil property. For $\mathrm{pH}$, the average value was very similar to the first layer value $(0-5 \mathrm{~cm})$, since $\mathrm{pH}$ was highly correlated in all six layers (see Appendix 4.2 for soil property characteristics in the studied plots). Second, we calculated weighted averages according to the layer thickness for sand content, silt content, clay content, bulk density and coarse fragments over the six layers. For ORC and CEC, we took the weighted average from the top two layers since most of the soil organic matter is found in these layers. Since we expected the soil properties to be strongly correlated (see Appendix 4.3), we carried out principal component analysis (PCA) based on the weighted averaged values of the seven soil properties and the first layer value of $\mathrm{pH}$ to determine the major soil 
gradients in our dataset. Finally, we combined the first and second principal components (PC1 and PC2) from the PCA with tree growth data in our study plots to assess the impact of soils on competitive interactions in different mixtures.

\section{Tree growth models}

We modelled the basal area growth of individual trees in three two-species mixed stand plots in relation to neighbouring trees using a similar approach to that taken in the study by Del Río et al (2014a). The dependent variable in this study was the annual basal area growth of individual trees $\left(\mathrm{cm}^{2}\right.$ year-1) obtained in two continuous inventories. Other studies have applied tree basal area growth, height growth and diameter growth models for individual tree growth. In our study, given the lack of height data for individual trees, we used tree basal area growth as a response variable since this considers the cross-section of the stem and is much more directly related to competition effects than diameter growth (Assmann, 1970). We included tree basal area as a predictor to account for possible size effects in the growth model. In addition, interactions between site descriptors and competition indices were included in the model to account for varying site conditions. An exploratory analysis indicated that negative and zero basal area increments were mainly due to random measurement errors and the dynamics of the tree bark. We therefore decided not to remove them from the data in order not to encounter biased results in the model.

Tree species growth in mixed stands depends on the stand density, which depends on the amount of resources used by trees in relation to the resource availability at a site (Dean and Baldwin, 1996). As different species can vary in their capacity to occupy a site, in other words different potential or maximum densities, species proportion should be estimated using relative densities (the proportion of the maximum density) in order to correct for this difference (Del Río et al., 2015). Since species-specific maximum density boundary lines are not available in the Netherlands, and considering that frequent thinning took place in the plots studied and stands were never fully stocked (Lu et al., 2016), we used absolute SDI and SDIL per species from Eq. (1) and Eq. (2) (Reineke, 1933; Condés and Del Río, 2015). The SDIL was derived by combining the concepts of SDI and the basal area of larger trees (Wykoff, 1990). Both the SDI and the SDIL have often been used in growth models to express sizesymmetric competition (SC) and size-asymmetric competition (AC) (Weiskittel et al., 2011). We selected indices based on the stand density index concept (SDI and SDIL) rather than indices based on basal area, as used in some studies (Manso et al., 2015). This is because basal area is more influenced by stand development and environmental conditions.

$$
\begin{aligned}
& S D I=N^{*}\left(25 / d_{g}\right)^{E} \\
& S D I L=N L^{*}\left(25 / d_{g \mathrm{~L}}\right)^{E}
\end{aligned}
$$

where $S D I$ is the stand density index $\left(\right.$ stem ha $\left.{ }^{-1}\right) ; N$ is the number of trees per hectare; $d_{g}$ is the quadratic mean diameter $(\mathrm{cm}) ; S D I L$ is the stand density index of trees larger than the target 
tree $\left(\right.$ stem $\left.\mathrm{ha}^{-1}\right) ; N L$ the number of trees larger than the target tree; $d_{g \mathrm{~L}}$ the quadratic mean diameter of these larger trees. $E$ is the generic value proposed by Reineke and $E=-1.605$ for all studied species because, as mentioned above, no species-specific boundary line values are given in the Netherlands.

The following basic model (Eq. (3)) was then fitted to the data. To test whether the basal area growth of a given tree species was better explained by size-symmetric or sizeasymmetric competition, these models were run separately to compare their results.

$\ln \left(I_{i}\right)=a_{0}+a_{1} \times \ln \left(g_{i}\right)+a_{2} \times C_{i}+\varepsilon_{i}$

where $I g_{i}$ is the basal area increment per year $\left(\mathrm{cm}^{2}\right.$ year $\left.^{-1}\right)$ (log-transformed) of tree $i$ with a given basal area $g_{i}\left(\mathrm{~cm}^{2}\right)$ (log-transformed) at breast height; $C_{i}$ is the different inclusion of competition factor $C$ for tree $i$ according to the competition structure for each species in the mixture (Table 4.2); $\varepsilon_{i}$ is the model residuals. Since the data were hierarchical (trees were measured on the same plot), plot was used as a random factor in the linear mixed-effects models. 
Table 4.1 Descriptive stand variables of the selected plots at the beginning of the studied growth period.

\begin{tabular}{|c|c|c|c|c|c|c|c|c|c|c|c|c|c|c|c|c|c|c|c|c|c|}
\hline \multirow{2}{*}{ Species } & & \multicolumn{4}{|c|}{$N\left(\right.$ trees ha $\left.^{-1}\right)$} & \multicolumn{4}{|c|}{$D_{g}(\mathbf{c m})$} & \multicolumn{4}{|c|}{$\boldsymbol{H}_{\text {dom }}(\mathbf{m})$} & \multicolumn{4}{|c|}{ Age (years) } & \multicolumn{4}{|c|}{ SDI (stem ha' $\left.{ }^{-1}\right)$} \\
\hline & & Mean & SD & Min & Max & Mean & SD & Min & Max & Mean & SD & Min & Max & Mean & SD & Min & Max & Mean & SD & Min & Max \\
\hline Pedunculate & Total & 872 & 669 & 96 & 3056 & 20.6 & 7 & 6.8 & 36.4 & 18.1 & 4.9 & 5.0 & 26.0 & 54 & 28 & 5 & 105 & 493.1 & 248.2 & 113.8 & 1554.3 \\
\hline oak-silver birch & Oak & 413 & 438 & 24 & 2419 & 24.3 & 10 & 5.4 & 51.8 & & & & & & & & & 289.3 & 209.9 & 25.0 & 1078.2 \\
\hline$(\mathrm{n}=37)$ & Birch & 446 & 420 & 26 & 1783 & 17.5 & 6.5 & 7.6 & 32.7 & & & & & & & & & 190.8 & 125.7 & 20.4 & 476.0 \\
\hline Scots pine- & Total & 692 & 405 & 167 & 2674 & 24.2 & 6.1 & 8 & 41.6 & 18.2 & 3.9 & 9.0 & 27.0 & 74 & 24 & 14 & 124 & 573.5 & 194.4 & 283.8 & 1235.7 \\
\hline pedunculate oak & Pine & 299 & 355 & 22 & 2292 & 31.1 & 9.3 & 8.4 & 59.6 & & & & & & & & & 319.0 & 206.8 & 28.5 & 1142.4 \\
\hline$(\mathrm{n}=53)$ & Oak & 290 & 229 & 32 & 1045 & 21.5 & 10.1 & 5.6 & 48.5 & & & & & & & & & 202.4 & 169.8 & 26.5 & 786.5 \\
\hline Scots pine- & Total & 854 & 650 & 210 & 3311 & 19.6 & 5.6 & 7.7 & 38.4 & 16.5 & 4.8 & 2.0 & 25.0 & 65 & 28 & 9 & 121 & 478.4 & 191.3 & 136.8 & 1077 \\
\hline silver birch & Pine & 433 & 571 & 53 & 2929 & 27.1 & 8.6 & 7.0 & 42.7 & & & & & & & & & 334.9 & 179.9 & 30.3 & 826.8 \\
\hline$(\mathrm{n}=55)$ & Birch & 376 & 377 & 16 & 2165 & 13.7 & 5.5 & 6.8 & 39.1 & & & & & & & & & 109.9 & 82.5 & 25.8 & 429.2 \\
\hline
\end{tabular}

n: number of plots; $\mathrm{D}_{\mathrm{g}}$ : quadratic mean diameter; $\mathrm{H}_{\mathrm{dom}}$ : dominant height; $\mathrm{SDI}$ : Reineke's stand density index. SD: standard deviation; Min: minimum value; Max: maximum value. 
Table 4.2 Tree characteristics and competitive status for each of the selected species in each mixture at the beginning of the studied growth period.

\begin{tabular}{|c|c|c|c|c|c|c|c|c|c|c|c|}
\hline Species & & & $d(\mathrm{~cm})$ & $\begin{array}{l}g \\
\left(\mathrm{~cm}^{2}\right)\end{array}$ & $\begin{array}{l}I_{g} \\
\left(\mathrm{~cm}^{2} \text { year }^{-1}\right)\end{array}$ & $\begin{array}{l}\text { SDIL }_{\text {intra }} \\
\left(\text { stem ha }^{-1}\right)\end{array}$ & $\begin{array}{l}\text { SDIL }_{\text {inter }} \\
\left(\text { stem ha }^{-1}\right)\end{array}$ & $\begin{array}{l}\text { SDIL } \\
\left(\text { stem ha }^{-1}\right)\end{array}$ & $\begin{array}{l}\text { SDI }_{\text {intra }} \\
\left(\text { stem ha }^{-1}\right)\end{array}$ & $\begin{array}{l}\text { SDI }_{\text {inter }} \\
\left(\text { stem ha }^{-1}\right)\end{array}$ & $\begin{array}{l}\text { SDI } \\
\left.\text { (stem ha }{ }^{-1}\right)\end{array}$ \\
\hline \multirow[t]{8}{*}{ Pedunculate oak-silver birch } & Oak $(\mathrm{n}=293)$ & Mean & 23.8 & 553.2 & 13.6 & 189.9 & 76.5 & 269.1 & 344.7 & 154.4 & 509.7 \\
\hline & & SD & 11.8 & 562.7 & 17.5 & 177.2 & 104 & 229.9 & 229.6 & 125.7 & 279.2 \\
\hline & & Min & 5.2 & 21.2 & -5 & 0 & 0 & 0 & 39.8 & 20.4 & 113.8 \\
\hline & & Max & 70.3 & 3881.5 & 131.9 & 939.3 & 476 & 1415.6 & 1078.2 & 476 & 1554.3 \\
\hline & $\operatorname{Birch}(n=289)$ & Mean & 16.3 & 267.4 & 5.4 & 113.5 & 183.5 & 304.3 & 212.2 & 241.1 & 467.2 \\
\hline & & SD & 8.6 & 274.9 & 7.2 & 93.9 & 151.3 & 187.9 & 119.4 & 183.2 & 224.9 \\
\hline & & Min & 5 & 19.6 & -8.3 & 0 & 0 & 0 & 20.4 & 25 & 113.8 \\
\hline & & Max & 42.7 & 1432 & 43.1 & 407.8 & 815.5 & 1223.9 & 476 & 1078.2 & 1554.3 \\
\hline \multirow[t]{8}{*}{ Scots pine-pedunculate oak } & Pine $(n=409)$ & Mean & 28.2 & 720.9 & 11.8 & 207.3 & 48.2 & 259 & 393.3 & 129.5 & 564.6 \\
\hline & & SD & 11 & 520.5 & 10.2 & 175.7 & 78.5 & 190.3 & 214.9 & 106.4 & 206.2 \\
\hline & & Min & 5 & 19.6 & -11.9 & 0 & 0 & 0 & 35.3 & 26.5 & 283.8 \\
\hline & & Max & 61.8 & 2999.6 & 59.1 & 1091.9 & 468.4 & 1170.5 & 1142.4 & 786.5 & 1235.7 \\
\hline & Oak $(\mathrm{n}=424)$ & Mean & 20.9 & 460.8 & 9.7 & 149.2 & 215.3 & 383.4 & 263.4 & 246.9 & 560 \\
\hline & & SD & 12.2 & 545 & 11.7 & 147.5 & 173.3 & 199.9 & 183.7 & 173.4 & 185.2 \\
\hline & & Min & 5 & 19.6 & -17.5 & 0 & 0 & 0 & 26.5 & 28.5 & 283.8 \\
\hline & & Max & 68.8 & 3717.6 & 77.8 & 755.9 & 1142.4 & 1220.7 & 786.5 & 1142.4 & 1235.7 \\
\hline \multirow[t]{8}{*}{ Scots pine-silver birch } & Pine $(n=482)$ & Mean & 24.1 & 558.2 & 13.1 & 211.7 & 27.2 & 240.4 & 384.7 & 81.4 & 488.3 \\
\hline & & SD & 11.5 & 471.7 & 11.6 & 154.8 & 42.6 & 170.4 & 179.6 & 55 & 190.4 \\
\hline & & Min & 5 & 19.6 & -11.2 & 0 & 0 & 0 & 30.3 & 25.8 & 136.8 \\
\hline & & Max & 62.7 & 3087.6 & 61.7 & 718.4 & 402.4 & 787.2 & 826.8 & 429.2 & 1077 \\
\hline & $\operatorname{Birch}(n=441)$ & Mean & 11.9 & 142.3 & 4.3 & 77.3 & 236 & 333.8 & 138.6 & 261.8 & 437.3 \\
\hline & & SD & 6.4 & 192.3 & 5.4 & 73 & 147.3 & 168.1 & 97 & 154.5 & 179.5 \\
\hline & & Min & 5 & 19.6 & -8.3 & 0 & 0 & 0 & 25.8 & 30.3 & 136.8 \\
\hline & & Max & 56.7 & 2525 & 33.5 & 416 & 744 & 1043.5 & 429.2 & 826.8 & 1077 \\
\hline
\end{tabular}

n: number of trees; d: diameter at breast height; g: basal area of each individual tree; Ig: annual basal area increment of each individual tree; SD: standard deviation; Min: minimum value;

Max: maximum value. 


\section{Size-symmetric and size-asymmetric competition}

To test whether the basal area growth of a given tree species was better explained by sizesymmetric and/or size-asymmetric competition, both $S C$ (expressed by the SDI) and $A C$ (expressed by the SDIL) were included in different growth models to compare their results (Eq. (4)).

$C_{i}=S C_{i}+A C_{i}$

where $C_{i}$ is the inclusion of both $S C_{i}$ and $A C_{i}$ for tree $i$ for each species in the mixture.

\section{Intra- and inter-specific competition}

To understand the relative importance of species interactions on different soils and in different combinations of species, we compared the impacts of intra-specific versus inter-specific competition on tree growth. As a null model, we assumed that intra- and inter-specific competition had equal effects. Alternatively, we hypothesised that inter-specific competition is weaker than intra-specific competition and therefore leads to higher growth rates. The models were tested for size-symmetric and size-asymmetric competition by separating intraand inter-specific competition components and considering their different effects. Correspondingly, the model structures included SDI $\mathrm{Sntra}_{+}+\mathrm{SDI}_{\text {inter }}, \mathrm{SDIL}_{\text {intra }}+\mathrm{SDIL}_{\text {inter }}$ and a combination of the two (Eq. (5)). Akaike Information Criterion (AIC) was applied to compare the model structure. If the goodness of fit of models that separate intra- and inter-specific competition is equal or worse in terms of AIC than models that do not separate them, this means that the effect of intra- and inter-specific competition is similar on tree basal area growth.

$C_{i}=S C_{\text {inter }}+S C_{\text {intra }}+A C_{\text {inter }}+A C_{\text {intra }}$

where $C_{i}$ is the inclusion of both $S C_{i}$ and $A C_{i}$ for tree $I$, but separated by intra and interspecific competition for each species in the mixture.

\section{Soil effect}

To examine the effect of soil on species interactions, the final model included the soil effect, expressed by PC1 and PC2: the first and second principal components from the PCA. The following model (Eq. (6)) was fitted to the data:

$$
\begin{aligned}
\ln \left(I g_{i}\right)= & a_{0}+a_{1} \times \ln \left(g_{i}\right)+a_{2} \times C_{i}+a_{3} \times P C 1+a_{4} \times P C 2 \\
& +a_{5} \times C_{i} \times P C 1+a_{6} \times C_{i} \times P C 2+\varepsilon_{i}
\end{aligned}
$$

where $I g_{i}$ is the basal area increment per year $\left(\mathrm{cm}^{2}\right.$ year $\left.{ }^{-1}\right)$ (log-transformed) of tree $i$ with a given basal area $g_{i}\left(\mathrm{~cm}^{2}\right)$ (log-transformed) at breast height; $C_{i}$ is the different inclusion of 
competition factor $C$ for tree $i$ according to the competition structure, in other words the intraand inter-specific, and size-symmetric and size-asymmetric competition indices for each species in the mixture (Table 4.2); $P C 1$ and $P C 2$ are the first and second principal components from the PCA of soil properties; $\varepsilon_{i}$ is the model residuals. Since the data were hierarchical (trees were measured on the same plot), plot was used as a random factor in the linear mixed-effects models.

All analyses were performed in R 3.2.0 (R Core Team, 2015). We used linear mixedeffects models (the lme() function) of the nlme package (Bates et al., 2013) to analyse individual tree growth for each species in the mixture. The default behaviour of lme(), which is to optimise the maximum likelihood criterion (ML), was used (Pinheiro and Bates, 2000). Normality and homogeneity of the model residuals were checked by visual inspections of diagnostic plots of residuals against fitted values (Zuur et al., 2009). For each test, the goodness of fit of the models was analysed, the lowest Akaike Information Criteria (AIC) chosen, and estimated p-values computed. We used the r.squaredGLMM() function of the MuMIn package (Barton, 2013) to compare $\mathrm{R}^{2}$ (conditional and marginal) in logarithmic transformation models for the final model of each species. A significance level of $p<0.05$ was considered.

\section{Results}

\section{Soil fertility gradient}

The PCA shows that eight soil properties strongly covary, and that the first principal component (PC1) explains $41 \%$ of the variance and the second principal component (PC2) $32 \%$. PC1 was negatively associated with silt, clay content and $\mathrm{pH}$, but positively associated with sand content and bulk density, while bulk density was not significantly correlated with any of the other soil properties (Figure 4.1). The correlations between the other soil properties (sand, silt, clay and $\mathrm{pH}$ ) were indeed in line with their projection on PC1 (Appendix 4.3). Here we interpret PC1 as a gradient of decreasing nutrient and water availability, driven by the soil texture over the whole soil profile $(0-200 \mathrm{~cm})$. PC2 was positively correlated with coarse fragments, ORC and CEC, and CEC was measured over the top layers (depths 0-15 $\mathrm{cm})$. PC2 reflects the accumulation of soil organic matter, which was strongly linked to CEC (Appendix 4.3). PC2 is interpreted here as a gradient of increasing nutrient availability (indicated by CEC), driven by decomposition of the organic layer (expressed by ORC). In short, PC1 is thus interpreted as a parent material-driven fertility gradient, and PC2 as an organic material-driven fertility gradient. 


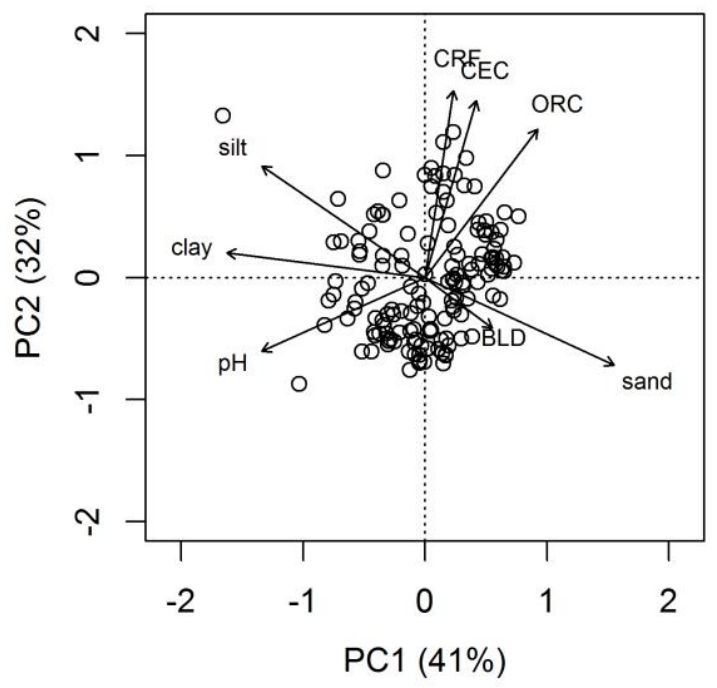

Figure 4.1 Principal component analysis of soil properties used in this study. ORC: soil organic carbon content; CEC: cation-exchange capacity; CRF: coarse fragments; BLD: bulk density. Dots are individual plots in this study.

\section{Competition effects on tree growth}

Competition effects on tree basal area growth were first explored without considering soils. In general, when competition was not split into intra- and inter-specific competition and when different competition effects were considered as a whole (models SC and AC), models with AC were always more significant and had lower AIC values than models with SC. In most cases, models with AC produced a lower AIC than models with SC, both when analysing competition as a whole and when splitting it into intra- and inter-specific competition. Nevertheless, the effects of both SC and AC significantly reduced growth for birch mixed with oak and pine, and for oak mixed with pine.

Considering the AIC values, separating intra- and inter-specific competition did not always improve the model fit. Moreover, intra-specific competition was generally stronger in reducing tree growth than inter-specific competition, both when analysed for size-symmetric and size-asymmetric competition (Table 4.3). 
Table 4.3 Comparison of Akaike Information Criterion (AIC) of growth models including the stand density index (SDI) and the stand density index of trees larger than the target tree (SDIL), calculated for size-symmetric competition (SC) and size-asymmetric competition (AC) for impacts of intra- and inter-specific competition on the three tree species in three different mixtures. The best model in each row when comparing AIC is shown in bold.

\begin{tabular}{|c|c|c|c|c|c|c|c|c|c|c|}
\hline \multirow[t]{2}{*}{ Species } & & \multicolumn{4}{|c|}{ All competitors together } & \multicolumn{5}{|c|}{ Separated into intra and inter-specific competition } \\
\hline & & & SDI & SDIL & AIC & SDI $_{\text {intra }}$ & SDI $_{\text {inter }}$ & SDIL $_{\text {intra }}$ & SDIL $_{\text {inter }}$ & AIC \\
\hline \multirow[t]{4}{*}{ Pedunculate oak-silver birch } & Oak & $\mathrm{SC}$ & -0.00087 & & 721.3505 & -0.00123 & n.s & & & 719.6259 \\
\hline & & $\mathrm{AC}$ & & -0.00191 & 684.4810 & & & -0.00242 & n.s & 683.7938 \\
\hline & Birch & $\mathrm{SC}$ & -0.00096 & & 603.5370 & -0.00160 & -0.00072 & & & 603.5796 \\
\hline & & $\mathrm{AC}$ & & -0.00129 & 595.4829 & & & -0.00167 & -0.00111 & 596.5782 \\
\hline \multirow[t]{4}{*}{ Scots pine-pedunculate oak } & Pine & $\mathrm{SC}$ & n.s & & 818.9598 & n.s & n.s & & & 818.9598 \\
\hline & & $\mathrm{AC}$ & & -0.00062 & 813.5976 & & & -0.00064 & n.s & 814.4787 \\
\hline & Oak & $\mathrm{SC}$ & n.s & & 720.4019 & n.s & n.s & & & 720.4019 \\
\hline & & $\mathrm{AC}$ & & -0.00074 & 706.6598 & & & -0.00102 & -0.00055 & 704.9248 \\
\hline \multirow[t]{4}{*}{ Scots pine-silver birch } & Pine & $\mathrm{SC}$ & -0.00084 & & 966.1029 & -0.00086 & n.s & & & 967.4326 \\
\hline & & $\mathrm{AC}$ & & -0.00080 & 967.4506 & & & -0.00081 & n.s & 967.5057 \\
\hline & Birch & $\mathrm{SC}$ & n.s & & 778.2724 & n.s & n.s & & & 778.2724 \\
\hline & & $\mathrm{AC}$ & & -0.00130 & 765.0896 & & & -0.00263 & -0.00088 & 763.2409 \\
\hline
\end{tabular}




\section{Soil and competition impacts on tree growth}

When incorporating both the soil and competition effect on the basal area growth in the final model, the interaction between soil and competition effect was much stronger in pine-oak and pine-birch mixtures than in oak-birch mixtures. All models showed that $R^{2}$ was higher than 0.45 when random and fixed effects were considered $\left(R^{2}\right.$ conditional), with the exception of the pine models, and that $R^{2}$ was only more than 0.40 for oak models when only fixed effects were included ( $R^{2}$ marginal) (Table 4.4).

More specifically, for birch in the oak-birch mixtures, significant size-symmetric, intraspecific competition $\left(\mathrm{SC}_{\text {intra }}\right)$ and the lack of significance of the size-symmetric, inter-specific competition $\left(\mathrm{SC}_{\mathrm{inter}}\right)$ indicated that birch clearly benefited from the presence of oak, as birch growth increased with an increase in the proportion of oak in the SDI (higher oak proportion in the stand). However, the slightly negative effect of larger oaks and birches on birch basal area growth may balance these positive effects, and together they may explain the neutral effect of the two species (Figure 4.2). For oak, only size-asymmetric, intra-specific competition $\left(\mathrm{AC}_{\text {intra }}\right)$ was significant (Table 4.4), showing that the basal area growth of oak was explained by competition with larger oaks. Size-asymmetric, inter-specific competition $\left(\mathrm{AC}_{\text {inter }}\right)$ was not significant, which suggested that oak was subjected to less competition with large birch trees. This competitive reduction effect was greater when the proportion of birch in the larger trees increased, as this increased oak growth (Figure 4.3a,b). Moreover, there was no soil effect on the tree growth of the two species in this mixture.

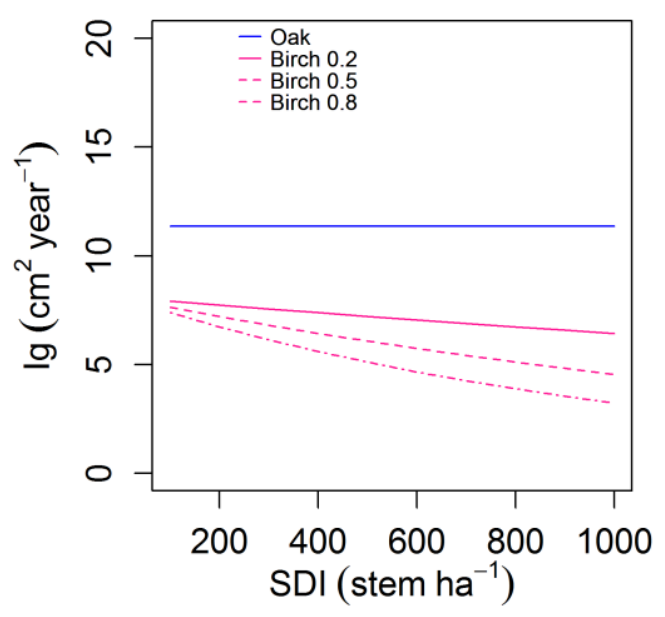

Figure 4.2 Oak and birch tree basal area growth (Ig) in oak-birch mixtures depending on birch proportion in stand density index $\left(\mathrm{SDI}_{\text {birch }} / \mathrm{SDI}\right)$ for an oak tree of diameter $23.8 \mathrm{~cm}$ with SDIL=190 stem ha ${ }^{-1}$.

In the pine-oak mixtures, both pine and oak were significantly influenced by $\mathrm{AC}$ and the interactions between AC and soils (Table 4.4). This AC effect was stronger and led to greater basal area growth reduction at rich sites compared with poor sites (Figure 4.3c,d). Similarly, pine in pine-birch mixtures was also significantly influenced by $\mathrm{AC}$ and the interactions between AC and soils (Table 4.4), and this AC effect was much greater at rich sites compared 
with poor sites (Figure $4.3 \mathrm{e}, \mathrm{f}$ ). In the case of birch, $\mathrm{AC}_{\mathrm{intra}}$ was greater than $\mathrm{AC}_{\mathrm{inter}}$ and the former one was even greater with improving site conditions (Table 4.4), resulting in a slightly positive effect of pine on birch basal area growth, although the benefit was greater at better site conditions.

In the case of birch, $\mathrm{AC}_{\text {intra }}$ was greater than $\mathrm{AC}_{\text {inter }}$ and increased with improving site conditions (Table 4.4), resulting in a slightly positive effect of pine on birch basal area growth, although the benefit increased with better site conditions. 
Table 4.4 Parameter estimations (standard errors in parentheses) for the final model of each of the three species in each of the three mixtures. The stand density index (SDI) and the stand density index of trees larger than the target tree (SDIL) are calculated for size-symmetric competition (SC) and size-asymmetric competition (AC) for impacts of intra- and inter-specific competition. Only significant variables are shown.

\begin{tabular}{|c|c|c|c|c|c|c|}
\hline \multirow[t]{2}{*}{ Species } & \multicolumn{2}{|c|}{ Pedunculate oak-silver birch } & \multicolumn{2}{|c|}{ Scots pine-pedunculate oak } & \multicolumn{2}{|c|}{ Scots pine-silver birch } \\
\hline & Oak & Birch & Pine & Oak & Pine & Birch \\
\hline Intercept & $\begin{array}{l}-0.1864 \\
(0.3592)\end{array}$ & $\begin{array}{l}0.3669 \\
(0.3112)\end{array}$ & $\begin{array}{l}1.1175 \\
(0.3858)\end{array}$ & $\begin{array}{l}1.1342 \\
(0.2186)\end{array}$ & $\begin{array}{l}1.5763 \\
(0.2787)\end{array}$ & $\begin{array}{l}1.3922 \\
(0.2942)\end{array}$ \\
\hline $\ln (g)$ & $\begin{array}{l}0.4874 \\
(0.0552)\end{array}$ & $\begin{array}{l}0.3709 \\
(0.0509)\end{array}$ & $\begin{array}{l}0.2564 \\
(0.0545)\end{array}$ & $\begin{array}{l}0.2943 \\
(0.0301)\end{array}$ & $\begin{array}{l}0.2035 \\
(0.0394)\end{array}$ & $\begin{array}{l}0.1617 \\
(0.0459)\end{array}$ \\
\hline $\mathrm{SDI}_{\text {intra }}$ & & $\begin{array}{l}-0.0012 \\
(0.0006)\end{array}$ & & & & \\
\hline SDIL $_{\text {intra }}$ & $\begin{array}{l}-0.0024 \\
(0.0004)\end{array}$ & & & & & $\begin{array}{l}-0.0036 \\
(0.0008)\end{array}$ \\
\hline SDIL $_{\text {inter }}$ & & & & & & $\begin{array}{l}-0.0009 \\
(0.0004)\end{array}$ \\
\hline SDIL & & $\begin{array}{l}-0.0012 \\
(0.0003)\end{array}$ & $\begin{array}{l}-0.0008 \\
(0.0002)\end{array}$ & $\begin{array}{l}-0.0008 \\
(0.0002)\end{array}$ & $\begin{array}{l}-0.0006 \\
(0.0003)\end{array}$ & \\
\hline PC1 & & & & $\begin{array}{l}-0.5390 \\
(0.1552)\end{array}$ & & \\
\hline PC2 & & & & & $\begin{array}{l}0.4742 \\
(0.1171)\end{array}$ & \\
\hline PC1:SDIL & & & $\begin{array}{l}0.0008 \\
(0.0003)\end{array}$ & $\begin{array}{l}0.0011 \\
(0.0004)\end{array}$ & & \\
\hline PC2:SDIL & & & & & $\begin{array}{l}-0.0009 \\
(0.0003)\end{array}$ & \\
\hline $\mathrm{PC}: \mathrm{SDIL}_{\text {intra }}$ & & & & & & $\begin{array}{l}0.0024 \\
(0.0009)\end{array}$ \\
\hline AIC & 683.7938 & 593.4861 & 810.1101 & 697.4806 & 955.7140 & 757.8123 \\
\hline $\mathrm{R}^{2}$ (marginal) & 0.4430 & 0.3449 & 0.1879 & 0.4355 & 0.2427 & 0.2115 \\
\hline $\begin{array}{l}\mathrm{R}^{2} \\
\text { (conditional) }\end{array}$ & 0.5813 & 0.4774 & 0.3192 & 0.4625 & 0.3461 & 0.5123 \\
\hline Random effect & tandard dev & & & & & \\
\hline $\begin{array}{l}\text { Plot } \\
\text { (Intercept) }\end{array}$ & 0.4097 & 0.3131 & 0.2619 & 0.1179 & 0.2399 & 0.3975 \\
\hline Residual & 0.7130 & 0.6219 & 0.5961 & 0.5259 & 0.6034 & 0.5061 \\
\hline
\end{tabular}



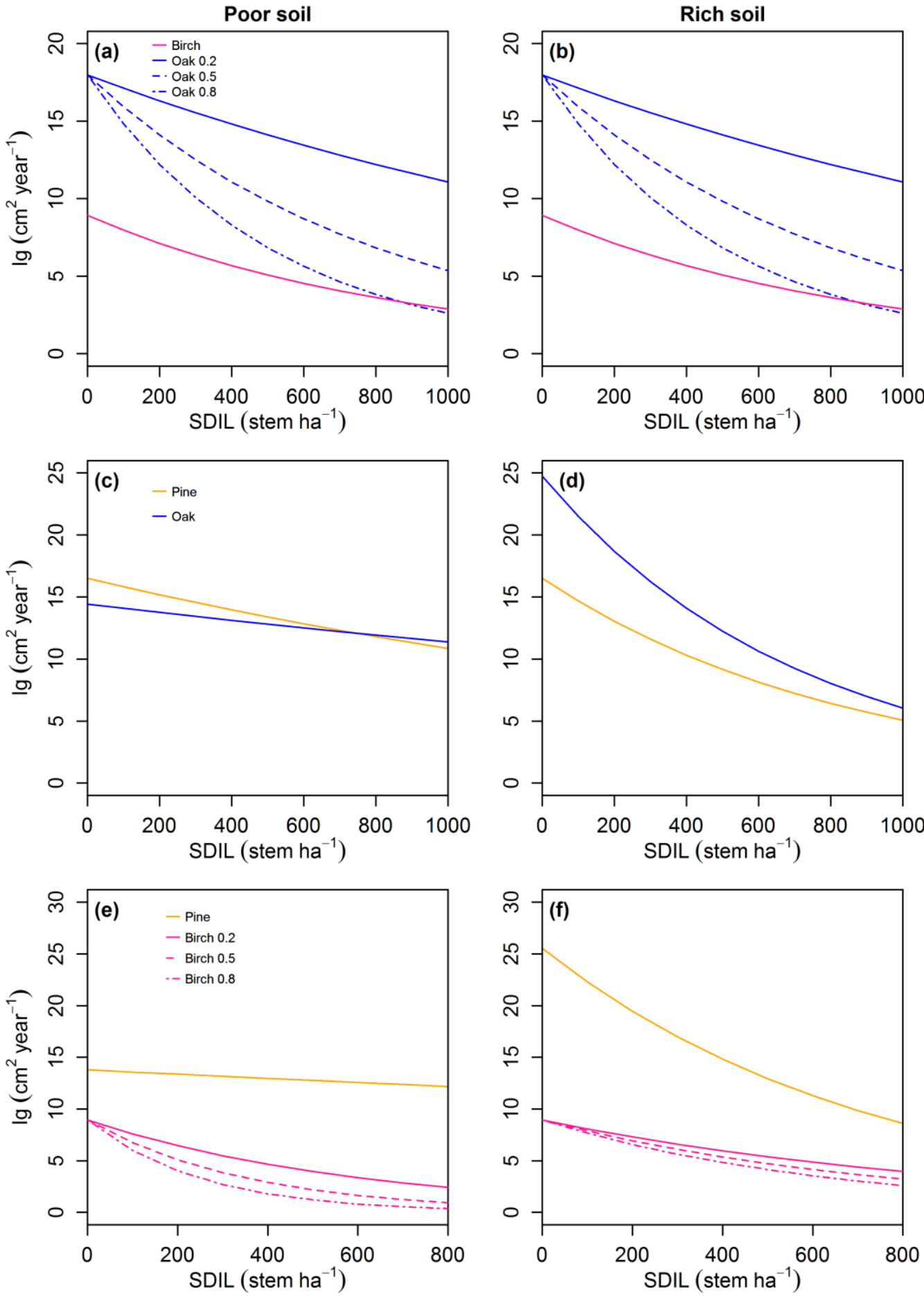

Figure 4.3 Tree basal area growth (Ig) changes with stand density index of large trees (SDIL) on poor soil (left panel) and rich soil (right panel). (a-b) Oak and birch in oak-birch mixtures depending on oak proportion in

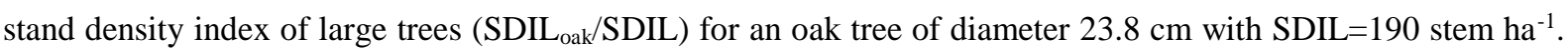
(c-d) Pine and oak in pine-oak mixtures at poor site with $\mathrm{PC} 1=0.5$ and at rich site with $\mathrm{PC} 1=-0.5$ according to PC1 values in Appendix 4.1. (e-f) Pine and birch in pine-birch mixtures depending on birch proportion in stand

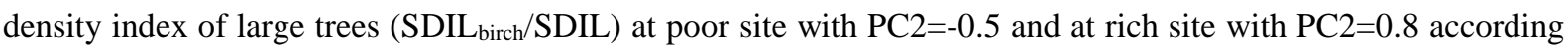
to PC2 values in Appendix 4.1. 


\section{Discussion}

In this study, we explored tree-tree interactions that can drive overyielding in mixed-species forests. We tested three hypotheses. First, we evaluated whether intra-specific competition is stronger than inter-specific competition and whether this is influenced by soil fertility, which would support species mixing benefits from niche complementarity. Second, we tested whether competition for light or soil resources is more important for reducing tree growth, by separating the impacts of size-asymmetric competition (AC) for light from size-symmetric competition (SC) for soil resources (Schwinning and Weiner, 1998). Third, we tested whether competition for light increased with increasing soil fertility, as predicted by the resource-ratio hypothesis. In the following, we discuss the hypotheses for each mixture separately, and then draw general conclusions on these hypotheses.

\section{Oak-birch mixtures}

For this mixture, inter-specific competition was weaker than intra-specific competition, but the competitive reduction was irrespective of soil fertility. Yet, we cannot exclude that the lack of significant soil fertility effects resulted from the limited soil fertility gradient across plots of this mixture (Appendix 4.3), or the low number of plots compared to the other two mixtures (Table 4.1). The results suggest that both oak and birch were affected by AC. For

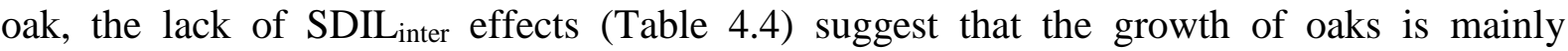
decreased by larger oaks, and hardly by larger birch trees (Figure 4.3a,b). This is because the larger trees in these mixtures were mostly pines, as suggested by the low mean value of

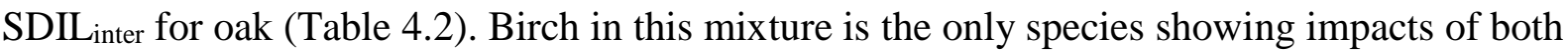
$\mathrm{AC}$ and SC. The competitive reduction by SC increased when birch trees were mixed with more oaks at higher stand density index (Figure 4.2). These results might have different impacts on possible overyielding in this mixture. In fact, in chapter 2 and 3, we showed that there was no empirical support for overyielding in this mixture at the stand level (chapter 2) or species level (chapter 3). We speculate that this is because the possible positive effects by competition for soil resources are offset by negative effects from size-asymmetric competition for light.

\section{Pine-oak mixtures}

For this mixture, the best model (with the lowest AIC value) suggests that intra- and interspecific competition were not significantly different, both for poor and rich soils, which is not supportive of the first hypothesis. However, when in a slightly weaker model (AIC value, Table 4.3) soil effects were not considered, it was suggested that intra-specific competition was stronger than inter-specific competition for oak (Table 4.3). This implies that the presence of pine to some extent reduced released the growth limitations for oak. This result is consistent with our previous study on stand level, which found that oak overyielded in this mixture on both poor and rich soils (chapter 3). Differences in crown architecture would allow 
pine to develop larger crowns in the mixture to receive more light, but allow for sufficient transmitted light for the oak at lower height (Jucker et al., 2014a). The larger mean values of SDIL $_{\text {intra }}$ than SDIL inter (Table 4.2) indeed indicate that pines occupy the upper canopy layer, and we speculate that the influence of larger trees on pines could be mostly or even always due to other, larger, pines. One experiment observed that pine enhanced oak height growth, and that oak was not suppressed by pine (Brown, 1992). In addition to these height and crown architecture related factors, the differences in leaf phenology and shade tolerance of pine and oak could further contribute to complementarity in light use (Lu et al., 2016).

In line with the last two hypotheses, asymmetric competition for light was more associated with tree basal area growth than symmetric competition for soil resources and this effect was much greater at rich soils (Table 4.4, Figure 4.3c,d). For both pine and oak, this led to a greater reduction in basal area growth with stand density of larger trees on rich soils compared with poor soils (Figure $4.3 \mathrm{c}$, d), as proposed by the resource-ratio hypothesis. Therefore, the main growth limiting factor might be light, and complementary light use may be expected as a driving factor of higher tree basal area growth. When considering soil effects on the asymmetric competition for light, the influence of soil fertility gradient was mainly driven by parent material (PC1, Figure 4.1) and not organic matter in the upper soil layer. Thus, in line with the resource-ratio hypothesis, it was observed that the larger basal area growth reduction on richer soils, resulted from stronger competition for light in mixed stands that can develop large basal areas due to the high nutrients and water availability (Forrester, 2014).

\section{Pine-birch mixtures}

For birch in this mixture, inter-specific competition was smaller than intra-specific competition, and this competitive reduction was stronger on less fertile soils (Table 4.4), which is in line with the first hypothesis and the predictions from the stress-gradient hypothesis. A positive effect of pine on birch was observed and this positive effect increased with the proportion of pine in the stand density index of larger trees (Figure 4.3e,f). For pine, intra- and inter-specific competition were not significantly different, which did not support the first hypothesis. Considering the higher mean value of SDIL intra than SDIL inter for pine and the opposite for birch (Table 4.2), it suggests that pines outgrow birches and occupy the upper layer of the canopy, and that pines are also mainly influenced by the larger pines.

The basal area growth of pine and birch were influenced by asymmetric competition and not symmetric competition, supporting the idea that competition for light is important. For pine, this effect of AC was much stronger on rich soils than on poor soils (Table 4.4, Figure 4.3e,f), suggesting that such competition for light becomes stronger on richer soils, in line with the second hypothesis and the resource-ratio hypothesis. For birch, however, this AC effect decreased with improving soil fertility, suggesting that for this species competition for light was strongest on poorer soils (Table 4.4, Figure 4.3e,f). Remarkably, $\mathrm{AC}_{\text {intra }}$ decreased for birch with improving soil fertility driven by organic matter and the high CEC associated 
with this organic matter (PC2, Figure 4.1). Possibly, the competition for soil nutrients and water becomes more severe owing to slower litter decomposition rate and nutrient cycling after mixing with the litter of pine, known for high lignin contents, as observed in one leaf litter experiment in Belgium (Setiawan et al., 2016). This latter trend is in line with the stressgradient hypothesis, which predicts facilitation or complementary resource use in harsh conditions. Both pine and birch are light-demanding species that grow fast in the early stand development with the relatively smaller of shade tolerance of pine than birch (Fischer et al., 2002; Niinemets and Valladares, 2006; Dekker et al., 2007), but pines generally overtopped birch trees in open high-light environments (Dekker et al., 2007). The resultant height stratification may allow such two-species mixed forests to exploit canopy space more efficiently and this could be even stronger under improved site conditions in which soil is not a limiting factor (Forrester, 2014).

\section{Conclusions}

For the studied species and mixtures, intra-specific competition was larger than inter-specific competition for the oak-birch and pine-birch mixtures, supporting the existence of niche complementarity when mixing species together. The competitive reduction was greater at low soil fertility for birch in pine-birch mixtures, which is in line with the stress-gradient hypothesis. However, no difference between inter- and intra-specific competition was observed for pine-oak mixtures. Size-asymmetric competition for light was shown to be more associated with tree growth than size-symmetric competition for soil resources, suggesting that light is the most limiting resource. This effect was stronger at high fertility soil for pine and oak in pine-oak mixtures, which supports the resource-ratio hypothesis, but there was no such empirical support from the oak-birch mixtures. This study thus shows that mixing different tree species reduced particularly the competition for light, both on rich and poor soils, and even stronger on poor soils for one of the mixtures. This competitive reduction by light is considered a potential key driver of higher productivity of mixed forests.

\section{Acknowledgements}

H.C.L. acknowledges the financial support from the China Scholarship Council (No. 201306600022), and she also thanks the COST Action FP1206 EuMIXFOR for funding the STSM-FP1206-33579 and STSM-FP1206-34833.

\section{Data access}

Dutch National Forest Inventory data for this study can be found online:

http://www.probos.nl/publicaties/overige/1094-mfv-2006-nbi-2012. 


\section{Appendix}

Appendix 4.1 Soil properties of SoilGrids250m used in this study.

\begin{tabular}{llll}
\hline Soil variable name & Units & Range & Mean \\
\hline Sand content (gravimetric) & $\mathrm{kg} / \mathrm{kg}$ & $23.5-90.1$ & 80.3 \\
Silt content (gravimetric) & $\mathrm{kg} / \mathrm{kg}$ & $6.4-52.7$ & 13.1 \\
Clay content (gravimetric) & $\mathrm{kg} / \mathrm{kg}$ & $3.3-23.3$ & 6.7 \\
$\mathrm{pH}\left(\mathrm{H}_{2} \mathrm{O}\right.$ solution) & & $4.7-6.7$ & 5.2 \\
Soil organic carbon (dry combustion) & $\mathrm{g} / \mathrm{kg}$ & $17.5-191.7$ & 81.7 \\
Cation-exchange capacity (fine earth fraction) & $\mathrm{cmol}+/ \mathrm{kg}$ & $11.2-28.2$ & 17.0 \\
Bulk density (fine earth fraction) & $\mathrm{kg} / \mathrm{m}^{3}$ & $1234-1498$ & 1428 \\
Coarse fragments (volumetric) & $\mathrm{cm}^{3} / \mathrm{cm}^{3}$ & $1.3-18.0$ & 7.3 \\
\hline
\end{tabular}

Appendix 4.2 Results of the correlation analysis based on the eight soil properties used in this study and eigenvalues of the soil properties on the two main principal components. For clay, sand, silt, pH, bulk density and coarse fragments, weighted average values were taken over six soil layers, while ORC and CEC took weighted average values from the top two soil layers. Clay, sand and silt represent clay content, sand content and silt content respectively; BLD: bulk density; CRF: coarse fragments; ORC: soil organic carbon; CEC: cationexchange capacity. Pearson pairwise correlation coefficients are given $(* P<0.05$; ** $P<0.01$; *** $P<0.001)$.

\begin{tabular}{lllllllllll}
\hline & clay & sand & silt & pH & BLD & CRF & ORC & CEC & $\begin{array}{l}\text { PC1 } \\
(\mathbf{4 1 \%})\end{array}$ & $\begin{array}{l}\text { PC2 } \\
(\mathbf{3 2 \%})\end{array}$ \\
\hline clay & & & & & & & & & -1.9115 & 0.2377 \\
sand & $-0.8553^{* * *}$ & & & & & & & 1.8217 & -0.8431 \\
silt & $0.6925^{* *}$ & $-0.9646^{* * *}$ & & & & & & & -1.5729 & 1.0754 \\
pH & $0.6967^{* *}$ & -0.4437 & 0.2580 & & & & & -1.5731 & -0.7076 \\
BLD & -0.2737 & 0.2192 & -0.1708 & -0.2997 & & & & 0.6483 & -0.4871 \\
CRF & -0.1128 & -0.2625 & 0.4296 & -0.4762 & -0.0862 & & & 0.2712 & 1.8039 \\
ORC & -0.3241 & 0.2143 & -0.1248 & $-0.5035^{*}$ & -0.0926 & $0.5100^{*}$ & & 1.0856 & 1.4312 \\
CEC & -0.0397 & -0.0682 & 0.1199 & -0.2867 & -0.1474 & $0.6170^{* *}$ & $0.7661^{* *}$ & & 0.494 & 1.7041 \\
\hline
\end{tabular}


Appendix 4.3 First and second principal components PC1 and PC2 in the three mixtures in this study.
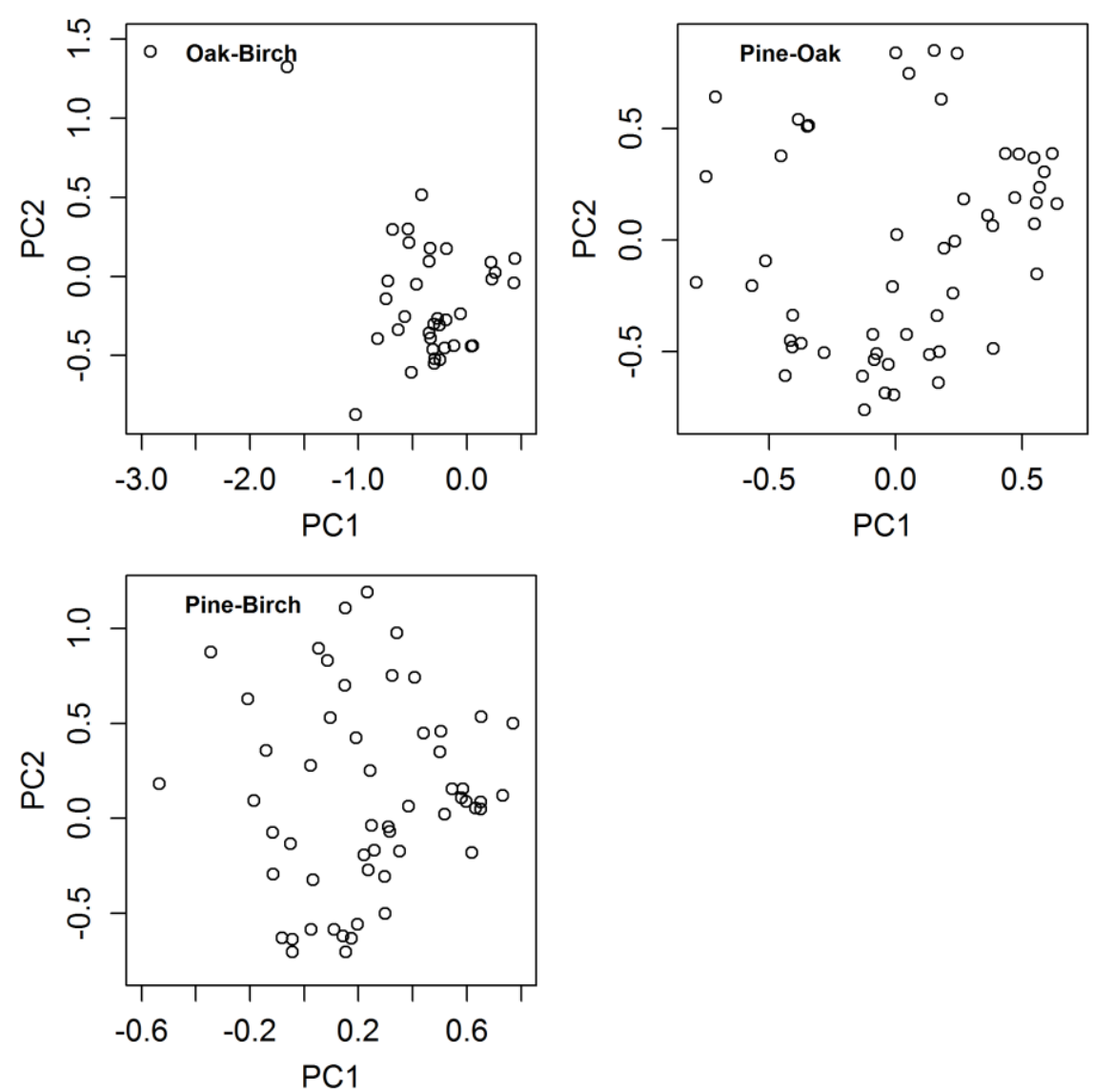
Chapter 4

十年树木，百年树人

一管子

It takes ten years to grow trees but a hundred years to rear people.

-Chinese proverb 



\section{Species mixing effects on forest productivity}

In Europe, monoculture forests have often been converted to mixed species forests to increase resilience, and to provide higher timber production as well as other ecosystem services (Vilà et al., 2013; Jucker et al., 2014b; van der Plas et al., 2016). The forest productivity typically changes as a stand develops, reaching a peak relatively soon followed by a substantial decline, probably due to aboveground and belowground allocation changes or hydraulic limitations (Ryan et al., 1997). Yield tables also show this productivity pattern in even-aged monocultures in the Netherlands, and it is well understood that this pattern varies with site conditions (Jansen et al., 1996). However, the productivity of mixed-species forests and their responses to different site conditions have been explored less, and recent studies on mixed forests showed divergent results. Some studies found overyielding of mixed-species stands at poor sites (Pretzsch et al., 2013a; Toïgo et al., 2015), while others reported overyielding at rich sites (Forrester et al., 2013a; Jucker et al., 2014a; Thurm and Pretzsch, 2016). Moreover, the same species mixture may show different growth patterns on different locations, possibly due to differences in climate, soil conditions and stand age. A better understanding of species mixing effects on forest productivity in relation to those factors is needed for improving the management of mixed forests.

This thesis addresses the question of species mixing effects on forest productivity, using two large datasets from the Netherlands. The general question was split into three specific questions (see also Figure 1.5). First, we evaluated the effects of species mixing on stand productivity during stand development (chapter 2), using an empirical model at stand level, based on growth and yield data (GYD) from long-term permanent field plots (Den Ouden and Mohren, 2016). Secondly, we analysed how each tree species in mixtures contributed to productivity on soils differing in fertility (chapter 3 ). For this, an empirical model at species level was applied to analyse the species-specific effects on overyielding by considering soil effects, using the same data (GYD) as used in chapter 2. Lastly, we examined competitive tree-tree interactions for light or soil resources (chapter 4). In order to analyse the consequences of inter-specific competitive interactions on different soils, an empirical model at tree level was applied using the Dutch national forest inventory (NFI) data (Schelhaas et al., 2014).

This thesis describes general productivity patterns in mixtures versus monocultures and shows the influences of stand development and soil fertility, and speculates on possible mechanisms responsible for the higher productivity of stands, species and or individual trees in mixed forest stands. As illustrated in Figure 5.1, in line with niche complementarity hypothesis (Kelty, 1992; Tilman, 1999), mixed tree species differing in leaf phenology and shade tolerance were expected to contribute to overyielding due to complementary light use. Differential crown architecture might also play a role in overyielding, but the two datasets used in this thesis did not include such information. Yet, tree height differences between species imply canopy stratification and hint to architectural differences between species. In 
addition, different root distributions may result in complementary soil resource use and hence explain overyielding, but direct measurements of roots were not available. Yet, in addition to complementary resource use, other mechanisms may lead to overyielding, such as effects of mixed litter on nutrient cycling (Dawud et al., 2017), litter decomposition (Setiawan et al., 2016) or mycorrhizal linkages (Kelty, 1992), and on pathogens (Hantsch et al., 2014), but such interactions are still little understood for mixed forests. Since there is lack of information on those processes, conclusions on such mechanisms remain speculative. In this thesis, the working hypothesis is that complementary resource use leads to higher productivity when mixing different species, and empirical data from Dutch NFI and permanent growth and yield plots are used to address this issue. In the following, the main results of this thesis are discussed in relation to stand age, species composition and soil fertility and mechanisms potentially leading to overyielding (see Figure 5.1).

In this general discussion, first the merits and limitations of field data and empirical approaches applied are discussed. Then the effect of species mixing on productivity is characterised by comparing original expectations and observations in last three chapters (chapter 2-4), and the implications for forest management are presented. Further, the general pattern of productivity in Dutch mixed-species forests is linked to the ecological theories. A new hypothesis is addressed for overyielding based on the results from Dutch forests presented in this thesis. Finally, an outlook is provided for future research challenges and the major conclusions from this thesis are drawn.

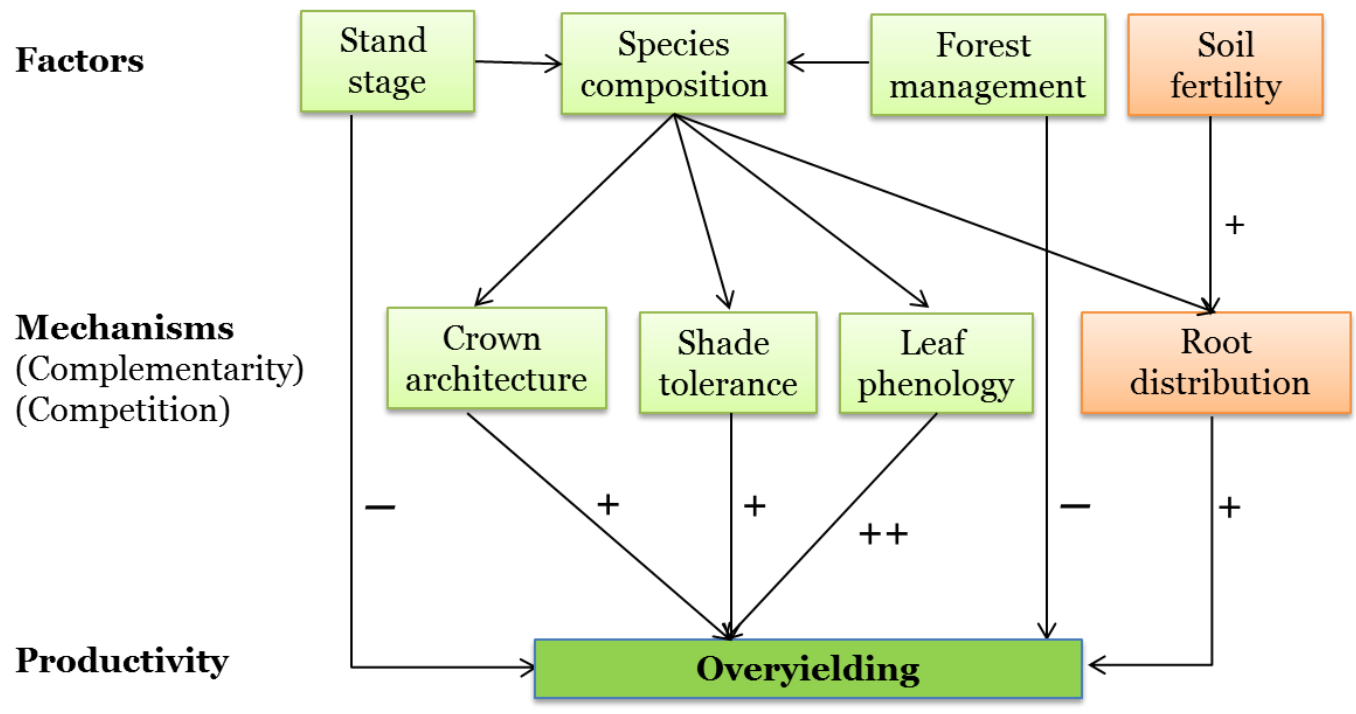

Figure 5.1 Diagram of the impacts of different factors and mechanisms on productivity discussed in this thesis. The discussed mechanisms refer to differences in species characteristics that can allow for complementarity or reduced competition for light and soil resources. The signs along the arrows represent the presence $(+$ or ++$)$ or absence (-) of significant effects detected by the results in this thesis, but in some cases we lack direct data. ++ : strong effect; +: weak effect; -: no effect. 


\section{An empirical approach based on field data}

In this thesis, species mixing effects on productivity were studied for forests in the Netherlands. Patterns of such mixing effects were explored for forest plots from the GYD of long-term dataset and Dutch NFI data, using empirical models at stand (chapter 2), species (chapter 3) and tree (chapter 4) level. At stand level, forest productivity patterns in mixtures and monocultures during stand development were compared for four different species combinations from the GYD (Table 5.1). At species level, the same GYD were analysed to show how each of the two species in a mixture contributed to productivity (and overyielding), and how such contributions varied between soils differing in fertility. At tree level, it was investigated how the individual tree growth was influenced by neighbouring trees in three mixed-species stands (Table 5.1) along a soil fertility gradient, using the Dutch NFI data. Size-asymmetric competition for light and size-symmetric competition for soil resources were separated in the analysis to show possible complementary impacts on productivity in mixed forests. The combination of stand-, species- and tree-level analyses allows for better understanding of mixing effects on forest productivity and forest functioning (Forrester and Pretzsch, 2015), and can indicate potential sources of error (Pretzsch et al., 2015a).

There are limitations in these data and approaches. The complementarity mechanisms (Figure 5.1) are not measured directly, but taken as a starting point for interpreting patterns in productivity of mixed forests. Other factors are also potentially relevant, but cannot be distinguished from these field data. For instance, root distributions and pathogen diversity were not measured but may influence the competition among individual trees (Hantsch et al., 2014). Moreover, forest management is a confounding factor when comparing productivity in mixed versus monoculture stands, as thinning aims to interfere with competition to favour one species over the other. Besides, the different species compositions in the two datasets (Table 5.1; also see chapter 1 description) limit generalising the results, since the missing mixtures at stand level analysis cannot be further explored at the tree level. The three organisation levels studied (stand, species and tree) allow to show how changes at one level influence patterns at another level (Pretzsch et al., 2015a), but such links remain indirect (dashed arrows in Figure 1.5). Keeping in mind these limitations, this study shows impacts of species mixing on productivity patterns in forests, and several hypotheses are considered to discuss underlying mechanisms. 
Table 5.1 Overview of the use of monocultures of five species and mixtures composed with those five species in this thesis. Upper-right triangle: the chapter number is indicated in which these stands were studied. Bottom left triangle: empirical support for overyielding of each species: $++/+,+/++,-/+,+/-,-/-$ where the first symbol refers to the species in the row, and the second symbol to the species in the column. ++: relatively strong overyielding; +: relatively weak overyielding; -: no overyielding effect; n.a. = not applicable; potential in parenthesis means higher tree growth of both species.

\begin{tabular}{llllll}
\hline & Douglas-fir & Common beech & Scots pine & Pedunculate oak & Silver birch \\
\hline Douglas-fir & chapter 2,3 & chapter 2,3 & n.a. & n.a. & n.a. \\
Common beech & $+/++$ & chapter 2,3 & n.a. & chapter 2,3 & n.a. \\
Scots pine & n.a. & n.a. & chapter 2, 3 & chapter $2,3,4$ & chapter 4 \\
Pedunculate oak & n.a. & $-/+$ & $++/+$ & chapter 2,3 & chapter $2,3,4$ \\
Silver birch & n.a. & n.a. & $+/$ (potential) & $-/-$ & chapter 2,3 \\
\hline
\end{tabular}

\section{Stand development and forest management}

In chapter 2, overyielding was observed for the Douglas-fir-common beech and Scots pinepedunculate oak mixed stands, but not for pedunculate oak-common beech, and pedunculate oak-silver birch stands. We expected that overyielding decreases with stand development because fully growing stands take all available limiting resources and limit resource partitioning between different species. In contrast with our hypothesis, stand age had no significant effect on the overyielding in the two evergreen-deciduous species mixtures (Figure 2.1 and 5.2). It can be argued that forest management by thinning may keep stands relatively open, as indicated by the relatively low basal areas (Figure 2.3). The forest stands studied here, may therefore never close completely and may have resources and growing space available for complementary use by the other species. Another study has even shown that overyielding in mixtures of Douglas-fir and beech increased with stand development (Thurm and Pretzsch, 2016). These authors argued that there was a shift of competition strength between the two species along the age gradient. After 15 years, Douglas-fir outcompeted beech and the difference in height triggered larger diameter growth of Douglasfir, thereby resulting in increasing overyielding during stand development (Thomas et al., 2015; Thurm and Pretzsch, 2016). These studies imply that overyielding occurs especially later during stand development. We argue that the thinning regime is responsible for this in both cases. Our constant overyielding over time could be partially explained by the lack of data for young forest stand in our data base ( $<15$ years old were absent). Moreover, in our analysis, we kept the possible forest management effects on overyielding, rather than removing the plots that had been managed during the last five years (Del Río and Sterba, 2009; Jucker et al., 2014b; Toïgo et al., 2015). In conclusion, overyielding appears to be maintained or even increased with stand age in the heavily managed forests stands in the Netherlands and elsewhere in Europe, and the management of forests by thinning is likely to play a key role in this. 


\section{Complementary resource use}

\section{Complementarity in light use}

In chapter 2, we explored the effect of species differences on productivity in mixed stands. In line with the niche complementarity hypothesis (Kelty, 1992; Tilman et al., 2001), we expected that mixing tree species that differ in leaf phenology and/or shade tolerance would overyield more strongly because of complementary light use. In line with this hypothesis, evergreen-deciduous species mixtures (Douglas-fir-beech and pine-oak) indeed showed overyielding whereas the deciduous-deciduous species mixtures (oak-beech and oak-birch) did not (Figure 2.1 and 5.2). In chapter 3, we explored how the individual species in these two-species mixtures contributed to overyielding. We hypothesized that the faster growing and more light-demanding species would dominate the slower growing and more shadetolerant species in mixed-species stands, and that the resulting stratified canopies and the subsequent partitioning of the light gradient would cause overyielding by complementary light use. Yet, the results show that both faster growing species (Douglas-fir in Douglas-firbeech) and slower growing species (oak in pine-oak) contributed to overyielding (Figure 3.2).
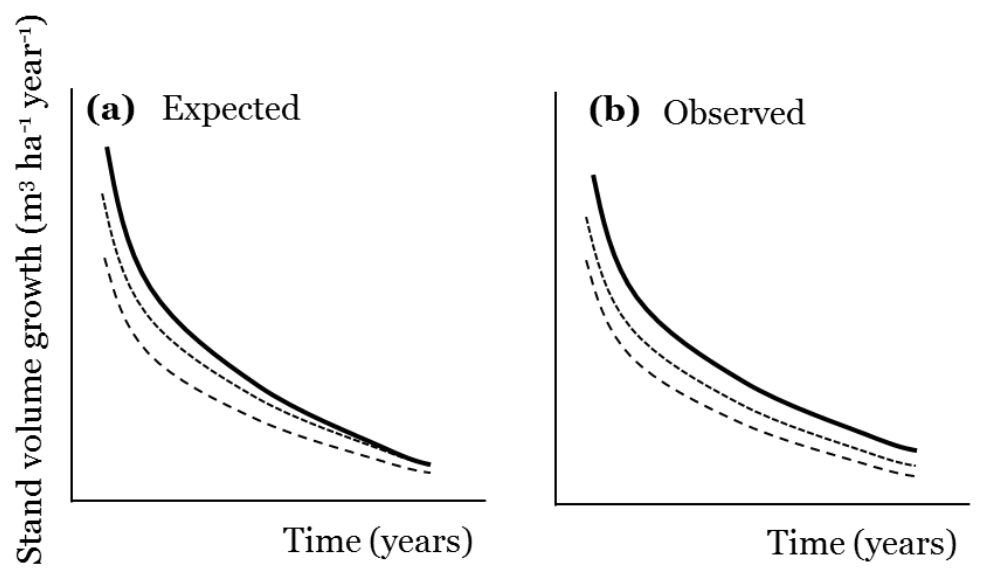

Figure 5.2 Conceptual diagram of stand volume growth over time for the (a) expected and (b) observed results in chapter 2 in this thesis. Two dashed lines represent light-demanding and shade-tolerant species monoculture stands. Solid lines represent mixtures composed of those two species in monoculture stands.

The observation that overyielding occurred in both evergreen-deciduous stands, but not in the deciduous-deciduous stands, suggests that differences in leaf phenology between the mixed species can contribute to higher productivity, or overyielding. Moreover, the overyielding was even stronger for the evergreen-deciduous species mixture with the largest difference in shade tolerance (Douglas-fir-beech), implying that differences in shade tolerance may be important too. Trees of fast-growing species grow rapidly and may establish a more favourable position in the canopy compared to trees of slow-growing species which are often more shade tolerant (Dekker et al., 2007; Janse et al., 2007). Such differences in height growth allow light-demanding species to occupy the upper layer of the canopy and 
may leave the shade-tolerant species in a lower layer, thus creating a canopy with multiple crown layers (Figure 5.3). Such a multi-layered canopy may be more effective in light absorption and hence in light use efficiency (Pretzsch, 2014; Jucker et al., 2015).
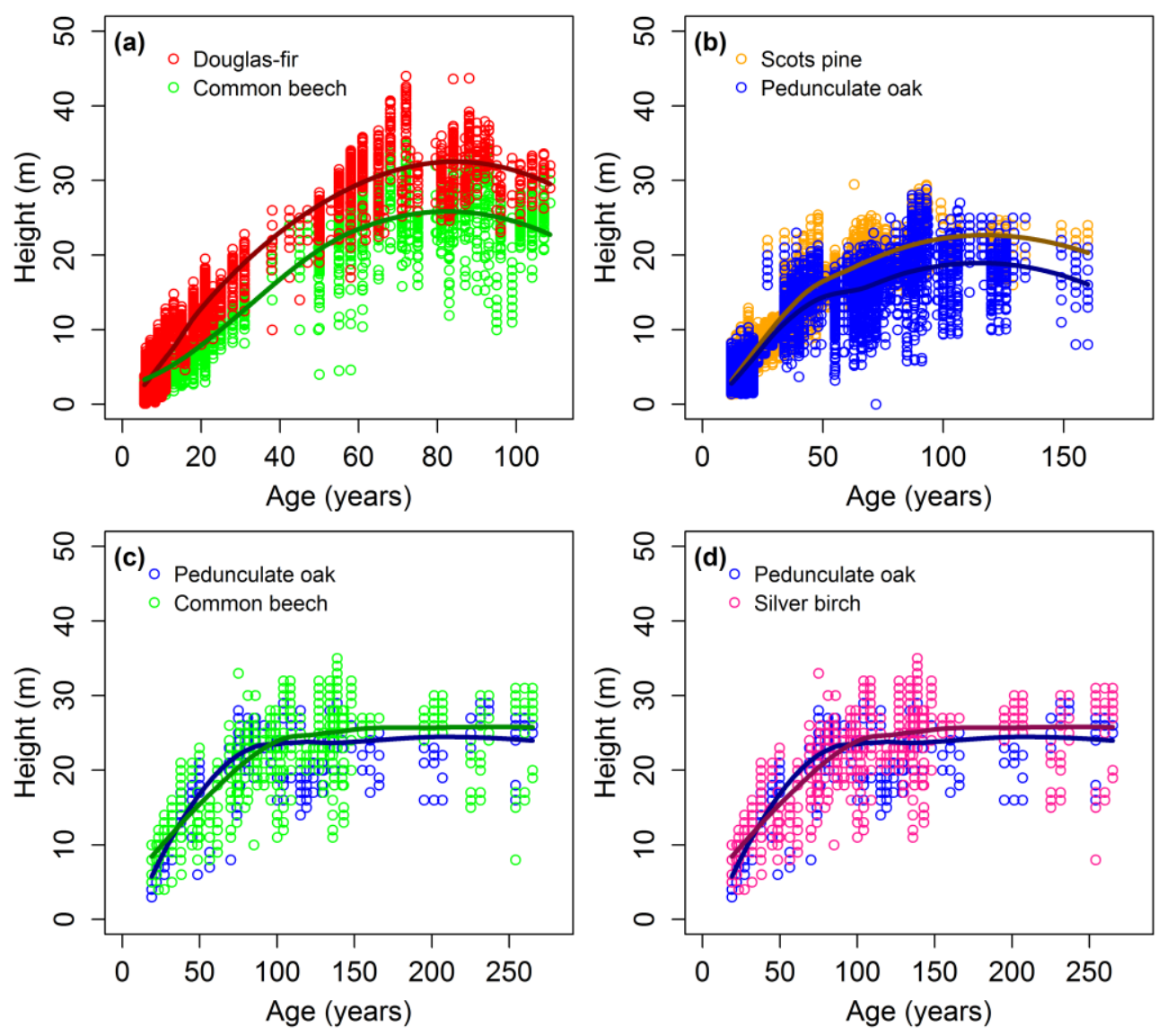

Figure 5.3 Tree height over time in 4 two-species mixtures derived from growth and yield data from permanent field plots in chapter 2 and 3. (a) mixed stands of Douglas-fir and common beech; (b) mixed stands of Scots pine and pedunculate oak; (c) mixed stands of pedunculate oak and common beech; (d) mixed stands of pedunculate oak and silver birch. Solid lines indicate the average height for each of the species over time.

In addition, the improved light interception and/or light use efficiency might be further supported by differences in species crown architecture. Crown complementarity has been shown to increase canopy packing and thus contribute to overyielding (Longuetaud et al., 2013; Pretzsch, 2014; Jucker et al., 2015; Williams et al., 2017). We did not have data describing crown properties, but used tree height in the mixed forest as an indicator for canopy stratification. The vertical distribution in tree height might change over time through tree growth, regular mortality, natural disturbances and forest management (Latham et al., 1998; Oliver et al., 1999). Our data show two distinct species layers in the two evergreendeciduous species mixtures across the studied ages (Figure 5.3a,b), while such stratification was much weaker for deciduous-deciduous forests (Figure $5.3 \mathrm{c}, \mathrm{d}$ ). These distinct canopy layers of the two evergreen-deciduous species mixtures over time might explain the 
overyielding over different stand ages. In conclusion, our results are in line with the niche complementarity hypothesis and imply effective complementary light use in evergreendeciduous species stands, particularly when the two species differ in shade tolerance.

\section{Soil impact}

Complementary light use between species can be altered by soil fertility. In chapter 3, we explored how soil fertility influenced the species mixing effects on the productivity of each species in the mixed stands. The stress-gradient hypothesis and the resource-ratio hypothesis give different arguments for possible soil effects on species interactions and productivity, as illustrated in Figure 5.4. The stress-gradient hypothesis describes a transition from facilitation or strong complementary resource use on low fertility soils, to competition on high fertility soils (Bertness and Callaway, 1994). As a consequence, competition for soil resources is modified with decreasing soil fertility through facilitation by which one species may effectively improve the soil resource availability for the other species or allows for complementary soil resource use, compared to the corresponding monoculture under the same soil conditions. The resource-ratio hypothesis argues that competition for light at high soil fertility switches to competition for soil resources at low soil fertility (Tilman, 1985), based on the argument that rich soils allow for a denser forest canopy with complementary light use (Forrester, 2014). Therefore, the species interactions result in a reduction in competition and more pronounced complementary use for light at high soil fertility.

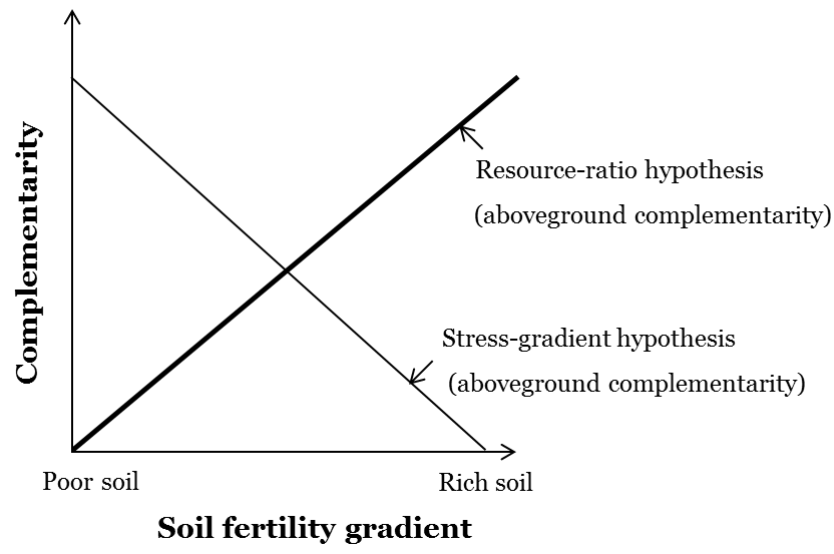

Figure 5.4 A conceptual model showing the relative complementarity of a given species growing in a mixture, which depends on a soil fertility gradient. The resource-ratio hypothesis predicts that complementarity increases with increasing soil fertility as competition for light becomes more intense in accordance with the resource-ratio hypothesis (thick line). The stress-gradient hypothesis predicts that complementarity increases and competition for soil resources decreases relatively with decreasing soil fertility, because one species improves the soil resource availability for the other species or allows for complementary soil resource use (thin line). Diagram adapted from Forrester (2014). 
Thus, while the stress-gradient hypothesis predicts that overyielding is stronger on poor soils than rich soils, the resource-ratio hypothesis predicts that overyielding is stronger on rich soils. We found stronger overyielding in Douglas-fir-beech and pine-oak stands on low fertility soils (Figure 3.2 and 5.5). Hence, our results support the stress-gradient hypothesis and not the resource-ratio hypothesis at first sight, suggesting there was complementary soil resource use at low soil fertility. This complementarity may be due to different root distributions in mixed-species stands and several mechanisms associated with explaining this overyielding were described in chapter 1. Previous empirical studies have reported that overyielding increased (Forrester et al., 2013a; Jucker et al., 2014a; Thurm and Pretzsch, 2016) or decreased (Pretzsch et al., 2013a; Pretzsch et al., 2015b; Toïgo et al., 2015) with improving site conditions. This divergent finding may arise from different growth-limiting factors. In our study, low fertility soil of Dutch forest might still allow for sufficient stand productivity and dense canopies. Therefore low fertility soil allows for complementary soil resource use, but can also allow for complementary light use, and both may promote aboveground stem growth. With canopy being less dense at low soil fertility, the competition for light may be less and maybe allow trees of different species to partition light more effectively than in the crowded, more dense, canopies on rich soils. This implies that complementary use of both light and soil resource can act as potential drivers underlying the stronger overyielding in stands on lower fertility soils.

More importantly, mixing effects on root growth could also be modified by soil fertility, and mixing effects may influence soil fertility by affecting litter decomposition. One study found that root growth was reduced at the benefit of stem growth in temperate mixed stands when growing conditions improved (Thurm et al., 2016a), but in this study the amount of roots in the mixed-species stands was unknown, and it was assumed that tree species mixing did not lead to significantly differences in the amount of roots. Another experimental study showed stronger complementarity in root productivity for soil resources in nutrient poor soils in a boreal mixed forest (Ma and Chen, 2017). So far, experiments about species mixing on root distributions in temperate forests remain scarce, and are almost absent for soil fertility gradients. In addition, studies have reported that mixing litter from different tree species increased litter decomposition rates through synergistic effects (Hättenschwiler et al., 2005), and one study suggests that admixing tree species with high-quality litter in post-agricultural plantations in Belgium increases the litter decomposition rate at early stand stage in 2 to 4 species mixtures (Setiawan et al., 2016). However, as far as we know, long-term litter decomposition experiment are still absent for mixed-species stands. We call for further study on this aspect to uncover the species mixing effect on root distribution and litter decomposition, and in turn, possible impacts on overyielding.

To conclude, our results of stronger overyielding at low fertility soils are in line with the prediction of the stress-gradient hypothesis, but not the resource-ratio hypothesis. Yet, we argue that better complementarity for both soil resources and light can both be responsible for the stronger overyielding on poor soils, but we cannot exclude other possible mechanisms. 
Our conclusions here are therefore restricted to tree-tree interactions, exploring whether reduced competition for light or soil resources contributed to overyielding in mixed forests stands.
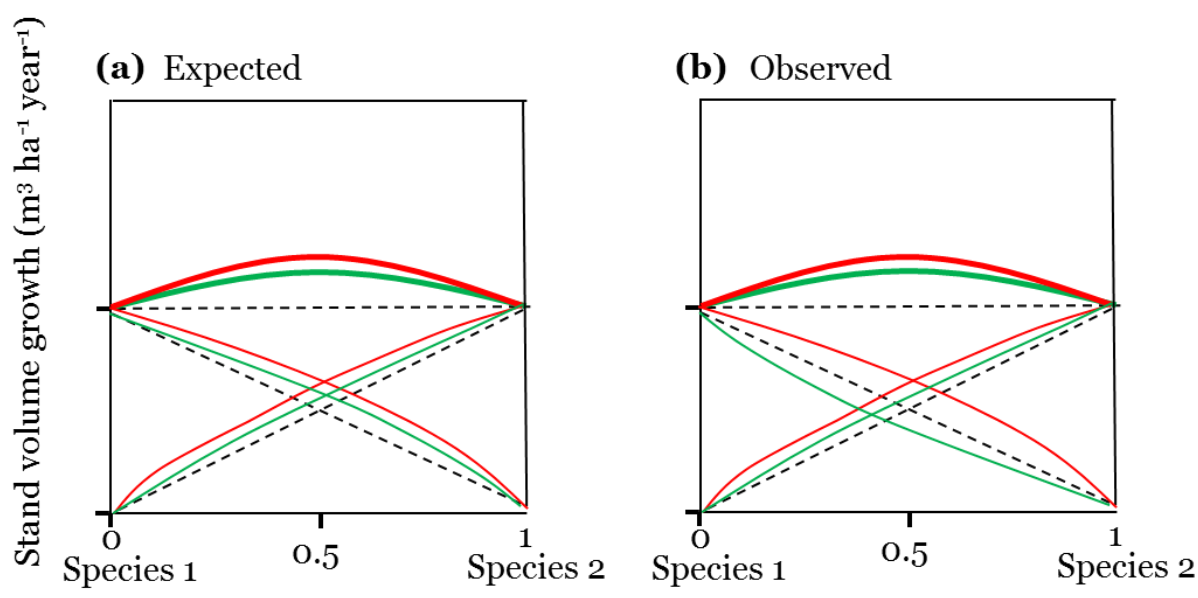

Figure 5.5 Conceptual diagram of volume growth of the total forest stand and each of the two species at different levels of mixtures, expressed by the proportion of one species. Predictions (a) and results (b, see also chapter 3) are shown for the impacts of low and high fertility soils on productivity. Dashed lines represent predicted values with null mixing effect, i.e. no overyielding, while red lines represent predicted and observed values with stronger overyielding at poor soils and green lines represent less overyielding and even (observed) underyielding on rich soils.

\section{Learning from tree-tree interactions}

\section{Intraspecific competition stronger than interspecific competition?}

Intra-specific competition is frequently considered to have a more pronounced negative effect on tree growth than inter-specific competition, particularly when niche complementarity would decrease competition. The phenomenon of lower inter-specific competition as compared to intra-specific competition is often referred to as competitive reduction, which would result in less growth reduction relative to reduction due to intra-specific competition. In chapter 4, we examined the competitive interactions in mixed stands, on individual tree growth growing on soils differing in fertility. We hypothesized that intra-specific competition is stronger than inter-specific competition and that the competitive reduction is more pronounced at low fertility soils, in accordance with our results from chapter 3, which means that the decrease in tree basal area growth resulting from competition is smaller at lower soil fertility (Figure 5.6a). We showed that for the studied species in the three mixtures in the study, intra-specific competition was larger than inter-specific competition for birch in oakbirch and pine-birch mixtures, as well as for oak in oak-birch mixtures. Yet, no significant differences were found between the impact of intra- versus inter-specific competition for pine in pine-oak and pine-birch mixtures, and neither for oak in pine-oak mixtures. The effect of 
competitive reduction was smaller with improving soil fertility for birch in pine-birch mixtures, but independent of soil fertility for oak and birch in oak-birch mixtures (different directions arrows in Figure 5.6b). The results were thus different for different stands and species mixtures, and we therefore did not find evidence for general support for either the stress-gradient hypothesis or resource-ratio hypothesis. Other studies found that the species complementarity led to more tree growth because of lower inter- compared to intra-specific competition (Del Río et al., 2014a; Condés and Del Río, 2015), but also concluded that this might depend on soil fertility, stand age and species composition (Cavard et al., 2011; Coates et al., 2013; Toïgo et al., 2015). In short, intra-specific competition is not necessarily stronger than inter-specific competition in mixed forests, and may depend on the species compositions of the mixtures under study.
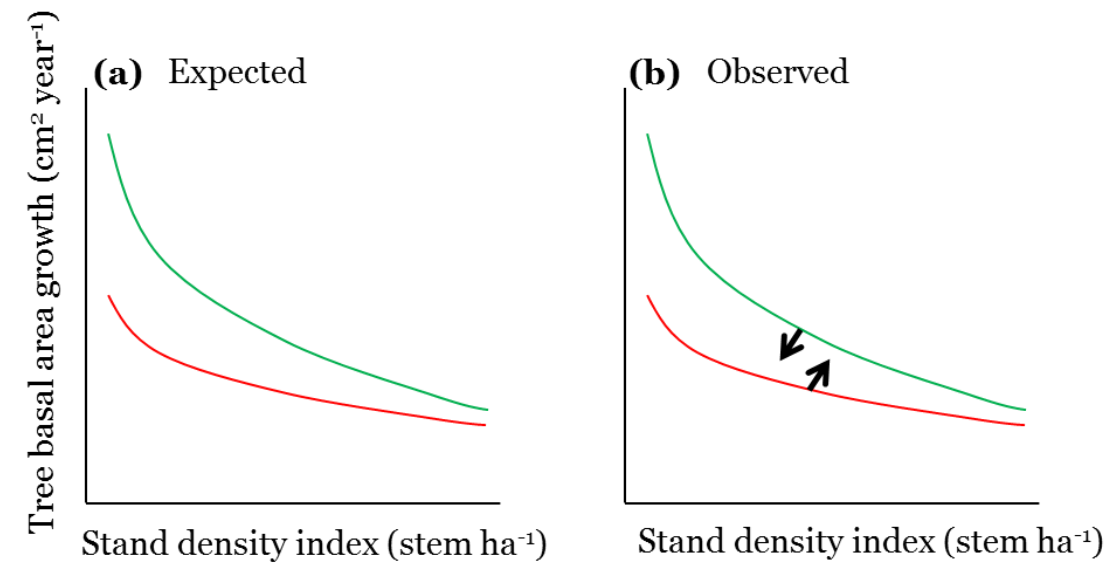

Figure 5.6 Conceptual diagram of tree basal area growth changes with stand density index for the (a) expectations and (b) results, as presented in chapter 4. (a) It was expected that growth reduction is smaller at poor soils (red line) and greater at rich soils (green line) with increasing stand density. (b) It was observed that growth reduction could be smaller or larger on poorer soils compared with rich soils, where two black bold arrows indicate the divergent trends.

\section{Competition for light or for soil resources?}

As illustrated in Figure 5.4, competition for soil resources varied with soil fertility. We expected that when light is the most important growth limiting factor, size-asymmetric competition for light is more relevant for tree growth than size-symmetric competition for soil resources. As expected, size-asymmetric competition for light was shown to be more associated with tree growth than size-symmetric competition for soil resources, suggesting that light is the most limiting resource. We further expected that since forests may establish a denser canopy at rich soils, size-asymmetric competition is larger at rich soils compared to poor soils following the resource-ratio hypothesis, and in turn this may allow for complementary light use rather than for more efficient soil resource use. We found that this effect was stronger at high soil fertility for pine in pine-oak and pine-birch mixtures, and for oak in pine-oak mixtures, which supports the resource-ratio hypothesis. However, this effect 
was not observed for birch in pine-birch mixtures since this species showed a smaller effect of competition for light at high soil fertility, and the effect was independent of soil fertility for oak and birch in oak-birch mixtures.

Our results are in line with some studies in temperate forests that found that competition for light was more relevant for tree growth than competition for soil resources (Forrester, 2014; Jucker et al., 2014a). However, other studies revealed that in terms of tree growth, the effects of competition for light or for soil resources differ depending on the competing species (Coates et al., 2009; Coates et al., 2013; Del Río et al., 2014a). Rich soils allow for a denser forest canopy with possibilities for complementary light use, particularly when species differ in shade tolerance or leaf phenology. Our results were consistent with studies that found stronger competition for light at rich soils (Baribault and Kobe, 2011; Forrester, 2014; Jucker et al., 2014a), but weaker competition for light on high fertility soils was also reported in the literature (Trinder et al., 2012; Coates et al., 2013). In the end, this complementary light use at tree level might improve individual tree growth and drive higher stand productivity in mixed forests stands, i.e. lead to overyielding. However, the tree level cannot always be directly extrapolated to stand level (Perot and Picard, 2012), and future research should clarify the dynamic process of species interaction in various types of mixtures along soil fertility gradients.

\section{Species mixing effects on productivity in Dutch forests}

\section{Revisiting the stress-gradient hypothesis and the resource-ratio hypothesis}

The stress-gradient hypothesis and the resource-ratio hypothesis state that species interactions vary along a soil fertility gradient. Figure 5.7 illustrates the species interactions on productivity and overyielding on poor and rich soils for the stress-gradient hypothesis, resource-ratio hypothesis, and our own hypothesis based on the results reported in this thesis, see,,+++- , n.a. and ? in Figure 5.7. The stress-gradient hypothesis essentially only refers to belowground soil resource use and does not explain the aboveground light use along the soil fertility gradient (n.a.). In short, the stress-gradient hypothesis predicts that complementary resource use belowground would be stronger on poor soils $(++)$ than on rich soils $(-)$. Alternatively, the resource-ratio hypothesis predicts that complementary resource use for aboveground is stronger and the key driver of higher overyielding on richer soils, thus overruling possible complementary for belowground resources on poor soils. Our results, however, suggest that overyielding of mixed forests is stronger on poor soils than on rich soils, as predicted by stress-gradient hypothesis but not by resource-ratio hypothesis (Figures 3.2, 3.3). Yet, our results also imply that there is stronger aboveground complementary use for light on poor soils $(++)$ than on rich soils $(+)$, but the role of complementary use of below ground resources remains actually largely unknown (?). 
Poor soil

Expectations from Stress-gradient hypothesis

Expectations from Resource-ratio hypothesis

Results in this thesis

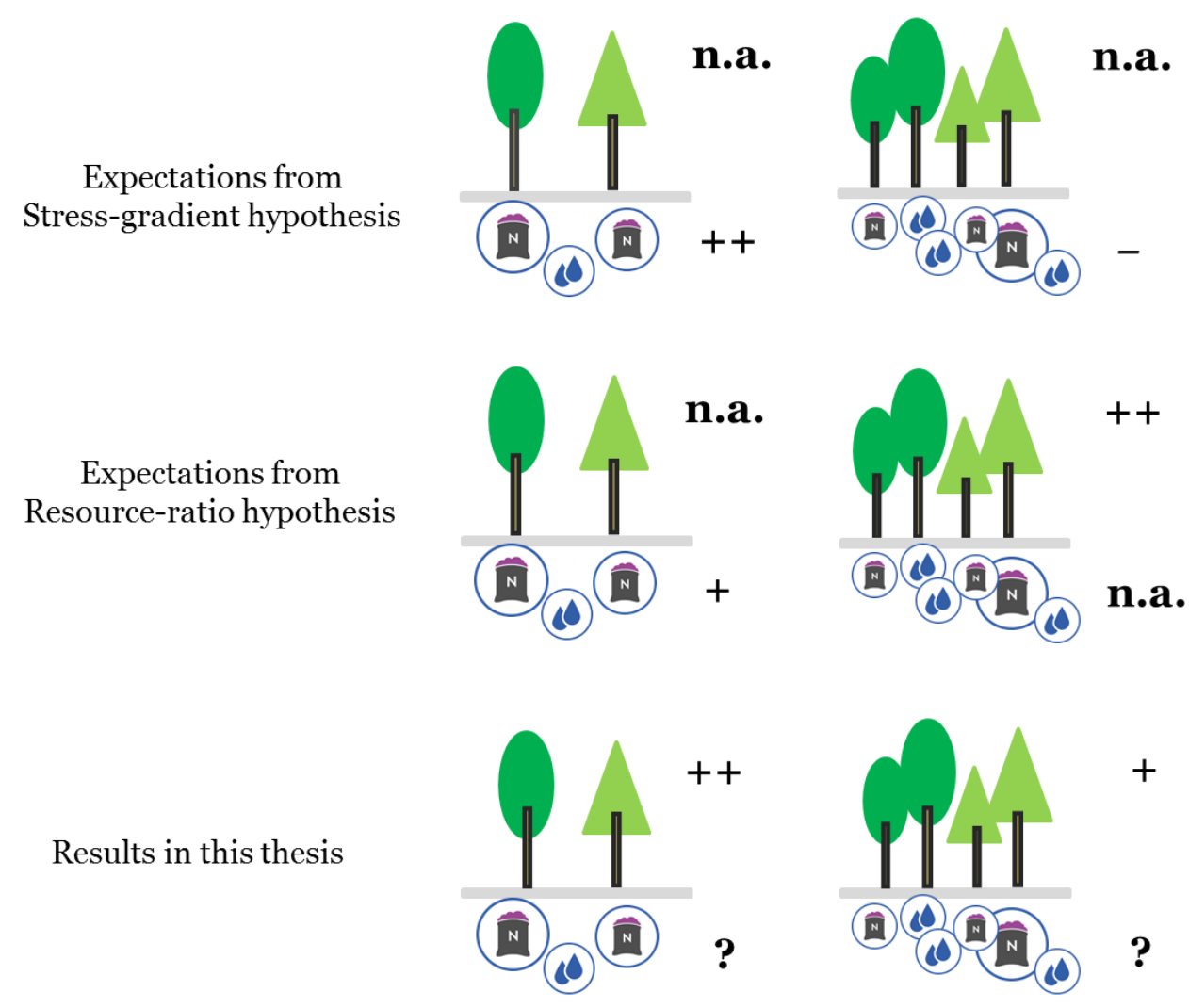

Rich soil

Figure 5.7 Schemes to illustrate the expectations and results of overyielding effects on soils contrasting in fertility (poor and rich soils) according to the concept of competition and complementarity from the stress-gradient hypothesis and resource-ratio hypothesis, and a newly formulated hypothesis based on the results of this thesis. Number of trees indicates the canopy density: more trees, denser canopy. The signs $++/+/-/$ n.a./? refer to above and belowground complementary effects; ++: stronger complementary; +: weaker complementarity; -: no complementarity ; n.a.: not applicable; ?: unknown. Soil sketch adapted from Weemstra (2017).

When improving soil fertility, the stress-gradient hypothesis posits a transition from facilitation or complementary resource use to competition, whereas the resource-ratio hypothesis comprises a transition from competition predominantly for belowground (soil) resources to competition predominantly for aboveground resources (light). However, our results in chapter 3 at stand level and species level suggest that the mechanisms for complementary soil resource use are stronger on poor soils. More specifically, the competitive reduction by inter-specific competition was larger for pine-oak mixtures on lower soil fertility soils. Yet, the competition for light was stronger on high fertility soils (Figures 4.2, 4.3). Thus, our studies of competition among tree species do not support either of the two dominant hypotheses. Under Dutch climatic conditions, the soil conditions and climate still allow for sufficient stand productivity and dense canopies on poor soils that may better allow for complementary use of light than the denser canopies on rich soils. On higher fertility soils, trees face stronger competition for light but with reduced potential for partitioning light, 
which thus results in weaker overyielding than on lower fertility soils. Our results and speculations thus shed new light on the stress-gradient and resource-ratio hypotheses. For mixed stands in the Netherlands, the greatest productivity gain is achieved on the poorer soils, and we argued that this is driven by complementary use of light, but with an unknown contribution of complementary use of soil resources.

\section{Suggestions for management of mixed forests}

The proportion of mixed forest stands was recently still increasing in the Netherlands, as suggested by the inventories of 2003 and 2013 in the Dutch NFI (Schelhaas et al., 2014). In total, 695 plots of the 3547 plots in the NFI data of 2013 are mixed species plots according to the mixed stand definition (based on proportion of basal area) presented in chapter 2 and 3 . These mixed stands include 596 of the five mixtures studied in this thesis (Table 5.1). Three of those five mixed stands were predicted to show overyielding: Douglas-fir-beech and pineoak as shown in chapter 2 and 3, and pine-birch as shown in chapter 4. In the NFI data, there are 629 corresponding monoculture stands of the species in those three mixtures, i.e. Douglasfir, common beech, Scots pine, pedunculate oak and silver birch. The highest productivity gain is predicted for Douglas-fir mixed with beech: for stands younger than 150 years, Douglas-fir-beech mixtures are predicted to produce up to $3.5 \mathrm{~m}^{3} \mathrm{ha}^{-1}$ year ${ }^{-1}$ more relative to Douglas-fir and beech monocultures (Figure 2.2a), and the relative increase in increment is highest on poor soils (Figure 3.2a,b). Remarkably, the most promising mixture, i.e. Douglasfir-beech mixture, currently comprises only 16 out of the 3547 plots (Schelhaas et al., 2014, Figure 5.8). The gains in pine-oak mixtures are lower, as they reach approximately $1 \mathrm{~m}^{3} \mathrm{ha}^{-1}$ year $^{-1}$ (Figure 2.2b), and again the relative gain is higher for this mixtures on poor soils (Figure 3.2c,d). For the third overyielding mixture, pine-birch, we have no volume gain values, as we only carried out tree-tree relationships (chapter 4). Overall, these studies suggest great potential for increasing productivity of Dutch forests, particularly when mixing results in evergreen-deciduous species stands on the poorer soils. This potential is indicated by the great number of monocultures that are predicted to increase in productivity after mixing, particularly across the sandy soils in the Netherlands (Figure 5.8). 


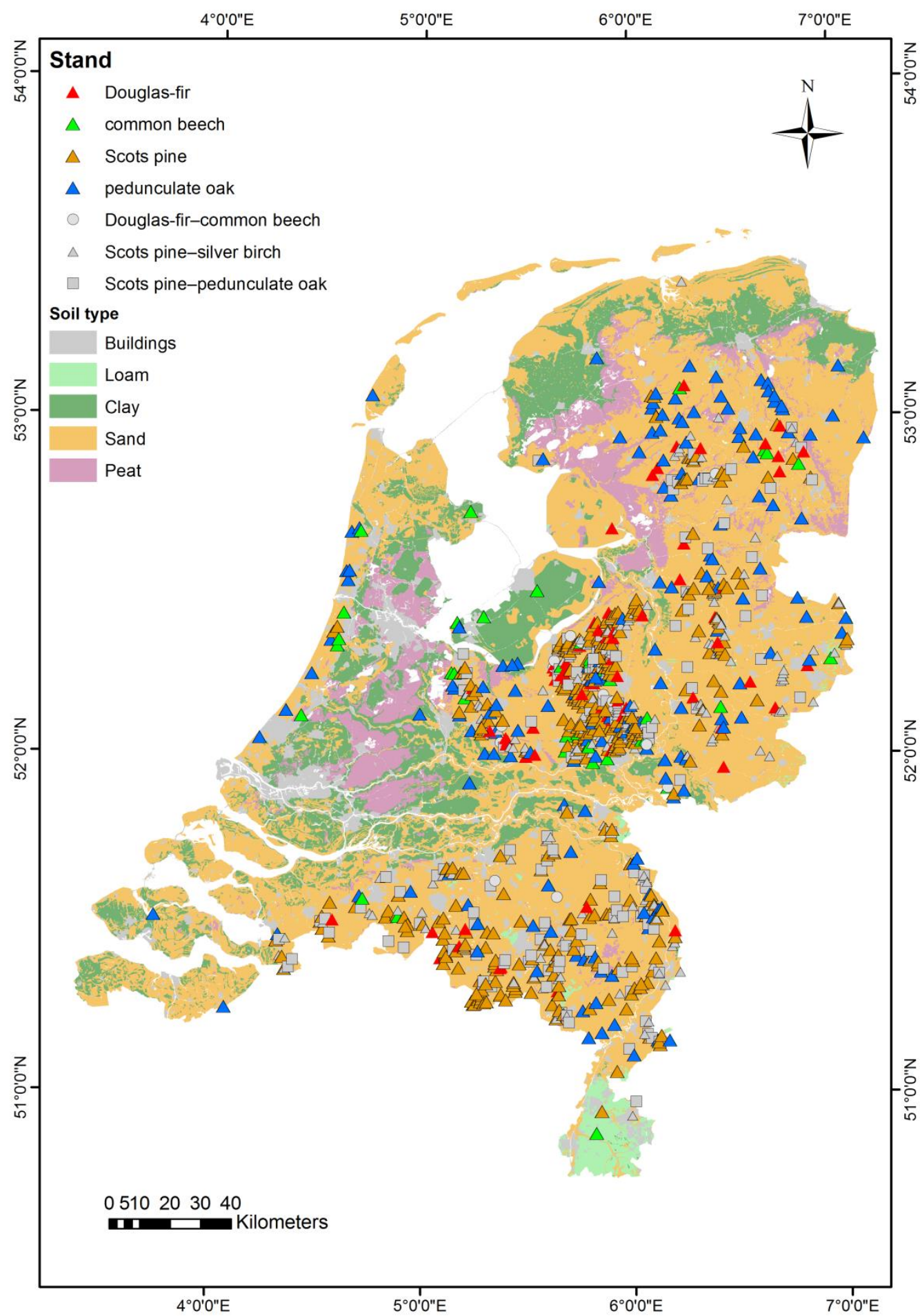

Figure 5.8 Stand locations that show overyielding or potential overyielding based on data analysis of chapter 24. Stands on the Dutch soil map are from the Dutch national forest inventory data. Douglas-fir-common beech and Scots pine-pedunculate oak are the mixtures that show overyielding in chapter 2 and 3 at stand and species level. Scots pine-silver birch is the mixture that shows potential overyielding in chapter 4 at tree-level. Common beech, Douglas-fir, Scots pine, pedunculate oak are monoculture stands that are predicted to show overyielding if mixing with Douglas-fir, common beech, pedunculate oak, and Scots pine, respectively. 


\section{Concluding remarks: benefits of mixed-species forests}

The increasing importance of mixed-species forests is a reflection of the increasing complexity of societal demands upon forest ecosystems, where mixed-species forests are expected to have higher productivity, and higher levels of stability and biodiversity, amongst other ecosystem services. Also, the increased relevance of mixed forests results from the increasing emphasis on the use of spontaneous processes in forest management, as in close-tonature forestry. This thesis addresses the question how species mixing influences forest productivity, and addresses this question at stand, species and tree level. This study shows that higher productivity, i.e. overyielding, occurred notably in stands with mixtures of evergreen and deciduous species. Moreover, this overyielding was maintained with stand development due to forest management (thinning) aiming at maintaining species mixtures, and was stronger for stands on low fertility soils compared with high fertility soils. It is suggested that differences in leaf phenology in mixed stands are a major determinant of overyielding, but also shade tolerance plays an important role. Yet, experimental studies will be required for understanding mixing effects on overyielding, and those studies should not only include mechanisms of complementary, but also others, including the role of litter mixing, pathogens, and other factors. Finally, this thesis identifies the competitive interactions on individual tree growth in mixed stands and shows that intra-specific competition is not necessarily stronger than inter-specific competition. Besides, our results imply that light is the most limiting resource for tree growth on most sites in the Netherlands, and that species mixing may alleviate competition for light among neighbouring trees on soils differing in fertility, but especially on poor soils. We conclude that mixing species, differing in resource acquiring strategies, contributes to a higher productivity in forests, and that complementary mechanisms are even more successful and leading to higher overyielding on poorer soils. Based on this, we call for developing forest management strategies that consider the complementarity in resource acquisition of tree species to convert monospecific forests to more productive mixedspecies forests. 


\section{References}

Agnoletti, M., 2006. Man, forestry, and forest landscapes. Trends and perspectives in the evolution of forestry and woodland history research. Schweizerische Zeitschrift fur Forstwesen 157, 384-392.

Agnoletti, M., Anderson, S., 2000. Forest History: International Studies on Socioeconomic and Forest Ecosystem Change: Report No. 2 of the IUFRO Task Force on Environmental Change. CAB International Wallingford, UK.

André, F., Jonard, M., Ponette, Q., 2008. Spatial and temporal patterns of throughfall chemistry within a temperate mixed oak-beech stand. Science of the total environment 397, 215-228.

Assmann, E., 1970. The Principles of Forest Yield Study. Oxford [etc.] : [s.n.] UK

Barbati, A., Bastrup-Birk, A., Baycheva, T., Bonhomme, C., Bozzano, M., Bücking, W., Camia, A., Caudullo, G., Cienciala, E., Cimini, D., 2011. State of Europel's forests, 2011: status \& trends in sustainable forest management in Europe. In. Ministerial Conference on the Protection of Forests in Europe, Forest Europe, Liaison Unit Oslo, Aas, Norway.

Baribault, T.W., Kobe, R.K., 2011. Neighbour interactions strengthen with increased soil resources in a northern hardwood forest. Journal of Ecology 99, 1358-1372.

Bartelink, H., 2000. Effects of stand composition and thinning in mixed-species forests: a modeling approach applied to Douglas-fir and beech. Tree Physiology 20, 399-406.

Bartelink, H., Olsthoorn, A., 1999. Introduction: mixed forest in western Europe. In: A.F.M. Olsthoorn, H.H.B., J.J. Gardiner, H. Pretzsch, H.J. Hekhuis, A. Franc (Ed.), Management of mixed-species forest: silviculture and economics Institute for Forestry and Nature Research, Wageningen, pp. 9-16.

Bartelink, H.H., 1998. Simulation of growth and competition in mixed stands of Douglas-fir and beech. In. Landbouwuniversiteit Wageningen.

Barton, K., 2013. MuMIn: Multi-model inference. $\mathrm{R}$ package version 1.9.5. http://cran.rproject.org/package=MuMIn.

Bates, D., Maechler, M., Bolker, B., Walker, S., 2013. lme4: Linear mixed-effects models using Eigen and S4. R package version 0.99999911-5. http://lme4.r-forge.r-project.org.

Bertness, M.D., Callaway, R., 1994. Positive interactions in communities. Trends in Ecology \& Evolution 9, 191-193.

Bolte, A., Villanueva, I., 2006. Interspecific competition impacts on the morphology and distribution of fine roots in European beech (Fagus sylvatica L.) and Norway spruce (Picea abies (L.) Karst.). European Journal of Forest Research 125, 15-26.

Bose, A.K., Schelhaas, M.-J., Mazerolle, M.J., Bongers, F., 2014. Temperate forest development during secondary succession: effects of soil, dominant species and management. European Journal of Forest Research 133, 511-523.

Bouillet, J.-P., Laclau, J.-P., Gonçalves, J.L.d.M., Voigtlaender, M., Gava, J.L., Leite, F.P., Hakamada, R., Mareschal, L., Mabiala, A., Tardy, F., 2013. Eucalyptus and Acacia tree growth over entire rotation in singleand mixed-species plantations across five sites in Brazil and Congo. Forest Ecology and Management 301, $89-101$.

Brassard, B.W., Chen, H.Y., Cavard, X., Laganiere, J.o., Reich, P.B., Bergeron, Y., Pare, D., Yuan, Z., 2013. Tree species diversity increases fine root productivity through increased soil volume filling. Journal of Ecology 101, 210-219.

Bravo-Oviedo, A., Pretzsch, H., Ammer, C., Andenmatten, E., and 33 more co-authors, 2014. European Mixed Forests: definition and research perspectives. Forest Systems 23, 518-533.

Brown, A., 1992. Functioning of mixed-species stands at Gisburn, NW England. In: M.G.R. Cannell, D.C.M., and P.A. Robertson (Ed.), The ecology of mixed-species stands of trees. Blackwell, Oxford, UK, pp. 125150

Cardinale, B.J., Wright, J.P., Cadotte, M.W., Carroll, I.T., Hector, A., Srivastava, D.S., Loreau, M., Weis, J.J., 2007. Impacts of plant diversity on biomass production increase through time because of species complementarity. Proceedings of the National Academy of Sciences 104, 18123-18128.

Cavard, X., Bergeron, Y., Chen, H.Y., Paré, D., Laganière, J., Brassard, B., 2011. Competition and facilitation between tree species change with stand development. Oikos 120, 1683-1695. 
Chamagne, J., Tanadini, M., Frank, D., Matula, R., Paine, C., Philipson, C.D., Svatek, M., Turnbull, L.A., Volař́k, D., Hector, A., 2016. Forest diversity promotes individual tree growth in central European forest stands. Journal of Applied Ecology 54, 71-79.

Coates, K.D., Canham, C.D., LePage, P.T., 2009. Above-versus below-ground competitive effects and responses of a guild of temperate tree species. Journal of Ecology 97, 118-130.

Coates, K.D., Lilles, E.B., Astrup, R., 2013. Competitive interactions across a soil fertility gradient in a multispecies forest. Journal of Ecology 101, 806-818.

Condés, S., Del Río, M., 2015. Climate modifies tree interactions in terms of basal area growth and mortality in monospecific and mixed Fagus sylvatica and Pinus sylvestris forests. European Journal of Forest Research 134, 1095-1108.

Condés, S., Río, M., Sterba, H., 2013. Mixing effect on volume growth of Fagus sylvatica and Pinus sylvestris is modulated by stand density. Forest Ecology and Management 292, 86-95.

Condés, S., Sterba, H., 2008. Comparing an individual tree growth model for Pinus halepensis Mill. in the Spanish region of Murcia with yield tables gained from the same area. European Journal of Forest Research $127,253-261$.

Dawud, S., Vesterdal, L., Raulund-Rasmussen, K., 2017. Mixed-Species Effects on Soil C and N Stocks, C/N Ratio and pH Using a Transboundary Approach in Adjacent Common Garden Douglas-Fir and Beech Stands. Forests 8, 95.

de-Dios-García, J., Pardos, M., Calama, R., 2015. Interannual variability in competitive effects in mixed and monospecific forests of Mediterranean stone pine. Forest Ecology and Management 358, 230-239.

De Kovel, C.F., Wilms, Y., Berendse, F., 2000. Carbon and nitrogen in soil and vegetation at sites differing in successional age. Plant Ecology 149, 43-50.

Dean, T.J., Baldwin, V.C., 1996. The relationship between Reineke's stand-density index and physical stem mechanics. Forest Ecology and Management 81, 25-34.

Dekker, M., van Breugel, M., Sterck, F.J., 2007. Effective height development of four co-occurring species in the gap-phase regeneration of Douglas fir monocultures under nature-oriented conversion. Forest ecology and management 238, 189-198.

Del Río, M., Condés, S., Pretzsch, H., 2014a. Analyzing size-symmetric vs. size-asymmetric and intra- vs. interspecific competition in beech (Fagus sylvatica L.) mixed stands. Forest Ecology and Management 325, 90-98.

Del Río, M., Pretzsch, H., Alberdi, I., Bielak, K., Bravo, F., Brunner, A., Condés, S., Ducey, M.J., Fonseca, T., von Lüpke, N., 2015. Characterization of the structure, dynamics, and productivity of mixed-species stands: review and perspectives. European Journal of Forest Research 135, 23-49.

Del Río, M., Pretzsch, H., Ruíz-Peinado, R., Ampoorter, E., Annighöfer, P., Barbeito, I., Bielak, K., Brazaitis, G., Coll, L., Drössler, L., 2017. Species interactions increase the temporal stability of community productivity in Pinus sylvestris-Fagus sylvatica mixtures across Europe. Journal of Ecology, Accepted.

Del Río, M., Sterba, H., 2009. Comparing volume growth in pure and mixed stands of Pinus sylvestris and Quercus pyrenaica. Annals of Forest Science 66, 1-11.

Del Río, M.d., Schütze, G., Pretzsch, H., 2014b. Temporal variation of competition and facilitation in mixed species forests in Central Europe. Plant Biology 16, 166-176.

Den Ouden, J., Mohren, G., 2016. Thematic collection: FEM growth and yield data. In: DANS (Ed.), The Netherlands.

Dieler, J., Pretzsch, H., 2013. Morphological plasticity of European beech (Fagus sylvatica L.) in pure and mixed-species stands. Forest Ecology and Management 295, 97-108.

Dirkse, G., Daamen, W., Schoonderwoerd, H., Japink, M., Van Jole, M., Van Moorsel, R., Schnitger, P., Stouthamer, W., Vocks, M., 2007. Meetnet Functievervulling Bos 2001-2005, Vijfde Nederlandse Bosstatistiek. In, Rapport Ministerie LNV Directie Kennis, Ministerie van Landbouw, Natuur en Voedselkwaliteit.

Dirnberger, G.F., Sterba, H., 2014. A comparison of different methods to estimate species proportions by area in mixed stands. Forest Systems 23, 534-546.

Drössler, L., Övergaard, R., Ekö, P.M., Gemmel, P., Böhlenius, H., 2015. Early development of pure and mixed tree species plantations in Snogeholm, southern Sweden. Scandinavian Journal of Forest Research 30, 304316. 
Epron, D., Nouvellon, Y., Mareschal, L., Koutika, L.-S., Geneste, B., Delgado-Rojas, J.S., Laclau, J.-P., Sola, G., Gonçalves, J.L.d.M., Bouillet, J.-P., 2013. Partitioning of net primary production in Eucalyptus and Acacia stands and in mixed-species plantations: Two case-studies in contrasting tropical environments. Forest Ecology and Management 301, 102-111.

Felton, A., Lindbladh, M., Brunet, J., Fritz, Ö., 2010. Replacing coniferous monocultures with mixed-species production stands: an assessment of the potential benefits for forest biodiversity in northern Europe. Forest Ecology and management 260, 939-947.

Fischer, A., Lindner, M., Abs, C., Lasch, P., 2002. Vegetation dynamics in central European forest ecos ystems (near-natural as well as managed) after storm events. Folia Geobotanica 37, 17-32.

Forrester, D.I., 2014. The spatial and temporal dynamics of species interactions in mixed-species forests: From pattern to process. Forest Ecology and Management 312, 282-292.

Forrester, D.I., Albrecht, A.T., 2014. Light absorption and light-use efficiency in mixtures of Abies alba and Picea abies along a productivity gradient. Forest Ecology and Management 328, 94-102.

Forrester, D.I., Bauhus, J., 2016. A Review of Processes Behind Diversity-Productivity Relationships in Forests. Current Forestry Reports 2, 45-61.

Forrester, D.I., Bauhus, J., Cowie, A.L., Vanclay, J.K., 2006. Mixed-species plantations of Eucalyptus with nitrogen-fixing trees: a review. Forest Ecology and Management 233, 211-230.

Forrester, D.I., Kohnle, U., Albrecht, A.T., Bauhus, J., 2013a. Complementarity in mixed-species stands of Abies alba and Picea abies varies with climate, site quality and stand density. Forest Ecology and Management 304, 233-242.

Forrester, D.I., Kohnle, U., Albrecht, A.T., Bauhus, J., 2013b. Complementarity in mixed-species stands of Abies alba and Picea abies varies with climate, site quality and stand density. Forest Ecology and Management 304, 233-242.

Forrester, D.I., Pretzsch, H., 2015. Tamm Review: On the strength of evidence when comparing ecosystem functions of mixtures with monocultures. Forest Ecology and Management 356, 41-53.

Forrester, D.I., Theiveyanathan, S., Collopy, J.J., Marcar, N.E., 2010. Enhanced water use efficiency in a mixed Eucalyptus globulus and Acacia mearnsii plantation. Forest Ecology and Management 259, 1761-1770.

Fox, J., Weisberg, S., 2010. An R companion to applied regression. Sage, Thousand Oaks, CA.

Fruleux, A., Bonal, D., Bogeat-Triboulot, M.-B., 2016. Interactive effects of competition and water availability on above- and below-ground growth and functional traits of European beech at juvenile level. Forest Ecology and Management 382, 21-30.

Gamfeldt, L., Snall, T., Bagchi, R., Jonsson, M., Gustafsson, L., Kjellander, P., Ruiz-Jaen, M.C., Froberg, M., Stendahl, J., Philipson, C.D., Mikusinski, G., Andersson, E., Westerlund, B., Andren, H., Moberg, F., Moen, J., Bengtsson, J., 2013. Higher levels of multiple ecosystem services are found in forests with more tree species. Nature Communications 4, 1340.

Gazol, A., Camarero, J.J., 2016. Functional diversity enhances silver fir growth resilience to an extreme drought. Journal of Ecology 104, 1063-1075

Göransson, H., Bambrick, M.T., Godbold, D.L., 2016. Overyielding of temperate deciduous tree mixtures is maintained under throughfall reduction. Plant and Soil 408, 285-298.

Hantsch, L., Bien, S., Radatz, S., Braun, U., Auge, H., Bruelheide, H., 2014. Tree diversity and the role of nonhost neighbour tree species in reducing fungal pathogen infestation. Journal of Ecology 102, 1673-1687.

Hara, T., 1993. Mode of Competition and Size-structure Dynamics in Plant Communities. Plant Species Biology $8,75-84$

Harper, J.L., 1977. Population biology of plants. Academic Press., London, UK.

Harry, J., SMITH, G., BAILEY, G.R., 1964. Influence of stocking and stand density on crown widths of Douglas fir and lodgepole pine. The Commonwealth Forestry Review 43, 243-246.

Hättenschwiler, S., Tiunov, A.V., Scheu, S., 2005. Biodiversity and litter decomposition in terrestrial ecosystems. Annual Review of Ecology, Evolution, and Systematics 36, 191-218.

Hendriks, C., Bianchi, F., 1995. Root density and root biomass in pure and mixed forest stands of Douglas-fir and Beech. Netherlands Journal of Agricultural Science 43, 321-331.

Hengl, T., Mendes de Jesus, J., Heuvelink, G., Ruiperez Gonzalez, M., Kilibarda, M., Blagotic, A., Shangguan, W., Wright, M., Geng, X., Bauer-Marschallinger, B., 2016. SoilGrids250 m: Global gridded soil information based on machine learning. PLoS One 12, e0169748. 
Huber, M.O., Sterba, H., Bernhard, L., 2014. Site conditions and definition of compositional proportion modify mixture effects in Picea abies-Abies alba stands. Canadian Journal of Forest Research 44, 1281-1291.

Hynynen, J., Repola, J., Mielikäinen, K., 2011. The effects of species mixture on the growth and yield of midrotation mixed stands of Scots pine and silver birch. Forest Ecology and Management 262, 1174-1183.

Jansen, J.J., Sevenster, J., Faber, J., 1996. Opbrengsttabellen voor belangrijke boomsoorten in Nederland. In, [Wageningen]: IBN-WATER [etc.] - 202 p. Institute for Forestry and Nature Research, Wageningen, the Netherlands p. 202.

Janse-Ten Klooster, S.H., Thomas, E.J., Sterck, F.J., 2007. Explaining interspecific differences in sapling growth and shade tolerance in temperate forests. Journal of Ecology 95, 1250-1260.

Johann, E., Agnoletti, M., Axelsson, A., Bürgi, M., Östlund, L., Rochel, X., Schmidt, U., Schuler, A., Skovsgaard, J., Winiwarter, V., 2004. History of secondary spruce forests in Europe. Norway Spruce Conversion, Option and Consequences, EFI research report 18, 25-62.

Jucker, T., Bouriaud, O., Avacaritei, D., Coomes, D.A., 2014a. Competition for light and water play contrasting roles in driving diversity-productivity relationships in Iberian forests. Journal of Ecology 102, 12021213.Jucker, T., Bouriaud, O., Avacaritei, D., Coomes, D.A., 2014b. Stabilizing effects of diversity on aboveground wood production in forest ecosystems: linking patterns and processes. Ecology letters 17, 15601569.

Jucker, T., Bouriaud, O., Coomes, D.A., 2015. Crown plasticity enables trees to optimize canopy packing in mixed-species forests. Funct Ecol 29, 1078-1086

Kelty, M.J., 1989. Productivity of New England hemlock/hardwood stands as affected by species composition and canopy structure. Forest Ecology and Management 28, 237-257.

Kelty, M.J., 1992. Comparative productivity of monocultures and mixed-species stands. Springer, New York.

KNMI 2015. Daggegevens van het weer in Nederland. Station Rotterdam. De Bilt, the Netherlands: KNMI. [WWW document] URL http://www.knmi.nl/cms/content/58105/zomer_in_flevoland [accessed 28 February 2015].

Larocque, G.R., Luckai, N., Adhikary, S.N., Groot, A., Bell, F.W., Sharma, M., 2012. Competition theoryscience and application in mixed forest stands: review of experimental and modelling methods and suggestions for future research. Environmental Reviews 21, 71-84.

Latham, P.A., Zuuring, H.R., Coble, D.W., 1998. A method for quantifying vertical forest structure. Forest Ecology and Management 104, 157-170.

Lebourgeois, F., Gomez, N., Pinto, P., Mérian, P., 2013. Mixed stands reduce Abies alba tree-ring sensitivity to summer drought in the Vosges mountains, western Europe. Forest Ecology and Management 303, 61-71.

Leikola, M., 1999. Definition and classification of mixed forests, with a special emphasis on boreal forests. Management of mixed-species forest: silviculture and economics (Olsthoorn AFM, Bartelink HH, Gardiner JJ, Pretzsch H, Hekhuis HJ, Franc A, eds). Wageningen: DLO Institute of Forestry and nature research. pp, 20-28.

Liang, J., Crowther, T.W., Picard, N., Wiser, S., Zhou, M., Alberti, G., Schulze, E.-D., McGuire, A.D., Bozzato, F., Pretzsch, H., 2016, and 71 more co-authors. Positive biodiversity-productivity relationship predominant in global forests. Science 354, aaf8957.

Longuetaud, F., Piboule, A., Wernsdörfer, H., Collet, C., 2013. Crown plasticity reduces inter-tree competition in a mixed broadleaved forest. European Journal of Forest Research 132, 621-634.

Loreau, M., 2004. Does functional redundancy exist? Oikos 104, 606-611.

Loreau, M., Hector, A., 2001. Partitioning selection and complementarity in biodiversity experiments. Nature 412, 72-76.

Lu, H., Mohren, G.M., den Ouden, J., Goudiaby, V., Sterck, F.J., 2016. Overyielding of temperate mixed forests occurs in evergreen-deciduous but not in deciduous-deciduous species mixtures over time in the Netherlands. Forest Ecology and Management 376, 321-332.

Ma, Z., Chen, H.Y., 2016. Effects of species diversity on fine root productivity in diverse ecosystems: a global meta-analysis. Global Ecology and Biogeography 25, 1387-1396.

Ma, Z., Chen, H.Y., 2017. Effects of species diversity on fine root productivity increase with stand development and associated mechanisms in a boreal forest. Journal of Ecology 105, 237-245.

Manso, R., Morneau, F., Ningre, F., Fortin, M., 2015. Effect of climate and intra-and inter-specific competition on diameter increment in beech and oak stands. Forestry 88, 540-551. 
McFadden, D., 1974. Conditional logit analysis of qualitative choice behavior. In, Frontiers in Econometrics, Academic Press: New York, pp. 105-142.

Morin, X., Fahse, L., Scherer-Lorenzen, M., Bugmann, H., 2011. Tree species richness promotes productivity in temperate forests through strong complementarity between species. Ecology Letters 14, 1211-1219.

Niinemets, Ü., Valladares, F., 2006. Tolerance to shade, drought, and waterlogging of temperate northern hemisphere trees and shrubs. Ecological Monographs 76, 521-547.

Oliver, C.D., Boydak, M., Segura, G., Bare, B.B., 1999. Forest organization, management, and policy. In, Maintaining biodiversity in forest ecosystems. M. Hunter (editor). Cambridge University Press, New York, NY, pp. 556-596.

Oliver, C.D., Larson, B.C., 1996. Forest stand dynamics: updated edition. John Wiley and Sons, New York.

Perot, T., Picard, N., 2012. Mixture enhances productivity in a two-species forest: evidence from a modeling approach. Ecological Research 27, 83-94.

Pinheiro, J., Bates, D., 2000. Mixed-Effects Models in S and S-PLUS. Springer, New York, NW.

Poorter, H., Niklas, K.J., Reich, P.B., Oleksyn, J., Poot, P., Mommer, L., 2012. Biomass allocation to leaves, stems and roots: meta-analyses of interspecific variation and environmental control. New Phytologist 193, $30-50$.

Pretzsch, H., 2010. Forest dynamics, growth, and yield. Springer, Heidelberg, Germany.

Pretzsch, H., 2014. Canopy space filling and tree crown morphology in mixed-species stands compared with monocultures. Forest Ecology and Management 327, 251-264.

Pretzsch, H., Biber, P., 2010. Size-symmetric versus size-asymmetric competition and growth partitioning among trees in forest stands along an ecological gradient in central Europe. Canadian Journal of Forest Research 40, 370-384.

Pretzsch, H., Biber, P., 2016. Tree species mixing can increase maximum stand density. Canadian Journal of Forest Research 46, 1179-1193.

Pretzsch, H., Biber, P., Schütze, G., Bielak, K., 2014. Changes of forest stand dynamics in Europe. Facts from long-term observational plots and their relevance for forest ecology and management. Forest Ecology and Management 316, 65-77.

Pretzsch, H., Bielak, K., Block, J., Bruchwald, A., Dieler, J., Ehrhart, H.P., Kohnle, U., Nagel, J., Spellmann, H., Zasada, M., Zingg, A., 2013a. Productivity of mixed versus pure stands of oak (Quercus petraea (Matt.) Liebl. and Quercus robur L.) and European beech (Fagus sylvatica L.) along an ecological gradient. European Journal of Forest Research 132, 263-280.

Pretzsch, H., Block, J., Dieler, J., Dong, P.H., Kohnle, U., Nagel, J., Spellmann, H., Zingg, A., 2010. Comparison between the productivity of pure and mixed stands of Norway spruce and European beech along an ecological gradient. Annals of Forest Science 67, 712.

Pretzsch, H., Forrester, D.I., Rötzer, T., 2015a. Representation of species mixing in forest growth models. A review and perspective. Ecological Modelling 313, 276-292.

Pretzsch, H., del Río, M., Ammer, C., Avdagic, A., Barbeito, I., Bielak, K., Brazaitis, G., Coll, L., Dirnberger, G., Drössler, L., and 26 more co-authors, 2015b. Growth and yield of mixed versus pure stands of Scots pine (Pinus sylvestris L.) and European beech (Fagus sylvatica L.) analysed along a productivity gradient through Europe. European Journal of Forest Research 134, 927-947.

Pretzsch, H., Schuetze, G., Uhl, E., 2013b. Resistance of European tree species to drought stress in mixed versus pure forests: evidence of stress release by inter-specific facilitation. Plant Biology 15, 483-495.

Pretzsch, H., Schütze, G., 2009. Transgressive overyielding in mixed compared with pure stands of Norway spruce and European beech in Central Europe: evidence on stand level and explanation on individual tree level. European Journal of Forest Research 128, 183-204.

Puettmann, K.J., Wilson, S.M., Baker, S.C., Donoso, P.J., Drössler, L., Amente, G., Harvey, B.D., Knoke, T., Lu, Y., Nocentini, S., 2015. Silvicultural alternatives to conventional even-aged forest management-what limits global adoption? Forest Ecosystems 2, 8.

Quero, J.L., Sterck, F.J., Martínez-Vilalta, J., Villar, R., 2011. Water-use strategies of six co-existing Mediterranean woody species during a summer drought. Oecologia 166, 45-57.

R Core Team, T., 2015. R: A language and environment for statistical computing. R Foundation for Statistical Computing. In, Vienna, Austria. 
Reineke, L.H., 1933. Perfecting a stand-density index for even-aged forests. Journal of Agricultural Research 46, 627-638.

Rewald, B., Leuschner, C., 2009. Belowground competition in a broad-leaved temperate mixed forest: pattern analysis and experiments in a four-species stand. European Journal of Forest Research 128, 387-398.

Reyer, C., Lasch, P., Mohren, G.M.J., Sterck, F.J., 2010. Inter-specific competition in mixed forests of Douglasfir (Pseudotsuga menziesii) and common beech (Fagus sylvatica) under climate change-a model-based analysis. Annals of Forest Science 67, 805.

Richards, A.E., Forrester, D.I., Bauhus, J., Scherer-Lorenzen, M., 2010. The influence of mixed tree plantations on the nutrition of individual species: a review. Tree Physiology 30, 1192-1208.

Ryan, M., Binkley, D., Fownes, J., 1997. Age-related decline in forest productivity. Advances in Ecological Research 27, 213-262.

Schelhaas, M., Clerkx, A.P.P.M., Daamen, W.P., Oldenburger, J.F., Velema, G., Schnitger, P., Schoonderwoerd, H., Kramer, H., 2014. Zesde Nederlandse bosinventarisatie: methoden en basisresultaten. In. Alterra Wageningen UR, Wageningen, the Netherlands. .

Schwinning, S., Weiner, J., 1998. Mechanisms determining the degree of size asymmetry in competition among plants. Oecologia 113, 447-455.

Setiawan, N.N., Vanhellemont, M., De Schrijver, A., Schelfhout, S., Baeten, L., Verheyen, K., 2016. Mixing effects on litter decomposition rates in a young tree diversity experiment. Acta Oecologica 70, 79-86.

Sterba, H., 1987. Estimating potential density from thinning experiments and inventory data. Forest Science 33, 1022-1034.

Sterba, H., 1998. The precision of species proportion by area when estimated by angle counts and yield tables. Forestry 71, 25-32.

Sterba, H., del Río, M., Brunner, A., Condes, S., 2014. Effect of species proportion definition on the evaluation of growth in pure vs. mixed stands. Forest Systems 23, 547-559.

Thomas, F., Bögelein, R., Werner, W., 2015. Interaction between Douglas fir and European beech: investigations in pure and mixed stands. Forstarchiv 86, 83-91.

Thurm, E.A., Biber, P., Pretzsch, H., 2016a. Stem growth is favored at expenses of root growth in mixed stands and humid conditions for Douglas-fir (Pseudotsuga menziesii) and European beech (Fagus sylvatica). Trees 31, 349-365.

Thurm, E.A., Pretzsch, H., 2016. Improved productivity and modified tree morphology of mixed versus pure stands of European beech (Fagus sylvatica) and Douglas-fir (Pseudotsuga menziesii) with increasing precipitation and age. Annals of Forest Science 73, 1047-1061.

Thurm, E.A., Uhl, E., Pretzsch, H., 2016b. Mixture reduces climate sensitivity of Douglas-fir stem growth. Forest Ecology and Management 376, 205-220.

Tilman, D., 1985. The resource-ratio hypothesis of plant succession. The American Naturalist 125, 827-852.

Tilman, D., 1999. The ecological consequences of changes in biodiversity: A search for general principles 101. Ecology 80, 1455-1474.

Tilman, D., Reich, P.B., Knops, J., Wedin, D., Mielke, T., Lehman, C., 2001. Diversity and productivity in a long-term grassland experiment. Science 294, 843-845.

Toïgo, M., Vallet, P., Perot, T., Bontemps, J.D., Piedallu, C., Courbaud, B., 2015. Overyielding in mixed forests decreases with site productivity. Journal of Ecology 103, 502-512.

Trinder, C.J., Brooker, R.W., Davidson, H., Robinson, D., 2012. A new hammer to crack an old nut: interspecific competitive resource capture by plants is regulated by nutrient supply, not climate. PloS one 7, e29413.

Vallet, P., Pérot, T., 2011. Silver fir stand productivity is enhanced when mixed with Norway spruce: evidence based on large-scale inventory data and a generic modelling approach. Journal of Vegetation Science 22, 932-942.

van der Plas, F., Manning, P., Soliveres, S., Allan, E., Scherer-Lorenzen, M., Verheyen, K., Wirth, C., Zavala, M.A., Ampoorter, E., Baeten, L., 2016. Biotic homogenization can decrease landscape-scale forest multifunctionality. Proceedings of the National Academy of Sciences 113, 3557-3562.

Vandermeer, J.H., 1989. The ecology of intercropping. Cambridge University Press, New York. 
Vilà, M., Carrillo-Gavilán, A., Vayreda, J., Bugmann, H., Fridman, J., Grodzki, W., Haase, J., Kunstler, G., Schelhaas, M., Trasobares, A., 2013. Disentangling biodiversity and climatic determinants of wood production. PloS One 8, e53530.

Weemstra, M., 2017. Belowground uptake strategies: how fine-root traits determine tree growth. In. Wageningen University.

Weiskittel, A.R., Hann, D.W., Kershaw Jr, J.A., Vanclay, J.K., 2011. Forest growth and yield modeling. John Wiley \& Sons, Chichester.

Williams, L.J., Paquette, A., Cavender-Bares, J., Messier, C., Reich, P.B., 2017. Spatial complementarity in tree crowns explains overyielding in species mixtures. Nature Ecology \& Evolution 1, 0063, 0061-0067.

Wykoff, W.R., 1990. A basal area increment model for individual conifers in the northern Rocky Mountains. Forest Science 36, 1077-1104.

Zeide, B., 2005. How to measure stand density. Trees 19, 1-14.

Zerbe, S., 2002. Restoration of natural broad-leaved woodland in Central Europe on sites with coniferous forest plantations. Forest Ecology and Management 167, 27-42.

Zhang, Y., Chen, H.Y., 2015. Individual size inequality links forest diversity and above-ground biomass. Journal of Ecology 103, 1245-1252.

Zhang, Y., Chen, H.Y., Reich, P.B., 2012. Forest productivity increases with evenness, species richness and trait variation: a global meta-analysis. Journal of Ecology 100, 742-749.

Zuur, A., Ieno, E.N., Walker, N., Saveliev, A., Smith, G.M., 2009. Mixed effects models and extensions in ecology with R. Springer, New York.

Zuur, A.F., Ieno, E.N., Elphick, C.S., 2010. A protocol for data exploration to avoid common statistical problems. Methods in Ecology and Evolution 1, 3-14. 
失之毫厘，差以千里

-孔子

A little error may lead to a large discrepancy.

-Confucius 


\section{Summary}


Many monoculture forests (dominated by a single tree species) have been converted to mixedspecies forests (dominated by more than one tree species) in Europe over the last decades. The main reason for this conversion was to increase productivity, including timber production, and enhance other ecosystem services, such as conservation of biodiversity and other nature values. In addition, it has been suggested that mixed-species forests are more resistant, resilient and stable to disturbances.

In line with the niche complementarity hypothesis, inter-specific differences in crown architecture, leaf phenology, shade tolerance and root distribution may allow tree species to partition resources in mixed forests. Such mechanisms may lead to a higher productivity of mixed forests versus monoculture forests, a phenomenon often referred to as overyielding. Interestingly, the stress-gradient hypothesis and the resource-ratio hypothesis suggests that such inter-specific interactions vary along a soil fertility gradient, but in different ways. The stress-gradient hypothesis emphasizes that more efficient partitioning increases overyielding at low fertility soils, whereas the resource ratio hypothesis considers that the denser packing of crowns on fertile soils allows for partitioning of light and overyielding on high fertility soils. Several studies have been carried out about species mixing effects on forest productivity, but so far their findings are ambiguous. Probably, this ambiguity comes from the sites that they studied, which differ in species, age, management history, and/or environmental conditions.

This thesis analyses the mixing effect on productivity in relation to the combination of species, stand age and soil fertility, and discusses possible consequences of forest management, for five two-species mixtures in the Netherlands: Douglas-fir (Pseudotsuga menziesii (Mirb.) Franco)-beech (Fagus sylvatica L.), pine (Pinus sylvestris L.)-oak (Quercus robur L.), oak-beech, oak-birch (Betula pendula Roth) and pine-birch. These mixtures and their corresponding monoculture stands were studied using long-term permanent forest plots over multiple decades, but also using two inventories (around 2003 and 2013) across the entire Netherlands. These forest plots data were used together with empirical models at total stand level (chapter 2), species level (chapter 3) and tree level (chapter 4) to evaluate the mixing effect on forest productivity.

In chapter 2, four two-species mixtures and their corresponding monospecific stands were compared for productivity (volume stem wood in $\mathrm{m}^{3} \mathrm{ha}^{-1}$ year ${ }^{-1}$ ). It was explored whether mixing species differing in leaf phenology and shade tolerance would lead to overyielding of mixed forest stands, and whether overyielding changes with stand development. In line with the niche complementarity hypothesis, the two evergreendeciduous species mixtures (Douglas-fir-beech and pine-oak) showed overyielding whereas deciduous-deciduous species mixtures (oak-beech and oak-birch) did not. The overyielding was strongest for the Douglas-fir-beech mixture than the pine-oak mixture, which can be attributed to the greater difference in shade tolerance in the former mixture. Overyielding did not significantly change with stand development. It is argued that the regular thinning maintained the ability of species to partition resources, i.e. the complementary resource use in those mixed stands over all stand ages. 
In chapter 3, it was analysed which of the two species in these four mixtures contributed to overyielding, and whether this overyielding changed along a soil fertility gradient. It was discovered that both the fast-growing and the slow-growing species could contribute to overyielding. Yet, it was mainly the fast-growing Douglas-fir that contributed to higher productivity in the Douglas-fir-beech mixtures, and the slow-growing oak that did so in the pine-oak mixtures. For both mixtures, the greatest relative productivity gain was achieved by mixtures on the poorer soils. At first sight, these results seem in line with the stress-gradient hypothesis and not the resource-ratio hypothesis. Yet, it was argued that not only complementary use of soil resources, but also use of light, may contribute to the higher productivity of mixed stands on the poorer soils.

In chapter 4, it was assessed how the growth of individual trees in mixtures was influenced by inter- and intra-specific competition, and whether this competition was mainly size-symmetric for soil resources or size-asymmetric for light on soils differing in fertility. This chapter focussed on three mixtures, i.e. oak-birch, pine-oak and pine-birch, which were available at sufficient numbers in the Dutch national forest inventory data. It was concluded that intra-specific competition was not necessarily stronger than inter-specific competition and this competitive reduction was less seen at lower soil fertility and dependent on species mixtures, which is not in line with the stress-gradient hypothesis. Moreover, size-asymmetric competition for light was more associated with tree basal area growth than size-symmetric competition for soil resources, suggesting that light is the most limiting resource. Competition for light was generally much stronger at high fertility soils, supporting the resource-ratio hypothesis. These results suggest that light is the most limiting resource for tree basal area growth and that reduced competition for light can be explained to some degree by complementarity in light use to increase tree growth in mixed forests.

This thesis thus described the productivity patterns when mixing tree species and explored possible mechanisms of higher productivity in mixed stands compared with monoculture stands in the Netherlands. Complementary use of aboveground and belowground resources probably contributes to the higher productivity in mixed stands, but other factors including pathogens, nutrient cycling and litter decomposition were not addressed but cannot be excluded. Overyielding in Douglas-fir-beech and pine-oak mixtures was maintained over time, probably owing to the intensive thinning in Dutch forests. The results shed new light on the stress-gradient and resource-ratio hypotheses. For mixtures in Dutch forest, the greatest productivity gain in Douglas-fir-beech and pine-oak mixtures was achieved on the poorer soils, and it was argued that this is at least partially driven by complementary use of light, while the role of complementarity in use of soil resources is more obscure. Overall, this thesis suggest a substantial potential of species mixing for increasing productivity, which may run in parallel with enhancing other ecosystem services such as conservation of diversity and other nature values. Yet, more experimental studies on productivity in mixed stands are required to better unravel alternative mechanisms. Such understanding is required to manage the forests effectively in a century of unpreceded human driven changes in environmental conditions. 
精诚所至，金石为开 一庄子

Nothing is impossible for a willing heart.

-Zhuangzi 

Four years ago, it was my first flight to go abroad. On the plane, I was worried and I did not know what was like on the other side of the planet and what I would find on my arrival. I burst into tears when I arrived at the Schiphol Airport. Loneliness and fear together difficult to imagine even now. During the $\mathrm{PhD}$, the effort required was much much more than I thought, both physically and mentally. Suffering, struggling and fury from work, but I still managed to finish within four years, and that is the thing I feel most proud of. This was my original goal when I came to FEM, but more importantly, I have learnt and grown a lot over the last four years. Making this period a valuable and unforgettable experience in my life.

During this time, I stayed mostly in Wageningen, although I spent some time also in Madrid and Lausanne. It seems so long ago since I left China and arrived at Wageningen on $20^{\text {th }}$ September, 2013, but it has also been so fast. I have met so many nice people and I have been so lucky to get their support and help. During my studies, I really had peace of mind enjoying the peaceful and quiet life of Wageningen. Although, without the support from colleagues, friends and family, I could have not managed to finish my $\mathrm{PhD}$ thesis on time. Thereby, I would like to reflect on these last four years and express my sincere gratitude to the people who helped me.

Frits: Firstly, thanks to you, my promotor. Thank you for all your thoughtful care and support since February 2013 when you first gave me the invitation letter for my scholarship application from China Scholarship Council, when we met in Yangling, China, and when you picked me up at Schiphol Airport on the first time I went abroad. You supported me through all administrative matters and small grant applications. Once you told me I was stubborn, and I know I am, although I would say that you are too. It was so difficult to convince you of my work, but that forced me to grow and now I am sure that was what you were looking for. I also know I can still grow even more.

Frank: to be honest, it would have not been possible for me to finish my $\mathrm{PhD}$ without your support and help! You joined my PhD supervision during my second year when my original project did not work out. You came up with ideas for my $\mathrm{PhD}$ proposal and helped a lot with the writing. Your commitment, responsibility and patience really impress me! You always supported me and gave me lots of prompt feedback on every file I sent to you. Especially during the last three months before I handed in my thesis, your encouragement and your timely comments on every version helped me meet the deadline. Over the past three years, I do not know how much I managed to understand my topic, or you learned how to help me improve my understanding, or if we both learned at the same time. I know I was sometimes a "knotty" PhD student because of my troubles inside or outside work, but no matter what the troubles were, you were always there supporting me. We spent so many times together sitting behind the computer editing manuscripts even until the building was closed.

Sonia and Miren: Muchas gracias! Since I first wrote to Sonia in 2015 about R codes, or when I spoke to Miren in one course in February 2016 in Palencia, Spain and she invited me 
to apply for a travel grant to discuss my study and apply your models, you were always willing to help. Once I got my first grant from COST Action, and went to Madrid for a one week scientific short stay. I knew I wanted to return and work together and that is why I kept applying and getting grants from the European Forest Institute and COST Action returning to Madrid four times for the collaboration. I had a great time and it was extremely productive. In total, I stayed there in April, June, July, October and November of 2016 and March of 2017 for more than two months. Your kind-hearted, support and hospitality really impressed me and I will remember you two respectful ladies my entire life. I really appreciate that you treated me with very nice typical Spanish sweets and bread every time I left Madrid. Gracias! You are my "right people".

Mart-Jan: I would like to express my gratitude to you. Since you started to explain the Dutch National Forest Inventory data and translated the data from Dutch to English for me, every time I went to your office with or without appointment, you explained to me everything in detail and spent more time than you had planned. I learned a lot about Dutch forests from you. You are a very nice collaborator, a nice colleague and I personally consider as a friend.

FEM group: I thank the group for providing me with a relaxing work environment, where the hierarchy between staff and students is not that marked. I could talk about everything during coffee/tee and lunch breaks and ate the most various and delicious sweets in my life so far and probably in my whole life. At the FEM corridor, the atmosphere is so lovely. I have learned from everyone and from very different aspects of life.

\section{Especially thanks go to the FEM staff}

Lourens: when I was so troubled during my first year of $\mathrm{PhD}$, you always lent a hand and helped me out. You did your best and in the end you succeeded. After that, my PhD went well. Your kindness, humour, big smile and enthusiasm for science have earned my admiration and respect! In work, you are a really responsible supervisor. It was so impressive to see your timely, careful, and extensive comments on the work of your PhD students. In life, you take good care of your family. It seems to me that you are the best at handling work and family so perfectly.

Leo: thanks for organising trips for me to the Dutch forests. I work only with data from Dutch forests, but it was you that showed me the real forests where the data came from. Your passion for forests, wood and nature really impresses me. You are very kind to invite my husband, Yang and I to your place for lunch and showed us around near the Rhine River. The apple pie became my husband's favourite sweet since he ate the home-made one at your house.

Marielos: I really appreciate your sweet heart, especially the last months during towards the end of my thesis writing. You sent me messages to encourage me before you left for holidays and even brought me a red fortune gift when you returned from your holidays in Italy. You 
told me that you remembered that once during a coffee break I said: "red means good luck in China". It was very touching. I cannot forget all the international dinners you organised at your place. I was always longing for the enjoyable evenings, the chatting, eating, looking around the decoration in your house and playing games with your daughter Franka. Your house and your warm sweet family (with Lourens and Franka) is a dream for my future.

Frans: your enthusiasm for science and your knowledge makes you forever young. I can still remember all the jokes and laughs with you during breaks or in the corridor. Pieter: thank you for organising the FEM Journal Club, and I learned a lot from it. I really appreciate your comments on my group presentations! Ute: when I arrived in the Netherlands, your house was the first one that I visited. Your passion for wood and your energetic and hard work really amazes me. Thanks for your encouragement every now and then in the corridor.

Ellen: you are one of the female power in FEM. Your elegance and wisdom inspired me a lot. Every time, during international dinner or parties at your houses, I was so joyful with the warm atmosphere and your hospitality. Thanks for your ice cream during hot summer days in the office and in "our" garden in Lumen. Joke: you always supported me with administrative things although I did not have a contract here. Thanks for the documents you made for me. You are a very conscientious secretary!

Jan: thank you for the collaboration! Your critical comments on my work made me more precise and specific, which improved my language and writing abilities. It always felt very warm to me when you said "ni hao (你好)"! Feeling lovely!

Gert-Jan and Koen: although you do not stay in FEM corridor so much due to the special appointment, thank you professors for inviting me for cake or parties. Geerten, thanks for inviting me to the global forest biodiversity network, I have learned a lot by now! Rein: you are the soil expert and who introduced to me by Mart-Jan. Thanks for every discussion and help with my soil research.

Next I will express my gratitude to several "M" PhD colleagues. It may be a coincidence that so many " $M$ " ladies are in FEM during my stay, but it is not a coincidence that they have all been very kind and willing to help me.

Masha and Monique: you are the two colleagues and friends that I should acknowledge first. Especially, during the last two months before I submitted my thesis, you revised my propositions and gave me feedback promptly, you cared about my progress and situation. You two are the best peer support while finalizing my thesis. Your great heart made me feel accompanied even when I was alone abroad.

Monique, you organised a nice trip to Giethoorn when my husband was here and Hans took so nice pictures for us. Your encouragement was always accompanying me when you were or not in the group. Thanks for your trust in choosing me as one of your paranymphs, it brought 
me more confidence! Masha, you introduced me to Zumba and we danced together for almost 2 years. Over there, I gave you a nickname saying "you are a monkey" and you remember well. After you left FEM, I hardly went back to Zumba. We gave massages for each other, at your place, Marlene place and my place. And I still remember you were like an angel when you wore my wedding dress, it was a pity that I did not attend your wedding ceremony.

Marlene: I would also like to express my best gratitude to you. You helped me out when I was suffering from neck and back pain. We shared many nice times taking massages and sauna together. Banana, apple and pear had a great time in Wageningen, and we are all finally a DOCTOR! I hope we would meet again somewhere in the world.

Meike: thank you for being there with me in Palencia, Madrid and Prague. Traveling with you was so relaxing with your translating and arranging everything for me. You were like an elder sister looking after me while travelling and working. Moreover, it was even nicer that we travelled to Sweden and Freiburg, where we had a great time together visiting the cities, forests and had awesome food. I hope that you can manage your teaching, your $\mathrm{PhD}$ and your family ever better. I appreciate you being one of my paranymphs and helped me through all the arrangements before and after my defence.

Madelon: you sold your bike to me at a very low price when I first arrived in Wageningen. I rode it for four years and I enjoyed it a lot. You helped me raise above my problems and face them bravely, especially during my second year. You are a very talented young female scientist and have achieved a lot. I hope your science career will be smoother and you manage to accomplish much more. I also hope that Bas will get his $\mathrm{PhD}$ quite soon.

Merel: you helped me with $\mathrm{R}$, from codes to the interpretation of model output. You were always helpful and patient during your explanations. Although I still cannot pronounce your name well, I will remember your kind help.

Thanks also to other previous FEM colleagues. Danae, I appreciate a lot the $\mathrm{R}$ codes you shared with me and you teaching me how to do some specific analysis. Catarina, you brought me a number of laughs and happy moments when we were at the parties, drinks and travelling in the Netherlands, and even in the WhatsApp group.

Lan: as the other Chinese $\mathrm{PhD}$ student in our group in recent years, it seems that we are "attracting" more Chinese girls to do their PhDs here and make the Chinese FEM community even larger. It has been pleasant with you around, sharing life and work, since we have similar ages and personalities. Kathelyn, it had been very nice with you around in the FEM corridor, on the sailing boat, at our places and many more locations. "If you are blossoming, the butterfly will visit you" was once the motto you like. You have attracted a "butterfly" and I am sure that you have had a great time with him... 
Next, some of my male colleagues with whom I could not have grown so much. Thanks for your help and joyful moments in your company.

Federico: thank you for making me "tough" by always being "mean" to me. I had to defend myself. For a while I was your "psychologist" and helped you with your cravings for Chinese food. I still remember that you complained about having never tried my dumplings, but you did eat a lot of them during the last two months. But you should believe that my "saint" husband is not invisible and you met him in person already. I enjoyed a lot every time you were in Wageningen, especially in 2017! Helping me through everything, and playing your role as my paranymph... Well done!

Linar: you Russian strong guy. Thanks for your frequent visits when I was locked inside the office, especially since it was only few of us $\mathrm{PhD}$ students around at that time. I still remember the great Russian dinner that you and your wife cooked for us on your birthday party. It was the first party where I arrived at home the latest, 4 am! Thanks for all the talks and nice moments! With you there is always laughter! You are a tough guy always making fun of me, but we were also always making fun of other colleagues together, especially Federico. That was so much fun!

Mathieu: thanks a lot for sharing with me so many good movies, these improved my English enormously. Thanks for inviting me to your place for a very nice Belgian stew, sharing your traveling experiences and tips with me. I really appreciate that you and Sarah allow my family and me to stay in your place for two months. We had a good time living there.

Peter Groenendijk: I really appreciate your patience and kindness. You were like a teacher and taught me statistics and R programming. Peter van de Sleen: when you were in FEM, three tall Dutch guys (you, Peter and Mart), it made a very nice team. I had so many joyful moments with you during coffee and lunch breaks in Lumen and anywhere we were together. Mart: you are the best organiser at FEM. Thank you for making everything happen!

Peter Schippers: thank you for organising and driving me through so many nice trips to Elburg, Kinderdijk, Gouda, Enkhuizen, Zuiderzee, and Muiden. I could not have visited so many places in the Netherlands without you. Paul: thank you for being my two-year officemate during my first two years. You cared about my progress, answered my doubts and helped me out when I was stuck. You are a very helpful person. Thanks for inviting me for Christmas dinner at your place!

Juan: thanks for accompanying me during my last two years at the office. We talked a lot about Dutch forests and shared some nice food. I still remember the day that you, Arildo and I went climbing together, my first rock climbing was so hard. Jose: you are the other Ecuadorian $\mathrm{PhD}$ who shared the office with me. When you were here during your first year, we had so much fun together and with other guys. Your famous drawing is still in our office and I do hope that your career is like lianas, growing fast, higher and deeper. Arildo: although 
you were a post-doc visitor in FEM and we shared office for only one year, we chatted a lot about everything. You made me laugh a lot after you left Wageningen when I remembered you talking a lot of "Chinese Wisdom”.

Jente: you are very humorous. Your cartoons on the Friday After Work Drinks (FRAWD) emails really amazed me. Although your jokes were not so funny sometimes and I even had to ask you... "do you know a funny one?". It felt very touching when you wore the "Sheldon team" T-shirt, since you know how much I like The Big Bang Theory and you bought it especially for me in Germany. It has been very pleasant to meet and know you in Wageningen. I wish you a successful and eventful journey in Sweden and hope to see you soon!

This thesis is inspired by FP1206 COST Action EUMIXFOR project on "Integrating Scientific Knowledge in Mixed Forests". Thanks for granting me two times on my "shortterm scientific missions" and completing my two chapters' analysis and reimbursing all my cost for the conference in Prague. Acknowledgements go to LEB Foundation 2017-033A from Wageningen University for funding my participation in a conference in Freiburg. Thanks for Gilles Hondius Foundation for granting me for the printing of this thesis.

Thank you all the colleagues, Alan, Arildo, Alejandra, Bernardo, Canisius, Carolina L., Catarina, Danae, Federico, Helen, Jamir, Jente, Juan, Kathelyn, Kwame, Jose, Linar, Lucy, Monique, Madelon, Mart, Masha, Marlene, Meike, Merel, Surya, Vency, Estela, Tiep, three Peters. Special thanks to Danae, Masha, Merel, Peter G. for your great help with my models in R. Thank you all for your patience with my poor English at the beginning and even now. It was highly appreciated!

Thanks to my Chinese friends: Mandy Bao (包曼), you are my “partner” when both of our husband were not around. We played Zumba and badminton, went to the gym, had meals and talked at your or my place. We shared joys and happiness, and even we talked each other's difficulties and struggles out. One day you told me that I was like an elder sister. Without you, four years in Wageningen would have been a jail for me. Yujie He (何玉洁), we became good friends during our last year. You, Bao and I usually had dinner together, sharing tips and tricks of our common work and life experience. In this period, when we were finalizing our thesis, we became "comrade in arms". Now, looking back, it was a tough stage but thoughtful care from friends were all paid off.

Thank you, Tao Zhao (赵涛) and Haikun Ma (马海鲲)! You made me feel quite achieved and proud to be a matchmaker for the first time and you becoming partners in such a short time. I like the wedding pictures you two and Mandy took of my husband and me and I called “世上最高含金量婚纱照” because all of the “think tanks” “卢婚纱照智囊团” are PhDs. Thanks for every chat, meal and everything! 
Thank you all other CSC family in Wageningen: Wenbiao Shi, Xiaomei Yang, Wei Xue, Peng Wang, Yingying Wang, Shenglai Yin, Zheng Huang, Yong Zhang, Xiao Lin, Minggang Wang, Fengjiao Bu, Yanjie Xu, Jinling Li, Dandan Liu, Fubiao Niu, Wenbo Liu, Qijun Jiang, Ying Zheng, Jinghui Hao for all the conversations!

我感激在我学生生涯 11 年里我的父母的理解与支持。这些年来, 随着攻读学位愈走愈 远, 我理解您们在千里之外及地球另一端等待每周六我的电话的急切心情。感激我的 姐姐, 妹妹和弟弟。自从我 2013 年 9 月出国攻读博士至今, 我没有回国一次, 是你们 在父母身边, 照顾他们, 陪他们聊天。我感激我的婆婆公公, 每次给您们打电话, 您 们体贴关心我的生活和学业, 精神上物质上对我的帮助以及经济上对我父母的帮助, 会让我感恩终身。感谢您们在 Bennekom 给我做了 3 个月的饭。

I owe my greatest gratefulness and gratitude to my husband Yang Zhao. Whenever I felt desperate and despaired about writing my proposal during my first year of $\mathrm{PhD}$, he would say: "If you do not believe in yourself, at least you have me to believe in you. Without you, I would not have come to the Netherlands; without you, I would not have managed the $\mathrm{PhD}$ thesis completion. Thank you for the patience, tolerance and support during these last seven years. You know how much I have learnt from you. I always say that you are my eternal supervisor, because you are the only one who has read my whole MSc and $\mathrm{PhD}$ theses asides from my supervisors. 一句中国的古话形容夫妻：彼此尊重，相互扶持. I realise that both of us have been bearing this in mind. Although I am now officially a $\mathrm{PhD}$, like you, what really makes me smart is to, have you in my life. 


\section{Short biography}

Huicui Lu, was born on August 13, 1987 in Heze, Shandong Province, China. She started to do her bachelor in 2006 in her home town at Heze University in Gardening and she got her BSc diploma with distinction in 2010. At the same year, she moved to Northeast Forestry University in Harbin to study forest ecology. She did large amount of field work in the largest forest areas in

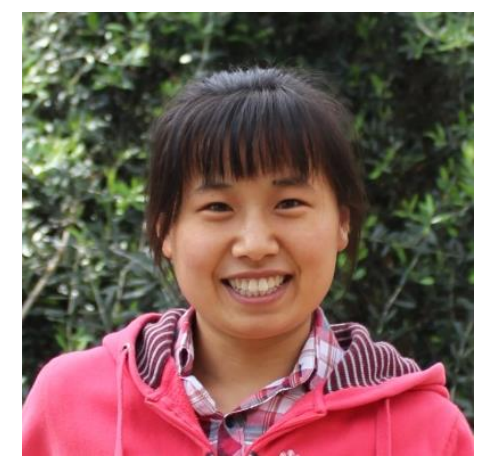
China: Changbai Mountain, Xiaoxinganling and Daxinganling. After three years' study, she obtained her MSc diploma with distinction in 2013 and also she got the grant from Chinese Scholarship Council (CSC) to do her $\mathrm{PhD}$ in Wageningen University. Besides the achievement at study, she tied the knot with Yang Zhao after three years' love journey.

In September 20, 2013, she moved to Wageningen and this was her first time to go abroad. She studied species mixture effects on productivity in the forests of the Netherlands. During the four years, she worked with people from different countries and has hugely broaden her horizons. After finishing her $\mathrm{PhD}$, she will go back to China to work in a university. 


\section{List of Publications}

\section{Published publications:}

1 Huicui Lu, Godefridus M. J. Mohren, Jan den Ouden, Venceslas Goudiaby, Frank J. Sterck (2016). Overyielding of temperate mixed forests occurs in evergreen-deciduous but not in deciduous-deciduous tree species mixtures over time in the Netherlands.

Forest Ecology and Management, 376, 321-332.

DOI: http://dx.doi.org/10.1016/j.foreco.2016.06.032

2 Jingjing Liang, Thomas W. Crowther,..., Huicui Lu, ..., Peter B. Reich (2016). Positive biodiversity-productivity relationship predominant in global forests. Science, 354:aaf8957. DOI: http://dx.doi.org/10.1126/science.aaf8957

3 Changcheng Mu, Huicui Lu, et al (2013). Short-term effects of harvesting on carbon storage of boreal Larix gmelinii-Carex schmidtii forested wetlands in Daxing'anling, northeast China. Forest Ecology and Management, 293, 140-148.

DOI: http://dx.doi.org/10.1016/j.foreco.2012.12.031

\section{Submitted publications}

4 Huicui Lu, Sonia Condés, Miren del Río, Venceslas Goudiaby, Jan den Ouden, Godefridus M. J. Mohren, Mart-Jan Schelhaas, Rein de Waal, Frank J. Sterck. Unraveling soil effect on overyielding of species mixture in forests of the Netherlands. Under review.

5 Huicui Lu, Miren del Río, Sonia Condés, Mart-Jan Schelhaas, Godefridus M. J. Mohren, Meike Bouwman, Frank J. Sterck. Competition on tree growth in mixed forests at different soils in the Netherlands. Under review. 


\section{Affiliations of co-authors}

\section{Godefridus M. J. Mohren}

Forest Ecology and Forest Management Group, Wageningen University and Research, Wageningen, the Netherlands

\section{Frank J. Sterck}

Forest Ecology and Forest Management Group, Wageningen University and Research, Wageningen, the Netherlands

\section{Sonia Condés}

Department of Natural Systems and Resources, School of Forestry, Universidad Politécnica de Madrid, Madrid, Spain

\section{Miren del Río}

Department of Silviculture and Forest Management, INIA, Forest Research Centre, Madrid, Spain \& Sustainable Forest Management Research Institute UVa-INIA, Spain

\section{Jan den Ouden}

Forest Ecology and Forest Management Group, Wageningen University and Research, Wageningen, the Netherlands

\section{Mart-Jan Schelhaas}

Team Vegetation, Forest and Landscape Ecology, Wageningen University and Research (Alterra), Wageningen, the Netherlands

\section{Rein de Waal}

Team Vegetation, Forest and Landscape Ecology, Wageningen University and Research (Alterra), Wageningen, the Netherlands.

\section{Meike Bouwman}

Forest Ecology and Forest Management Group, Wageningen University and Research, Wageningen, the Netherlands

\section{Venceslas Goudiaby}

Forest Ecology and Forest Management Group, Wageningen University and Research, Wageningen, the Netherlands 


\section{PE\&RC Training and Education Statement}

With the training and education activities listed below the $\mathrm{PhD}$ candidate has complied with the requirements set by the C.T. de Wit Graduate School for Production Ecology and Resource Conservation (PE\&RC) which comprises of a minimum total of 32 ECTS (= 22 weeks of activities)

\section{Review of literature (4.5 ECTS)}

- The impact of management on mixed forest dynamics and productivity

\section{Writing of project proposal (3 ECTS)}

- Assessing the impact of managing tree species on the productivity of mixed forests in the Netherlands

\section{Post-graduate courses (4.1 ECTS)}

- Introduction to R for statistical analysis; PE\&RC (2013)

- Linear models; PE\&RC (2014)

- Mixed linear models; PE\&RC (2015)

- Course on silviculture of complex forests; University of Valladolid, Palencia, Spain (2016)

\section{Laboratory training and working visits (4.5 ECTS)}

- Model application in mixed-species stands in Dutch forests; Technical University of Madrid (2016)

- Model application in mixed-species stands on different soils in Dutch forests; INIACIFOR (2016)

- Species competition in mixed forests from growth models based on Dutch national forest inventory data; INIA-CIFOR (2017)

\section{Invited review of (unpublished) journal manuscript (1 ECTS)}

- Forestry: mixing effect on forest productivity (2016) 
Deficiency, refresh, brush-up courses (2.5 ECTS)

- Basic statistics; PE\&RC (2013)

- Advanced forest ecology and forest management; FEM (2014)

- Lectures of the course ecological methods; REG (2014)

\section{Competence strengthening / skills courses (5.3 ECTS)}

- Competence assessment; WGS (2013)

- PhD Peer consultation; WGS (2015)

- Scientific writing; WGS (2016)

- Presenting with impact; WGS (2016)PE\&RC Annual meetings, seminars and the PE\&RC weekend (2.4 ECTS)

- PE\&RC First year PhD weekend (2013)

- PE\&RC Day $(2013,2014,2016)$

- PE\&RC Midterm PhD weekend (2014)

Discussion groups / local seminars / other scientific meetings (4.6 ECTS)

- $\quad$ R Users meeting (2013-2014)

- FEM Journal club discussion group (2013-2017)

- Ecological theory and application (2014-2017)

- Netherlands Annual Ecology Meeting; poster presentation; Lunteren, the Netherlands (2016)

International symposia, workshops and conferences (4.4 ECTS)

- EuMIXFOR Final conference; oral presentation; Prague, Czech Republic (2016)

- IUFRO 125th Anniversary congress; poster presentation; Freiburg, Germany (2017)

\section{Lecturing / supervision of practicals / tutorials (0.6 ECTS)}

- Resource use and sustainable utilization; WUR (2016) 
The research described in this thesis was financially supported by China Scholarship Council.

Financial support from Wageningen University and Stichting Gilles Hondius Foundation for printing this thesis is gratefully acknowledged.

\section{Cover design}

Federico Alice Guier and White\&Bold Brand Communication

\section{Photography}

Huicui Lu

\section{Printed by}

GVO Drukkers \& Vormgevers B.V. Ede, the Netherlands 


$$
\text { | }
$$

